\title{
Audit committee design and effectiveness
}

Citation for published version (APA):

Böhm, F. (2015). Audit committee design and effectiveness. [Doctoral Thesis, Maastricht University]. Datawyse / Universitaire Pers Maastricht. https://doi.org/10.26481/dis.20150130fb

Document status and date:

Published: 01/01/2015

DOI:

$10.26481 /$ dis.20150130fb

Document Version:

Publisher's PDF, also known as Version of record

\section{Please check the document version of this publication:}

- A submitted manuscript is the version of the article upon submission and before peer-review. There can be important differences between the submitted version and the official published version of record.

People interested in the research are advised to contact the author for the final version of the publication, or visit the DOI to the publisher's website.

- The final author version and the galley proof are versions of the publication after peer review.

- The final published version features the final layout of the paper including the volume, issue and page numbers.

Link to publication

\footnotetext{
General rights rights.

- You may freely distribute the URL identifying the publication in the public portal. please follow below link for the End User Agreement:

www.umlib.nl/taverne-license

Take down policy

If you believe that this document breaches copyright please contact us at:

repository@maastrichtuniversity.nl

providing details and we will investigate your claim.
}

Copyright and moral rights for the publications made accessible in the public portal are retained by the authors and/or other copyright owners and it is a condition of accessing publications that users recognise and abide by the legal requirements associated with these

- Users may download and print one copy of any publication from the public portal for the purpose of private study or research.

- You may not further distribute the material or use it for any profit-making activity or commercial gain

If the publication is distributed under the terms of Article $25 \mathrm{fa}$ of the Dutch Copyright Act, indicated by the "Taverne" license above, 


\section{AUDIT GOMMITTEEE DESIGN \& EFFEGTIVENESS}

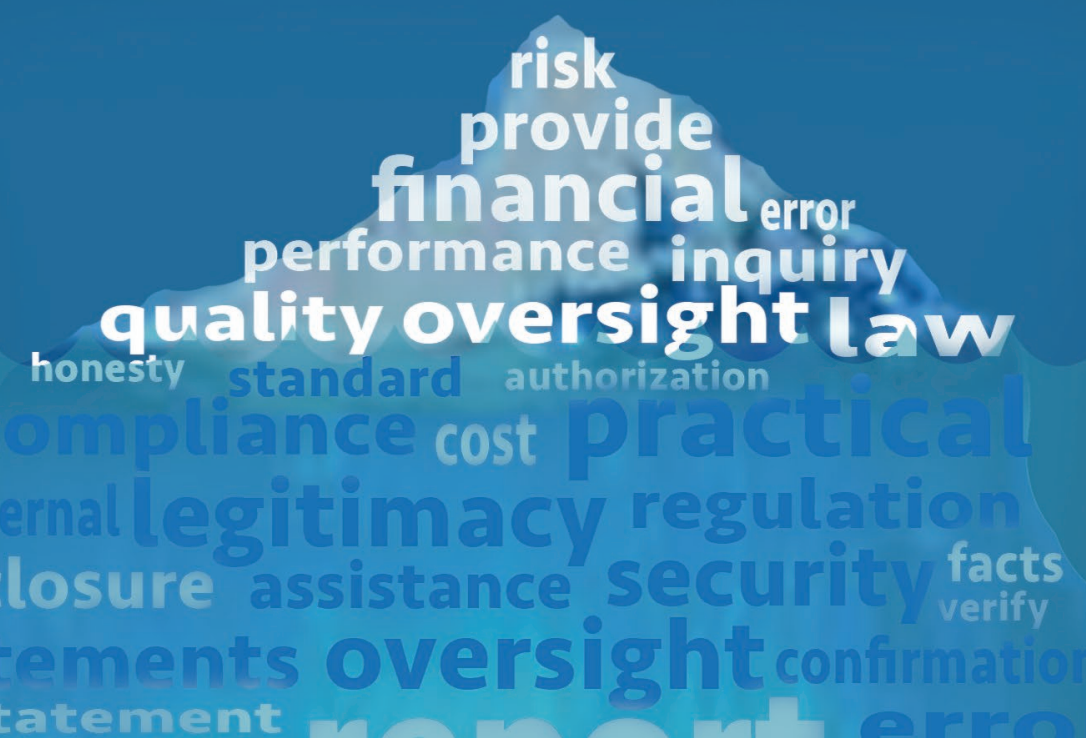

disclosure assistance Security facts
statementy
mistatement

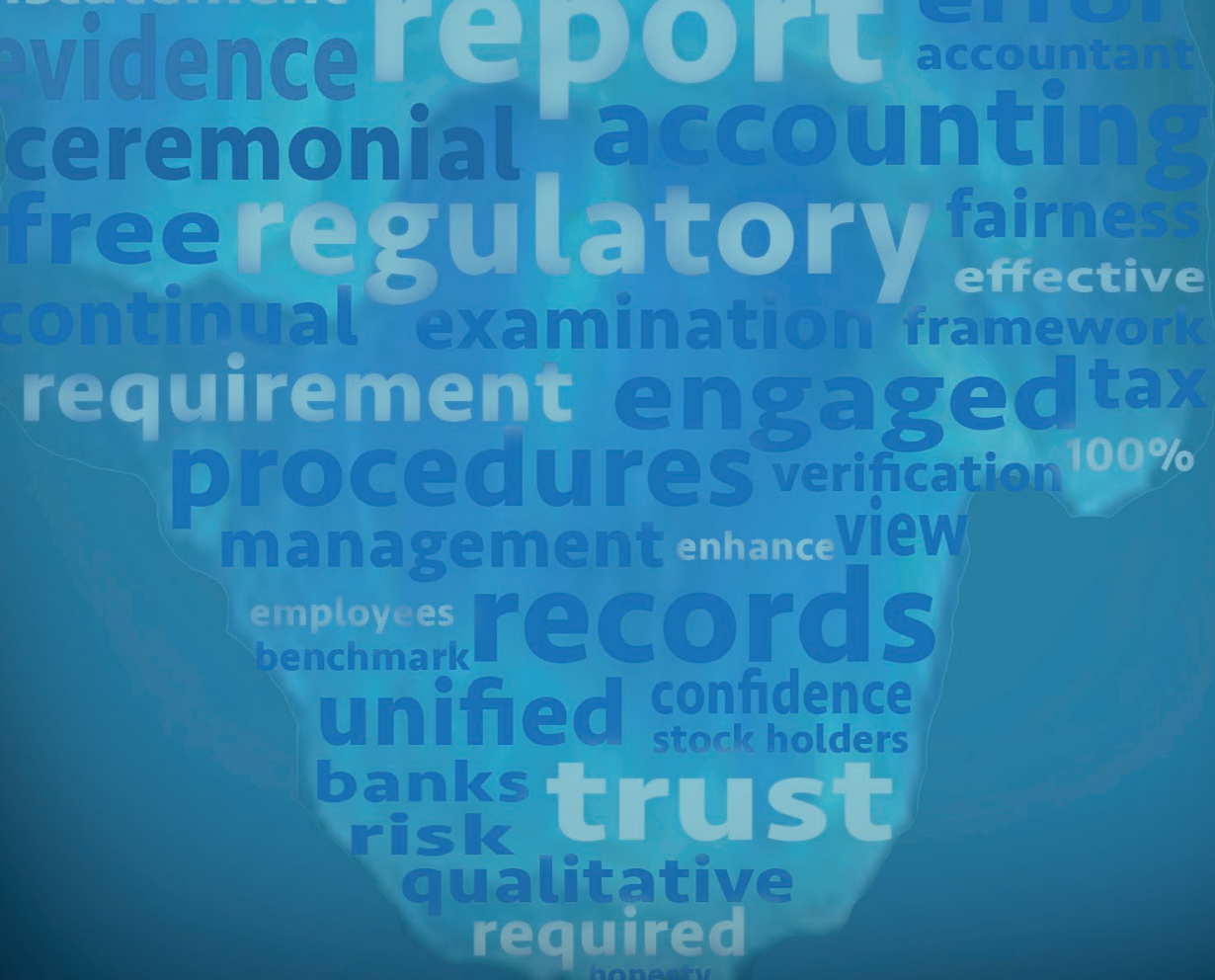

FАLKО ВÖНМ 
Audit Committee Design and Effectiveness

(C) Falko Böhm, Maastricht 2014

All rights reserved. No part of this publication may be reproduced, stored in a retrieval system or transmitted, in any form, or by any means, electronic, photography, photocopying, recording or otherwise, without the prior permission in writing from the author

ISBN 9789461594006

Cover design by: Matt Woodworth

Layout and printing by: Datawyse Maastricht 


\title{
Audit Committee Design and Effectiveness
}

\author{
DISSERTATION \\ to obtain the degree of Doctor at Maastricht University, \\ on the authority of the Rector Magnificus, Prof.dr. L.L.G Soete \\ in accordance with the decision of the Board of Deans, \\ to be defended in public \\ on Friday January 30, 2015, at 14.00 hours
}

by

\section{Falko Böhm}

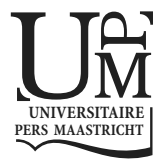




\section{Promoters}

Prof. dr. Harold Hassink

Dr. Laury Bollen

\section{Assessment Committee}

Prof. dr. Roger Meuwissen (Chair)

Prof. dr. Rob Bauer

Prof. dr. Peter Eimers (VU University Amsterdam)

Prof. dr. Steven De Haes (University of Antwerp) 


\section{Acknowledgements}

On September 13 ${ }^{\text {th }}, 2012$, I ran up a mountain in Switzerland. You may be asking yourself what I was doing there and how this event relates to my dissertation. Well, I participated in the $20^{\text {th }}$ edition of the Jungfrau marathon, supposedly one of the most beautiful and challenging marathon races in the world. The first half of the race was pretty flat and convenient to run; however, the second half of the race moved steadily uphill where you have to climb around $1.600 \mathrm{~m}$ in altitude. Starting the race, I had no clue what I had gotten myself into. After five long hours, 17 minutes and 15 seconds, I reached the finish line at $2.061 \mathrm{~m}$ altitude.

Even today, I see many parallels between running the mountain marathon and writing my dissertation. First, I approached both the race and my dissertation with an optimism bias, thinking that I could finish the race and my dissertation much earlier. Consequently, I started the first part of the race and my dissertation (the flat part) with full speed, only to realize that the most difficult part (the uphill part) was still ahead of me. Second, even though I was running behind my (too ambitiously) set target timeline and the race got more difficult, I did not give up. At one point in the mountain race, I was starting to walk rather than run, but I kept going. The same happened with my dissertation over time. Speed was going down and it became more "painful" to keep going. However, at the finish line of the Jungfrau marathon as well as when writing these lines, I have to say that persistency and hard effort was rewarding and paid off.

Third, the support of special persons helped me to complete my dissertation. I would like to acknowledge them in the following paragraphs. First and foremost, I would like to thank my promoters Harold Hassink and Laury Bollen. I want to thank both of you for giving me the chance to enter the marathon-like challenge to obtain a PhD from Maastricht University. You both gave me the flexibility to write my dissertation at my own speed, while giving me the right guidance that helped me to develop my research skills and improved my dissertation over time. You also gave me the chance to pursue my interest in teaching and become part of the department of Accounting and Information Management for some time. In this context, I also have to say thank you to Johannes Dick, Robin Braun and Anant Joshi for helping me with particular aspects of this dissertation. I want to extend my gratitude to the members of the assessment committee Roger Meuwissen, Rob Bauer, Peter Eimers and Steven De Haes for taking the time to read and evaluate my dissertation. Last but not least, I would like to thank Götz Otto for giving me the pos- 
sibility to split my time between working in consulting and also researching and teaching.

I want to congratulate my family. This dissertation is also your success. Gertrud and Jürgen, you should both be proud of yourselves. We will definitely celebrate this achievement together. I am also grateful to Renate, Marianne and Benno Böhm, Katharine, Lothar, Andreas, Stephanie, Oliver, and Judith Schalle, Gerhard Zachrau, and Siegmund Fuchs. I want to express a particular kind of appreciation for Marianne and Benno. Marianne, your curiosity for what I am doing and encouragement means a lot to me. Benno, I think it is fair to say that your broad knowledge in many subjects from natural sciences to politics and history combined with a doctor in Chemistry really sparked my interest to pursue a PhD.

Without my wife Myriam, this all would not have been possible. You really get the best of me and I admire you in many ways. After all, it felt like a piece of cake when you completed your dissertation next to studying medicine. You helped me when I was struggling during the past six years. You listened to me and gave me concrete advice on how to move forward. You encouraged me to keep going, like you did when I was running up the mountain two years ago. At that time, knowing that you were waiting at different points of the race and the finish line gave me an extra boost of motivation. I also would like to thank Hanne, Peter, Marja, and Patrik Vogtel. Especially, Peter for pushing me towards the end of this project to get it done. I would also like to thank Patrik, for being the best brother-in-law.

Before starting with the dissertation, I also would like to acknowledge the good time that I had with good friends. Janis, Sabine, Bartosz, Eliza, Sören, Anna, Sharid, Kathi, Nicolas, Andrea, Jonas, Pia, Tina, Tobi, Silvia, Mathi, Timi, Mara, Jörg, Amrei, Luisa, Denis, Thomas, Maja, Ferdi, Flo, Andre, Alex, Sebastian, Pavel, and Dominik, to name just a few. During these good times together, I gained some healthy distance from this dissertation and could recharge my batteries. Thanks also to Matt Woodworth for a great weekend in New York and for designing the cover page.

I would like to end with a simple question that I was asked quite frequently: "Would you do it again?" The answer is yes. I would definitely take up the PhD challenge again. Why? First, because it was good to experience the freedom and challenges that come with working in an academic environment. Second, because I enjoy writing. And third, because of my family and friends. One should not underestimate the impact that stability and positive energy from family and friends have for one's own success. Well, I had lots of it, and I am grateful to it.

Frankfurt, December 2014

Falko Böhm 


\section{Contents}

CHAPTER 1 Introduction 9

1.1 Audit committee design 13

1.2 The role of audit committee charters 14

1.3 Audit committees and firm performance during a financial crisis 15

$\begin{array}{ll}1.4 \text { Contributions } & 16\end{array}$

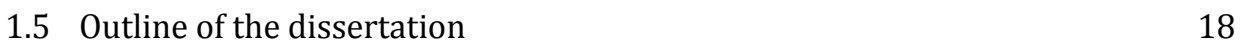

CHAPTER 2 The Design of Audit Committees in Continental Europe $\quad 19$

2.1 Introduction 20

2.2 Designing an audit committee $\quad 22$

2.3 The institutional setting in continental Europe 24

2.3.1 Audit committees in continental Europe 24

2.3.2 Isomorphism and differentiation in audit committee design 26

2.4 Methodology 28

2.5 Empirical findings $\quad 32$

2.5.1 Audit committee responsibilities 32

2.5.2 Competences required of audit committee members 37

2.5.3 Audit committee independence 38

2.5.4 Audit committee size 42

2.5.5 Audit committee meetings 43

2.5.6 Mimetic isomorphism in audit committee charters 43

2.6 Discussion and conclusions $\quad 45$

Appendix: Eight EU Directive on Company Law 50

CHAPTER 3 The Role of Audit Committee Charters

3.1 Introduction $\quad 52$

3.2 The promise and peril of audit committee charters 54

3.3 Development of hypotheses 58

3.3.1 Firm level determinants of audit committee scope 58

3.3.2 Nominal audit committee scope and actual audit committee activity 60

3.3.3 The impact of institutional pressure on isomorphism and decoupling 61

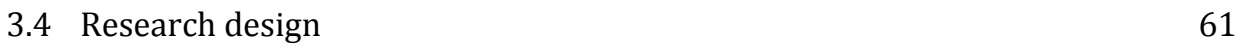

3.4.1 Sample selection and data collection $\quad 61$

3.4.2 Content analysis of audit committee charters 63

3.4.3 Analytical approach 64 
3.5 Empirical results $\quad 65$

3.5.1 Descriptive statistics $\quad 65$

3.5.2 Determinants of audit committee scope 69

3.5.3 Audit committee scope and audit committee activity 70

$\begin{array}{lll}3.6 & \text { Discussion and conclusion } & 73\end{array}$

Appendix: Audit committee scope categorization scheme $\quad 76$

CHAPTER 4 Audit Committee Oversight of Enterprise Risk Management and Firm Performance during the 2007-2011 Financial Crisis 77

$\begin{array}{lll}4.1 & \text { Introduction } & 78\end{array}$

4.2 Research background 80

4.2.1 Audit committees and firm performance during a crisis period 80

4.2.2 What makes fully independent audit committees effective? 84

4.3 Hypothesis development 85

4.3.1 Audit committee authority differentiation 85

4.3.2 Audit committee skill differentiation 88

4.3.3 The Temporal (in)stability of audit committees 90

4.4 Research design $\quad 91$

4.4.1 Sample and timeline $\quad 91$

4.4.2 Model specifications 93

4.4.3 Firm performance measures 94

4.4.4 Measuring audit committee authority differentiation 95

4.4.5 Measuring audit committee skill differentiation 95

4.4.6 Measuring audit committee temporal stability 96

$\begin{array}{ll}4.4 .7 & \text { Control variables } \\ & 97\end{array}$

4.5 Empirical results 98

4.5.1 Descriptive statistics 98

4.5.2 Audit committees and firm performance during the GFC 99

4.5.3 Audit committees and firm performance variability 100

$\begin{array}{ll}\text { 4.5.4 Endogeneity concerns } & 101\end{array}$

$\begin{array}{lll}4.6 & \text { Conclusions } & 107\end{array}$

Appendix: Examples of Audit Committee Oversight of Risk Management 109

$\begin{array}{ll}\text { CHAPTER } 5 \text { Conclusion } & \mathbf{1 1 1}\end{array}$

5.1 Summary of main findings $\quad 111$

$\begin{array}{lll}5.2 & \text { Limitations } & 114\end{array}$

5.3 Implications and future research opportunities 115

References $\quad 121$

Valorization $\quad 133$

Nederlandse samenvatting (Summary in Dutch) 139

$\begin{array}{lc}\text { Curriculum Vitae } & 143\end{array}$ 


\section{CHAPTER 1 Introduction}

"Qualified, committed, independent and tough-minded audit committees represent the most reliable guardians of the public interest. Sadly, stories abound of audit committees whose members lack expertise in the basic principles of financial reporting as well as the mandate to ask probing questions. In fact, I've heard of one audit committee that convenes only twice a year before the regular board meeting for 15 minutes and whose duties are limited to a perfunctory presentation. Compare that situation with the audit committee which meets twelve times a year before each board meeting; where every member has a financial background; where there are no personal ties to the chairman or the company; where they have their own advisers; where they ask tough questions of management and outside auditors; and where, ultimately, the investor interest is being served."

Arthur Levitt (former Chairman of the SEC) speech at New York University about "The Numbers Game" - September 28, 1998. 
In a much-publicized speech, former Chairman of the US Securities and Exchange Commission (SEC) Arthur Levitt classified audit committees as the most reliable guardians of the public interest. At the same time, he expressed anecdotal concerns about their state of expertise, mandate and diligence. While these statements underscore the apparent importance of my dissertation topic, they also raise a number of questions. What are audit committees and why are they considered to be so important for the public interest? Further, what are these committees doing to guard the public interest and what do we know or not know about their effectiveness? In the following, I will briefly elaborate on these questions.

An audit committee is a specialized sub-committee of the board of directors or supervisory board in a two-tier board system (e.g., as in Germany and the Netherlands), consisting in majority or entirely of independent outside board members and charged with specific oversight responsibilities. ${ }^{1}$ Audit committees are considered important for the public interest, because they are expected to enhance the quality of board oversight and thereby contribute to corporate legitimacy and investor confidence in financial markets. The main areas of audit committee oversight include financial reporting, external auditing, internal auditing, internal control, and more recently also risk management matters.

The first accounts of audit committees date back to the birth of US industrial capitalism in the $19^{\text {th }}$ century and the separation of ownership from management. As pointed out by the distinguished business historian Alfred Chandler, Jr., the separation of ownership and management became necessary in the US at that time due to the massive investments required to construct new railroads and telegraph systems and the complexity of these operations. According to Chandler (1990: 1), "the enlarged enterprise came to be operated by teams of salaried managers who had little or no equity in the firm. The owners, numerous and scattered, were investors with neither the experience, the information, nor the time to make the myriad decisions needed". However, even though salaried managers are expected to possess the expertise to run complex organizations, they cannot be expected to watch over the firm's assets with the same anxious vigilance with which the partners in a private co-partnership watch over their own (Smith, 1776). Hence, professional managers (the agents) will not always act in the best interest of a firm's owners (the principals) and from time to time engage in activities that reduce rather than increase firm value (Jensen and Meckling, 1976).

It is precisely the aforementioned agency problem which helps to explain why audit committees are considered so important for the public interest. When ownership is separated from control in public firms, independent audit committees can provide the necessary oversight and assurance to protect the principals (i.e. shareholders) from the aberrant activities of agents (i.e. salaried managers). Investors,

\footnotetext{
${ }^{1} \mathrm{An}$ independent outside board member is a non-executive director appointed to serve on the board of an organization, who has no meaningful connection to the organization other than serving on the board and the board's committees.
} 
who financed the expansion of the US railroad in the $19^{\text {th }}$ century, for example, required the formation of an audit committee to inspect the company's accounts and expenditures on a quarterly basis and to resolve unprecedented control and responsibility issues (Flesher et al., 2005). This illustrates that audit committees are mechanisms for strengthening investor confidence in corporate governance. Investor confidence in corporate governance and capital markets, in turn, is a prerequisite for widely available sources of funding which played a key role in the evolution of capitalism and the prosperity of the modern world (Bernstein, 2004).

During the $20^{\text {th }}$ century, audit committees evolved into mandatory corporate governance mechanisms with the rise of world capital markets (especially stock markets). In 1977, the US was the first country to adopt a requirement that each domestic company with common stock listed on the NYSE must establish an audit committee comprised solely of independent directors as a condition of listing. By the early $21^{\text {st }}$ century, audit committee formation had become a standard practice for publicly held firms in just about all of the 30 largest economies by GDP. The implicit assumption behind audit committee formation is that a smaller group comprised of independent directors and charged with a narrower field of responsibilities will be more effective than the entire board, which is also comprised of executives and handles a broader array of topics. Bédard and Gendron (2010) show that prior research finds positive associations between audit committee formation and the quality of corporate governance and that the dominant theory which has been guiding this stream of research is agency theory (Jensen and Meckling, 1976).

However, the wide-scale proliferation of audit committees first in the US and then on a global scale cannot be explained solely on the basis of agency theory and efficiency considerations. In the US, the expanding role of audit committees can be linked directly to landmark corporate governance scandals that prompted regulators to strengthen the role of independent audit committees as a way to restore investor confidence in public companies and financial markets (Vanasco, 1994). In continental Europe, in turn, audit committee formation was rather rare, until the EU Eighth Directive on Company Law (2006) required their formation for entities operating in the public interest. The point here is that the institutional environment has a strong influence on the development of formal governance structures in organizations, such as the formation and design of audit committees (Cohen et al., 2008). Thus, explanations for the popularity and design of audit committees may also be found in their ceremonial function, which validates corporate legitimacy and enables access to resources for survival and growth rather than enhancing the effectiveness of corporate governance (Spira, 1999).

With this as a background, the question emerges: what do we know or not know about the design and effectiveness of audit committees? A number of scholars, including DeZoort et al. (2002), Bédard and Gendron (2010), and Carcello et al. (2011), have conducted comprehensive reviews of the audit committee literature 
in order to identify systematic associations between audit committee characteristics and measures of audit committee effectiveness. Next, I will briefly summarize the main input and output factors that have been used in empirical research on audit committee effectiveness. Subsequently, I will point out three research gaps that will be addressed in the course of this dissertation. Each of these gaps is grounded in the aforementioned literature reviews and has been identified as an important area for further research by the corporate governance community (Ahrens et al., 2011).

On the input side, five factors have been predominantly used in empirical research to study cross-sectional variations in audit committee effectiveness. According to Bédard and Gendron (2010), the factors that have been found to be most frequently correlated with measures of effectiveness are the responsibilities assigned to the audit committee by means of a written charter, the degree of audit committee independence, and the competencies of audit committee members. Comparatively few studies, in turn, report evidence on associations between committee meeting frequency and size and audit committee effectiveness.

On the output side, prior studies have focused on measures of audit committee effectiveness in one of the following oversight areas: financial reporting, external auditing, internal control, as well as on investor perceptions. In the area of financial reporting, effective audit committees have been found to constrain earnings management (Bédard et al., 2004), reduce the occurrence of misstatements in financial reports (Abbott et al. 2004), increase the level of voluntary disclosure (Kelton and Yang, 2008), and improve the accuracy of earnings forecasts (Karamanou and Vafeas, 2005). In terms of raising the quality of the external audit process, audit committees have been found to impact the selection of the auditor (Abbott and Parker, 2000), the level of external audit work (Bédard and Johnston, 2004), and the independence of the external audit process (Ng and Tan, 2003). Effective audit committees have also been found to constrain internal control weaknesses (Zhang et al., 2007). Finally, empirical evidence suggests that investors react favorably when firms establish an audit committee that meets certain criteria considered best practice (Anderson et al., 2004; DeFond et al., 2005: Farber, 2005).

In terms of research gaps in the existing audit committee and corporate governance literature, I would like to point out three areas that constitute the point of departure for the three studies that form my dissertation. These gaps and the corresponding studies are closely related to the three themes by which Ahrens et al. (2011) describe the contemporary research frontier in corporate governance. Theme number one is the interplay between national institutions, audit committee design and committee effectiveness. Theme number two is based on a more practical understanding of what audit committees are responsible for and actually do. Theme number three, in turn, encompasses the role of audit committees in a period of economic distress, such as the financial crisis that took hold in 2007-2008. 


\subsection{Audit committee design}

To begin with, the extant audit committee literature is based by and large on insights derived from studying firms listed in the US. Studies that combine agency with institutional theory have shown, however, that differences in national institutions can impact the setup and efficacy of corporate governance mechanisms at firm level (Denis and McConnell, 2003; Aguilera et al., 2008). Consequently, it is important to better understand the role that institutional considerations play in the design of audit committees outside the North American domain. By drawing on institutional theory (DiMaggio and Powell, 1983), my first study sheds light on the degree of differentiation and isomorphism in audit committee design standards across six continental European countries. I define audit committee design as the implementation and stipulation of audit committee characteristics that are thought to contribute to audit committee effectiveness or institutional legitimacy.

More specifically, the study presented in Chapter 2 of this dissertation sheds light on the design of audit committees in continental Europe by analyzing the contents of the Eighth EU Company Law Directive, European codes of governance and corporate audit committee charters. The countries featured in this study are Belgium, France, Germany, Italy, Spain, and the Netherlands. The objectives are twofold. First, I assess whether different regulatory regimes in continental Europe favor the establishment of audit committee design standards that are commonly recognized as making a difference in terms of audit committee effectiveness. Thereby, I aim to enrich the scant knowledge about audit committees outside the Anglo-Saxon domain and contribute to a better understanding of the commonalities and differences in corporate governance among members states of the European Union (Weil, Gotshal \& Manges, 2002). Second, I study the effectiveness of the EU Eighth Directive and national codes in creating isomorphism in audit committee design at the corporate level by providing evidence for convergence in content and language of audit committee charters as proxies for coercive and mimetic isomorphism, respectively. Thereby, I provide evidence for a strong interplay between national institutional forces and audit committee design throughout the EU.

The results presented in Chapter 2 reveal noticeable differences in audit committee design standards among EU Member States. These differences concern the scope of responsibilities assigned to audit committees, the competencies that audit committee members should possess, and the proportion of independent directors serving on the committee. Standards related to audit committee size and meeting frequency, in turn, are fairly isomorphic across my sample. At the corporate level, I find high levels of implementation of the Eighth Directive and the national code in the Netherlands, intermediate levels in Belgium and Spain, and low levels in France, Germany, and Italy. These results suggest that one avenue for ironing out inconsistencies in audit committee design among EU Member States is to mandate the disclosure of complete audit committee charters. 
However, regulators should carefully evaluate this step. Consistent with prior literature, I observe that regulatory pressure leads to an increase in the percentage of unoriginal content in audit committee charters. By passing audit committee charters through software to detect plagiarism in narrative documents, I detect an elevated percentage of unoriginal content in the charters of firms listed in a stringent disclosure environment on audit committee charters. These results suggest that regulation leads to 'copy-and-paste' or 'box-ticking' approaches when developing corporate narrative documents. Given that audit committee charters are meant to provide firm-specific information to the investing public and strengthen audit committee effectiveness, these results may not be in the best interest of standard setters and investors.

\subsection{The role of audit committee charters}

One of key findings of my first study is that regulatory pressure to disclose an audit committee charter will increase the degree of mimetic isomorphism in these charters. This indicates that a disclosure regime may turn audit committee charters of different firms into boilerplate copies of each other, describing the same set of roles and responsibilities (cf. Forster et al., 2009; Holder-Webb and Cohen, 2012). Extant literature also indicates that firms decouple actual organizational practices from publicly available codes and charters once the disclosure of these documents turns from voluntary to coercive and then mandatory (Harvard Law Review, 2003). Accordingly, there is evidence to suggest that the value added of audit committee charters for the investing public and audit committee effectiveness diminishes perversely in those institutional settings characterized by a stringent disclosure regime.

In order to investigate whether the aforementioned concerns are justified, I examine associations between the scope of responsibilities set forth in audit committee charters and measures of actual audit committee activity in different disclosure regimes in my second study, presented in Chapter 3 . The analysis presented in Chapter 3 is based on a thorough content analysis of the distinct responsibilities disclosed in publicly available audit committee charters from firms listed on AngloSaxon and continental European stock exchanges. I first investigate whether the number of responsibilities disclosed in audit committee charters differs significantly and systematically among firms that operate under similar disclosure regimes. Subsequently, I test whether measures of actual audit committee activity can be associated with the nominal scope of responsibilities set forth in the charters. The key question addressed here is whether audit committees actually do what is promised in publicly available audit committee charters.

Interestingly, I document statistically significant associations between the scope of responsibilities set forth in audit committee charters and the level of audit com- 
mittee activity for firms with a primary listing in Anglo-Saxon countries (stringent disclosure regime) and an absence thereof in continental Europe (voluntary disclosure setting). These results suggest that the audit committee charters of firms listed in institutional settings with a stringent disclosure regime seem to contain more substantive instead of symbolic firm-specific content, and vice versa for audit committee charters from voluntary disclosure settings.

I consequently argue that audit committee charters that are being voluntarily disclosed seem to function primarily as vehicles used by firms to gain external legitimacy via front-stage impression management, but not as a means of informing legitimate interest groups about the committees' actual responsibilities, nor of directing the internal work program of audit committees. In coercive or mandatory disclosure regimes, in turn, the professed activities of audit committees seem to be more closely related to their actual work. Implications for regulators on both sides of the Atlantic are discussed in the concluding part of Chapter 3. For my own research, these results indicate that it would be worthwhile to study cross-sectional variations in the responsibilities set forth in audit committee charters of firms operating in a mandatory disclosure environment, such as the US. I take up this point in Chapter 4, which focuses on the role of US audit committees with respect to overseeing risk management.

\subsection{Audit committees and firm performance during a financial crisis}

Can audit committees mitigate the impact of severe adverse economic events, such as the recent financial crisis, on firm performance? A number of papers provide empirical evidence suggesting that they can (e.g., Yeh et al., 2011; Aldamen et al., 2012). According to Yeh et al., independent directors on audit committees affected the level of risk-taking and subsequent performance of the 20 largest financial institutions from G8 countries during the global financial crisis which took hold in 2007. The authors argue that firms with more independent directors on their audit committees performed better during 2007-2008, because independent directors curb excessive managerial risk-taking and have incentives to provide their expert prestige and monitoring power in a crisis period leading, in turn, to better firm performance.

As far as the US is concerned, however, listed firms were already required to maintain a fully independent audit committee several years before this financial crisis took hold, according to Section 301 of the Sarbanes-Oxley-Act (SOX) of 2002. This casts doubt on the proposition that audit committee independence moved the needle in terms of audit committee effectiveness and firm performance for US listed firms during the financial crisis. Consequently, the question emerges, which factors can determine the effectiveness of fully independent audit committees to safeguard firm performance during a crisis period? 
To address this question, I follow a novel approach by applying a threedimensional framework established by Hollenbeck et al. (2012) and published in the Academy of Management Review to audit committees of S\&P 500 firms during the financial crisis that took hold in 2007. The three dimensions are authority differentiation, skill differentiation and temporal stability. For the purpose of this study, and in light of the existing audit committee literature, I define them as follows: authority differentiation is the degree to which audit committees are charged with substantial authority to oversee risk management; skill differentiation relates to the financial, governance, and firm-specific expertise of audit committee members; and temporal stability is the turnover among audit committee members.

In the study presented in Chapter 4 of this dissertation, I provide to the best of my knowledge the first empirical evidence for positive relationships between the extent of audit committee authority to oversee risk management and subsequent firm performance during a period of financial crisis. To substantiate my hypothesis that independent audit committee can safeguard firm performance during a crisis period by overseeing risk management, I run an additional analysis looking into the relation between within-firm performance variability and the three audit committee characteristics extracted from Hollenbeck et al.'s framework. The empirical results show a negative relation between firm performance variability during the financial crisis studied here and the degree of audit committee authority to oversee risk management. Based on these results, the concluding part of Chapter 4 discusses the promising role of audit committees in the context of enterprise risk management.

\subsection{Contributions}

The first study of this dissertation, presented in Chapter 2, contributes to the existing literature in several ways. First and foremost, it addresses the numerous calls that have been raised within the corporate governance community to study audit committees outside the Anglo-Saxon domain (DeZoort et al., 2002; Carcello et al., 2011). Continental Europe constitutes an interesting domain for studying the implementation of audit committee design standards in different institutional settings which fall under the common roof of the Eighth EU Directive on Company Law. The ongoing discussion about the convergence of corporate governance practices in the EU attracts considerable attention from practitioners and researchers (e.g., Becht and Meyer, 2004; Collier, 2007). There is a tremendous interest on behalf of European issuers and investors, member states and the European Commission in understanding the commonalities and differences among national corporate governance practices (Weil, Gotshal \& Manges, 2002). As far as the audit committee is concerned, a number of these commonalities and differences are presented in Chapter 2. Further, Chapter 2 adds to research that analyses the in- 
terplay between the contents of corporate narrative documents and institutional pressure for public disclosure (Holder-Webb and Cohen, 2012). Finally, the first study presented in this dissertation reinforces the merit of institutional theory and the proposition that agency theory alone may be insufficient to explain the popularity and effectiveness of audit committees in different countries and institutional settings (Cohen et al., 2004).

The second study presented in Chapter 3 contributes to the literature on audit committees, disclosure and the effectiveness of regulation in three ways. First, it provides countervailing evidence to the conclusions of Carcello et al. (2002). By studying the relationship between audit committee charters and reports, the aforementioned authors find that what audit committees say they are doing differs from what the charters say the committee should be doing. My study, however, shows significant associations between the information disclosed in audit committee charters and measures of actual audit committee activity. Second, Chapter 3 extends the literature on the determinants of audit committee diligence, which has so far not taken into account cross-sectional variations in audit committee scope (Raghunandan and Rama, 2007; Sharma et al., 2009). Third, the results show that professed audit committee responsibilities are more closely related to the committees' actual work in stringent disclosure regimes. Such evidence is important for informing policymakers and investors about the effectiveness of regulation and the informativeness of audit committee charters.

The final and third study presented in Chapter 4 makes two major contributions to the existing audit committee literature. First, it corroborates mounting empirical evidence suggesting that effective audit committees can mitigate the impact of significant adverse economic events, such as a financial crisis, on firm performance (Yeh et al., 2011; Aldamen et al., 2012). Second, it shows the merit of combining two strands of research that have hitherto been undertaken mostly separate from each other. The existing audit committee literature is dominated by agency theory which dictates that the degree of independence is the primary determinant of audit committee effectiveness. However, in a setting like the US, which mandates that all audit committee members need to be independent from management and the company's affairs, agency theory alone may be insufficient to explain variations in audit committee effectiveness. By drawing from the literature on team effectiveness published in the realm of organizational studies and social psychology, Chapter 4 provides new insights and evidence regarding the factors that may determine the effectiveness of audit committee staffed exclusively with independent directors. 


\subsection{Outline of the dissertation}

The following three chapters provide new insights into audit committee design and effectiveness. Figure 1.1 illustrates the research framework followed in this dissertation, using the Input-Process-Output (I-P-O) model to study team effectiveness (McGrath, 1984; Hackman, 1987). Input factors are audit committee design components that contribute to audit committee effectiveness and that can be made explicit, i.e. the responsibilities or size of the audit committee. Processes, in turn, relate to the actual work done by audit committees. Finally, output factors are measures of audit committee effectiveness, such or improved information quality, stronger internal controls, or higher levels of investor confidence. Each chapter is focused on one element of the I-P-O model. I draw on the information set forth in publicly available audit committee charters in each chapter.

In Chapter 2, I study audit committee charters as an instrument used by regulators to establish audit committee design standards (i.e. input factors). In Chapter 3 , I investigate if the actual work of audit committees is related to what is promised in the charters (input $\rightarrow$ process). In Chapter 4, I study the relationship between the mandate defined in audit committee charters to oversee risk management and firm performance during a financial crisis (input $\rightarrow$ output).

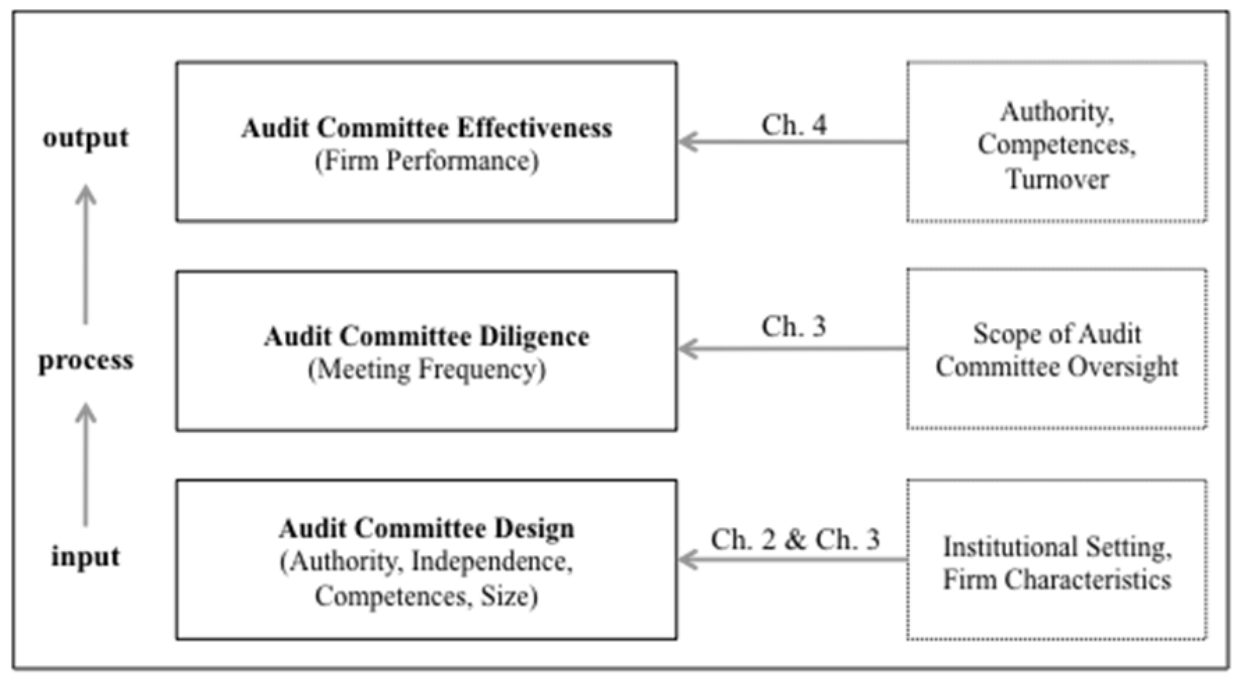

Figure 1.1 Overview of research framework based on an input-process-output model of audit committee effectiveness (see also: DeZoort et al., 2002; Bédard and Gendron, 2010). 


\title{
CHAPTER 2 The Design of Audit Committees in Continental Europe ${ }^{2}$
}

\begin{abstract}
In this study we shed light on the design of audit committees in continental Europe by analysing the contents of the Eighth EU Company Law Directive, European codes of governance, and corporate audit committee charters. Our results show substantial cross-national differences in the scope of responsibilities to be addressed by audit committees, in the competences required of committee members, and the proportion of independent committee members. The extent of differentiation comes as a surprise in light of prevailing pressures for isomorphism in the design of audit committees. A closer analysis of publicly available audit committee charters shows that compulsory disclosure requirements can increase the effectiveness of coercive isomorphism, but, consistent with prior literature, can also increase the percentage of unoriginal content in corporate documents. Our results contribute to the scant knowledge about audit committees outside the Anglo-Saxon domain and inform practice about implementing audit committee design standards in the EU.
\end{abstract}

\footnotetext{
2 This chapter is based on Böhm, Bollen, and Hassink (2013), published in the International Journal of Auditing under the title "Spotlight on the Design of European Audit Committees: A Comparative Descriptive Study.
} 


\subsection{Introduction}

The European Parliament and Council amended the Eighth Directive on Company Law in 2006, requiring entities operating in the public interest to establish an audit committee (henceforth AC). The EU Eight Directive highlights that ACs have evolved from a virtually unheard and purely voluntary initiative (Vanasco, 1994), into an essential and mandatory element in the continental European system of corporate governance. Consequently, the question that corporate governance committees, boards of directors and supervisory boards in Europe face today is not whether ACs should be established, but how to design an effective and efficient AC. ${ }^{3}$ It is of importance to address this question, because competent and independent ACs can strengthen and maintain investor confidence in financial information and markets (Davidson et al., 2004; DeFond et al., 2005). Since investor confidence in capital markets is a prerequisite for widely available sources of funding and the evolution of capitalism and prosperity (Bernstein, 2004), European policymakers and firms should have a keen interest in specifying AC design standards that strengthen AC effectiveness and corporate legitimacy.

However, relatively little is known about the way ACs are designed in continental Europe. The vast majority of published AC research focuses on ACs within Anglo-Saxon corporate governance environments (Bédard and Gendron, 2010). ${ }^{4}$ Since interdependencies between organizations and their environments may lead to variations in the effectiveness of governance practices (Denis and McConnell, 2003; Aguilera et al., 2008), it cannot be assumed without further evidence that an effective and efficient AC in continental Europe should be designed in the same way as for example in the US, UK, or Australia. On the contrary, research indicates that parties having a say on AC design should be careful when mimicking AC design standards, because cross-national differences have been found to impact the relationship between AC characteristics and AC effectiveness. In other words, ACs do not operate in a vacuum and they cannot be designed and studied properly without regard to the institutional and organizational context in which they function (Turley and Zaman, 2004).

Europe constitutes an interesting area for studying ACs, because the EU Eighth Directive mandates AC formation for listed companies without setting stringent rules on how ACs should be designed. Furthermore, the Eighth Directive does not indicate how AC design standards should be implemented at the national level. Thus, national governance committees and corporate boards enjoy considerable

\footnotetext{
${ }^{3}$ We define AC design as the implementation and stipulation of AC characteristics that are thought to contribute to the committees' effectiveness or institutional legitimacy. Guzo and Dickson (1996: 334) suggest that the design of a group is one out of three primary points of leverage for intervening to enhance team effectiveness, the other two points being team processes and context.

${ }^{4}$ The literature review of Bédard and Gendron (2010) shows the research gap regarding ACs in continental Europe. Out of 103 studies reviewed by the authors, 86 have been conducted in an Anglo-Saxon context (Australia, Canada, UK, US, New Zealand), and merely six in a continental European setting.
} 
leeway in implementing and extending the standards set by the Eighth Directive. Because the historic reliance on ACs as well as the environments in which ACs work differ from one country to another in continental Europe, it is interesting to study the ebb and flow of differentiation and isomorphism in AC design standards.

Specifically, we examine the extent to which the design of corporate ACs in continental Europe is driven by regulatory regimes, which foster the establishment of isomorphic AC design standards, versus firm- or country-specific forces that lead to differentiation in $\mathrm{AC}$ design in order to enhance the effectiveness of the committee within a specific national or corporate context. By analysing the contents of corporate AC charters and national codes of governance in a multiple country setting, we shed light on the way ACs have been designed at the national and corporate level in continental Europe after the EU Eighth Directive came into effect. Thereby, we provide empirical evidence for isomorphism and differentiation in AC design standards across the EU, on whether coercive pressures for isomorphism enacted by the EU Eighth Directive and national codes have been effectively implemented in $\mathrm{AC}$ charters, and whether the AC charters contain significant boilerplate language as a proxy for mimetic isomorphism.

The results presented in this study address calls for AC research outside the Anglo-Saxon domain (e.g., DeZoort et al., 2002; Bédard and Gendron, 2010; Carcello et al., 2011) and contribute to a better understanding of the commonalities and differences between governance practices in EU Member States (Weil, Gotshal \& Manges, 2002). The ongoing discussion about the convergence of corporate governance practices in (continental) Europe attracts considerable attention from practitioners as well as from the academic community (Becht and Mayer, 2004; Collier, 2007; Enriques and Volpin, 2007). By studying the contents of corporate $\mathrm{AC}$ charters we inform research and practice about firm level convergence in AC design and the effectiveness of coercive pressures enacted by the EU Eighth Directive and national codes to establish isomorphism in AC design at the firm level. ${ }^{5}$

Our sample includes the most recent governance codes from six continental European countries and the AC charters of 157 firms with a primary listing on the respective stock exchanges. The countries featured here are Belgium, France, Germany, Italy, Spain, and the Netherlands. To focus our study on relevant AC design factors, we make use of AC specific literature reviews by DeZoort et al. (2002) and Bédard and Gendron (2010). Both studies identify five potential input factors for AC effectiveness: (1) the responsibilities assigned to the AC, (2) the competence of

\footnotetext{
${ }^{5}$ Yoshikawa and Rasheed (2009) convincingly argue that it is not enough to study institutional convergence. It is also important to investigate firm-level convergence as well as the relationship between institutional and firm-level convergence, in particular in civil law countries, where governance codes tend to be more lenient.
} 
committee members, (3) the independence of committee members, (4) the size of the committee and (5) the meeting frequency of the committee. 6

This chapter is organized as follows. The next two sections provide information on AC design, the institutional setting in continental Europe, and our research questions. Thereafter, we outline the sample and data collection procedures employed, followed by content analysis of the EU Eighth Directive, national codes, and AC charters. We conclude this chapter with a discussion of the main findings, and of the limitations and implications of the study at hand.

\subsection{Designing an audit committee}

Addressing the question of how an AC should be designed has become a central theme of corporate governance reform and research. Regulatory authorities on both sides of the Atlantic attribute a key role to ACs when it comes to safeguarding high quality financial reporting, external auditing and internal control, thereby contributing to the perception of ACs as 'guardians of public interest' (Levitt, 1998; Bolkenstein, 2004). Consequently, it does not come as a surprise that ACs may serve as a common denominator for investors assessing corporate governance quality (Hopt and Leyens, 2004).

Due to the importance attributed to ACs for safeguarding investor confidence in financial information and markets, parties that have a say on audit committee responsibilities, compositions and working procedures should have a keen interest in specifying standards that are thought to contribute to committees' effectiveness and to investor confidence in the work of the committee. Prior research shows that setting AC standards matters, because differences in AC characteristics may impact direct measures of $\mathrm{AC}$ performance, like preventing fraud in financial statements or the aggressive management of earnings, (e.g., Beasley et al., 2000; Bédard et al., 2004; Lin and Hwang, 2010), but also choices of participants in the financial market (Davidson et al., 2004; DeFond et al., 2005).

DeZoort et al. (2002) as well as Bédard and Gendron (2010) have reviewed the literature on ACs with the objective of summarizing the input factors of effective ACs. Both studies identify five AC characteristics that have been used predominantly to study AC effectiveness: (1) responsibilities granted to the AC, (2) the competences of committee members, (3) AC members' independence from management and the company's affairs, (4) the number of members serving on the AC, and (5) the frequency of AC meetings. Bédard and Gendron show that the first three AC characteristics have been found to be correlated quite frequently with

\footnotetext{
${ }^{6}$ Even though in the main the first three input factors have been found in literature to be frequently correlated with measures of AC effectiveness, we do not exclude AC size and frequency of meetings from our study. The reason is that these findings are based on US data and to date have not been confirmed internationally.
} 
measures of AC effectiveness, while empirical evidence is less convincing for a correlation between AC size or meeting frequency and effectiveness. Regarding AC size, Bédard and Gendron find that the proportion of studies finding a negative relation to $\mathrm{AC}$ effectiveness is almost as high as the proportion reporting a positive relation. Consequently, we would expect that parties that have a say on AC design place particular emphasis on AC responsibilities, competences and independence and are less stringent in setting standards for AC size and meeting frequency.

However, setting standards for AC responsibilities, competences and independence that can make a difference in terms of AC effectiveness or efficiency is neither a simple nor tautological matter. It is not a simple matter because it requires precise answers about the scope of responsibilities to be delegated from the board to the AC and the corresponding tasks the committee should assume in fulfilling these responsibilities; answers are also required about the competences that AC members need to bring with them and the number or proportion of committee members who should possess these respective competences, and about the number or proportion of AC members who should be independent from the company's affairs and the criteria used in designating these members as independent.

Due to the evolving role of ACs in the corporate governance mosaic, expectations regarding the scope of responsibilities to be addressed by ACs, as well as exigencies regarding $\mathrm{AC}$ competences and independence have increased considerably over time (Cohen et al., 2004). ACs have been under constant pressure to increase the scope of their oversight work (Zaman, 2001; Beasley et al., 2009). However, given the limited time and resources available to ACs, it is critical to determine the scope of their responsibilities, while keeping in mind that the set of responsibilities should have an impact on the competences that AC members should possess, as well as on the size and meeting frequency of the committee (Lee and Stone, 1997; Verschoor, 2008). Moreover, corporate governance scandals have increased demand for more independent ACs, leaving standard setters with the challenging task of defining the level of AC independence (Bronson et al., 2009).

So far, regulators, practitioners and researchers around the world have not yet agreed on a generally accepted specification of the five AC design factors described here, pointing to the fact that after all, designing an AC is not a tautological matter. Evidence from the field of comparative corporate governance indicates that interdependencies between organizations and their environments lead to variations in the effectiveness and legitimacy of governance mechanisms and practices (e.g., Denis and McConnell, 2003; Khanna et al., 2006; Aguilera et al., 2008). Thus, parties that have a say on AC design should be careful when mimicking AC design standards across institutional settings (Bédard and Gendron, 2010). For AC research, this implies that ACs cannot be designed and studied properly without regard to the institutional and organizational context in which they function (Turley and Zaman, 2004). 


\subsection{The institutional setting in continental Europe}

\subsubsection{Audit committees in continental Europe}

In the US, mandating the formation of ACs for listed companies and extending the committees' roles and responsibilities has been an integral part of corporate governance reform since the 1940s. In continental Europe, on the other hand, ACs did not play an important role in the governance of publicly held companies for most of the twentieth century. In 1994, Vanasco published an article entitled 'The Audit Committee: An International Perspective'. The article outlines that ACs had become important features of publicly owned corporations not only in the US, but also internationally. By the early 1990s, ACs were required by statute for public companies in Canada, Israel, and Singapore and were gaining broad acceptance in inter alia Australia, New Zealand, South Africa, and the UK. By contrast, in continental Europe ACs were still rare at that time (Vanasco, 1994: 23).

Shortly after the publication of Vanasco's article, corporate governance reports were issued in France (Viénot, 1995) and the Netherlands (Peters Report, 1997), recommending the formation of ACs for listed companies. Sparked by the promotion of the AC concept in France and the Netherlands, the impact of international market forces and the increasing interest of authorities and regulators in governance issues (PriceWaterhouse, 1997), the AC concept gained momentum in continental Europe. By 2003, the vast majority of corporate governance codes issued in Europe included a recommendation for listed companies to establish an AC (Collier and Zaman, 2005).

However, due to the non-binding nature of these corporate governance codes, AC formation remained voluntary for companies listed on continental European stock exchanges. Data gathered between 2001 and 2003 in Belgium, France, and Spain shows that voluntary AC formation rates were between 50 and $63 \%$ (Willekens et al., 2004; Piot and Janin, 2007; Ruiz-Barbadillo et al., 2007). Köhler (2005) finds higher AC formation rates in Germany, as 29 out of 30 companies quoted on the DAX and 39 out of 50 companies quoted on the MDAX had established an AC by 2003.7 These numbers illustrate that unlike in many Anglo-Saxon countries, establishing an $\mathrm{AC}$ was not a standard board practice in Europe at that time.

This was due to change when the EU Eighth Directive came into effect 17 May 2006. According to Borchardt $(2010,90)$, EU directives aim to gradually iron out inconsistencies between national regulations so that, as far as possible, the same material conditions exist in all member states; this is generally seen as a prerequi-

\footnotetext{
${ }^{7}$ The German Cromme Commission Code, issued in 2002, already required DAX and MDAX constituents to disclose, on a 'comply or explain' basis, whether they have established an AC. The respective Belgian, French and Dutch codes in existence at that time 'only' encouraged voluntary disclosure of AC formation.
} 
site in order to establish a single European market. ${ }^{8}$ The EU Eighth Directive defines statutory auditing standards for EU Member States. Implementing the standards defined by the EU Eighth Directive is important for the establishment of a single European capital market, because we are concerned with 7,000 listed companies and the need for improving and harmonizing the approximately two million statutory audits conducted annually in the EU (Braiotta and Zhou, 2008).

One of the key standards stipulated by the EU Eighth Directive is the requirement that all public interest entities establish an AC. Interestingly, Article 41 of the Eighth Directive requires member states to make sure that listed companies establish an AC, but it does not set stringent standards on how ACs should be designed (see Appendix for excerpts from the EU Eighth Directive). The rationale of the European Commission for taking this approach is based on the premise that a detailed pan-European corporate governance code that fits well with the varying legal frameworks in Europe is more likely to express a negotiated 'lowest' common denominator of 'acceptable' practice, rather than true 'best practice' (Weil, Gotshal \& Manges, 2002: 7). Resulting from the European Commission's approach of mandating AC formation without setting stringent AC design standards, national standard setters and corporate boards enjoy considerable leeway in defining more stringent AC design standards.

At the national level in Europe, corporate governance committees provide recommendations, in the form of corporate governance codes, regarding the way the ACs in the respective country should be designed. Collier and Zaman (2005) have analyzed the AC design recommendations of 20 European corporate governance codes, before the EU Eighth Directive came into effect. Their results show that European codes were not consistent in the specification of AC design in terms of membership, independence, financial qualification and frequency of meetings. Similarly, the ACs' wider role in financial reporting, external auditor selection, internal control, and risk assessment was not always explicitly stated in the codes. The authors conclude that the AC concept has been widely accepted in Europe, but that there is limited consistency in AC design recommendations at an operational level.

However, the insights presented by Collier and Zaman concern AC design recommendations provided by codes of good governance, which are not legally binding. Since corporate governance codes are non-binding sets of principles, standards or best practices, adopting their recommendations at firm level is voluntary.

\footnotetext{
${ }^{8}$ Borchardt (2010: 90) outlines that EU directives are binding on Member States as regards to the objectives to be achieved but leave it up to national authorities to decide on how the agreed objective is to be incorporated into their domestic legal systems. Thus, EU directives do not supersede national laws, but place Member States under the obligation to adapt their laws accordingly. The judgments on Francovich and Bonificaci in 1991 shows that the Court of Justice of the European Union does not tolerate disadvantages accruing to EU citizens due to non-implementation of EU directives. Both cases were brought against Italy for failure to transpose a Directive on the protection of employees in the event of the employer's insolvency.
} 
Thus, boards of directors or supervisory boards might decide to design ACs in a different manner; that is they have the freedom to specify more stringent, less stringent, or different AC design standards than those recommended by the respective code of governance. Willekens et al. (2004) for example find that a substantial number of Belgian-listed companies did not follow the recommendations of the Brussels stock exchange, and Talaulicar and Werder (2008) point out that companies can deviate from the recommendation of corporate governance codes in order to better incorporate sector and industry-specific requirements. Therefore, we agree with Yoshikawa and Rasheed (2009) that it is important to complement corporate governance research at the institutional (national) with corporate (firm) level studies.

\subsubsection{Isomorphism and differentiation in audit committee design}

One of the key debates in corporate governance research concerns the question whether corporate governance practices are becoming homogenous, or whether they remain differentiated across countries and firms (Jeffers, 2005; Khanna et al., 2006; Yoshikawa and Rasheed, 2009). The concept that best captures the process of homogenization in corporate governance is called isomorphism, which can be defined as a constraining process that forces one unit in a population to resemble other units that face the same set of environmental conditions (Hawley, 1968).

Continental Europe constitutes an interesting setting for studying isomorphism in corporate governance practices due to the diversity in institutional settings combined with the common umbrella of the EU and its goal of establishing a single European market. In a study conducted on behalf of the European Commission, the law firm Weil, Gotshal \& Manges (2002: 1) outlines that: "The adoption of a common European currency, the freer flow of capital, goods, services and people across EU borders, the competitive pressures of globalisation, the growth and diffusion of shareholding, and increased merger activity among large European corporations and stock exchanges, all create tremendous interest on behalf of European issuers and investors, Member States and the European Commission in understanding the commonalities and differences between national corporate governance practices, and any related barriers to the development of a single EU capital market". Consequently, we study the following research question regarding the degree of isomorphism and differentiation in AC design standards in continental Europe:

RQ1a: To what extent are AC design standards as set in corporate governance codes and $A C$ charters isomorphic and to what extent differentiated in continental Europe? 
In searching for theories that can explain the degree of differentiation and isomorphism in AC design standards, we find that most scholars refer to efficiency and institutional theory when explaining the adoption of new practices within a social system (DiMaggio and Powell, 1983; Tolbert and Zucker, 1983; Strang and Macy, 2001). Efficiency theory considers organizations as rational actors, and points to the gains in effectiveness or efficiency following the adoption of a new practice (Thompson, 1967). Institutional theorists, in turn, outline that organizations compete not just for resources and customers, but also for political power and legitimacy and consequently become captives of the institutional environment in which they exist (Carroll and Delacroix, 1982; Zattoni and Cuomo, 2008).

In their seminal paper on what makes organizations similar, DiMaggio and Powell (1983) establish three kinds of institutional isomorphic change: coercive, mimetic, and normative isomorphism. ${ }^{9}$ Coercive isomorphism comes about as the result of external regulatory-type pressures for organizational convergence (Cohen et al., 2008). Coercive isomorphism pressures in Europe primarily stem from EU bodies and national corporate governance committees aiming to harmonize governance practices on a pan-European and on a national level, respectively. If these pressures are strong enough, we would expect that national corporate governance committees and boards of directors implement the minimum AC design requirements set by the EU Eighth Directive and that boards of directors follow the recommendations of the respective governance code. To study the degree to which coercive pressures from the European Commission and national corporate governance committees are effective, we address the following research questions:

RQ2a: Are AC design requirements of the EU Eighth Directive implemented in national corporate governance codes (coercive isomorphism: Eighth Directive CG codes)?

RQ2b: Are AC design recommendations provided by the EU Eighth Directive implemented in corporate AC charters (coercive isomorphism: Eighth Directive - AC charters)?

RQ2c: Are AC design recommendations given by national codes of governance implemented in corporate $A C$ charters (coercive isomorphism: CG codes - AC charters)?

However, not only coercive forces shape the adoption of organizational practices, but also pressures for mimetic isomorphism. Uncertainty and goal ambiguity is a

\footnotetext{
${ }^{9}$ Normative pressures for institutional isomorphism primarily stem from professional associations (Galaskiewicz, 1985). We do not study the degree of normative isomorphism in the context of AC design standards in continental Europe, due to the absence of professional associations like the American Institute of CPAs (AICPA) or the Institute of Chartered Accountants in England and Wales (ICAEW).
} 
powerful force for imitation and mimetic isomorphism (DiMaggio and Powell, 1983). Since ACs have historically been an Anglo-Saxon corporate governance mechanism, not firmly established in continental Europe, we expect certain levels of uncertainty regarding AC design. The aim of the EU Eighth Directive is to set minimum AC design standards and leave member states and corporate boards considerable leeway to develop AC design standards that reflect national institutional as well as firm-specific considerations. As a response to uncertainty and AC goal ambiguity, corporate governance committees and corporate boards in continental Europe may model themselves and follow a 'copy and paste' approach to AC design. Holder-Webb and Cohen (2012) point out that unoriginal material in form of boilerplate information in codes and charters is a natural response to uncertainty and mimetic isomorphism. ${ }^{10}$ Thus, convergence in the language used in corporate $\mathrm{AC}$ charters can be seen as a sign of mimetic isomorphism. In order to study the presence of mimetic isomorphism in AC design across continental Europe, we investigate whether boilerplate language is used when setting AC design standards.

RQ3: Do corporations in continental Europe resort to unoriginal, boilerplate type language in AC charters consistent with mimetic isomorphic pressures (mimetic isomorphism)?

By addressing these research questions we aim to contribute to academic literature and inform practice by shedding light on the establishment of AC design standards in continental Europe. We add to literature in the field of comparative corporate governance by providing evidence for differentiation and isomorphism in relevant AC design standards throughout continental Europe. For parties that have a say on AC design, we offer interesting evidence whether the coercive pressures of the EU Eighth Directive and national codes have been effectively implemented in corporate $\mathrm{AC}$ charters. We complete our analysis regarding $\mathrm{AC}$ design standards in continental Europe by providing evidence for the degree of boilerplate language in $\mathrm{AC}$ charters as a proxy for mimetic isomorphism.

\subsection{Methodology}

In order to study the way ACs are designed in continental Europe and to address the research questions we analyze the contents of the EU Eighth Directive, corporate governance codes and corporate AC charters. We analyze publicly available, front-stage information regarding AC design matters, because structural parameters can play a major role in shaping the authority, composition and practices of

10 "Boilerplate" is defined by the American Heritage Dictionary of the English Language as "inconsequential, formulaic, or stereotypical language". 
ACs. After all, empirical and anecdotal evidence suggests that society cannot rely solely on market mechanisms and that some form of regulation is necessary (Kirkbride and Letza, 2004). AC charters indicate how corporations have formally adopted authoritative guidance in designing their AC. Although these documents do not necessarily reflect actual $\mathrm{AC}$ activity, they can provide power and legitimacy to AC members and signal the committees' responsibilities to external parties (Greene and Falk, 1979; Kalbers and Fogarty, 1993). Thus, AC charters constitute relevant data for researchers (Bédard and Gendron, 2010) and for the objectives of the study at hand.

For comparative purposes, we limit the scope of this study to the following six continental European countries: Belgium, France, Germany, Italy, Spain, and the Netherlands. ${ }^{11}$ Continental Europe constitutes an interesting setting for studying the adoption of AC design standards outside the Anglo-Saxon corporate governance domain, due to the dichotomy between the two institutional settings in terms of corporate governance systems and practices (e.g., Becht and Mayer, 2003; Clarke, 2007). Accordingly, we exclude the UK and Ireland from the scope of this research. We retrieved the latest corporate governance codes issued in the six countries selected for the purpose of this study from the ECGI website (http://www.ecgi.org). Table 2.1 details the codes analyzed. We outline per code: the type of issuer, the compliance mechanism used, whether the code requires or recommends that companies disclose an audit committee charter.

As specified in Table 2.1, five out of the six codes featured here rely on a mandatory disclosure requirement to encourage compliance. The so-called "comply or explain" principle used by these codes implies that companies falling within the scope of the code are required to publicly explain non-compliance with the codes' recommendations. However, the comply or explain principle does not apply to all recommendations given by the respective codes. The word "shall" implies that companies need to publicly explain deviations from the respective code recommendation, while the term "should" means they can deviate from the recommendation without further explanation. The Belgian and Spanish codes state that companies should disclose an $\mathrm{AC}$ charter, while the Dutch code requires that companies shall make an AC charter available on their website. The French, German, and Italian codes give no recommendations for establishing an $\mathrm{AC}$ charter at the time of this study.

In order to study the contents of corporate AC charters, we selected the main stock market index of the countries featured in this study as our sample. Consequently, our primary research population for conducting a content analysis of corporate $\mathrm{AC}$ charters constitutes all corporations included in the following stock market indices: BEL20, CAC40, DAX30, FTSE MIB40, IBEX-35 and AEX25. This provided an initial sample of 190 corporations. We excluded all corporations with

11 These countries are selected based on the number of constituents in the FTSE EURO 100 index and represented $93 \%$ of the index constituents at the time of this study. 
a cross listing either in the UK or US due to the specific requirements regarding AC design for corporations cross-listed on Anglo-Saxon stock exchanges. Moreover, double counting of European cross listings was prevented. The final sample contained 157 corporations. ${ }^{12}$ In June 2010, we retrieved the most recent AC charters from the respective corporate websites, and annual or corporate governance reports.

To address our research questions, we apply content analysis techniques to the EU Eighth Directive, national corporate governance codes and corporate AC charters. This allows us to study the degree of isomorphism and differentiation in AC design standards throughout continental Europe (RQ1) as well as the effectiveness of the coercive pressures for isomorphism enacted by the Eighth Directive (RQ2a \& $\mathrm{RQ} 2 \mathrm{~b}$ ) and national corporate governance codes (RQ2c). To analyze the degree of unoriginal language in AC charters we employ content analysis software designed to discriminate between original and unoriginal material in narrative documents. In line with Holder-Webb and Cohen (2012) we use the web-based artificial intelligence program SafeAssign (2011) to address RQ3.13

\footnotetext{
${ }^{12}$ For the content analysis regarding AC responsibilities we used 'human-scored schemes'. A drawback compared to 'word-count' or 'artificial intelligence measurement of disclosure' based approaches is that human scoring requires considerable effort, and thus limits our sample size to 157 observations. However, we chose this approach as it provides comparatively high validity in the context of this research (e.g., Conway, 2006).

${ }^{13}$ Holder-Webb and Cohen (2012) used the predecessor of SafeAssign called Mydropbox to analyze the level of boilerplate language in codes of ethics. The analysis is based on a comparison of a given document with a database composed of publicly available Internet documents and body of literature indexed by the ProQuest ABI/Inform database, institutional documents archives, and a Global Reference Database (see www.safeassign.com). Thus, sample charters are compared against the text indexed by these sources, as well as the charters that were submitted for all other sample firms.
} 


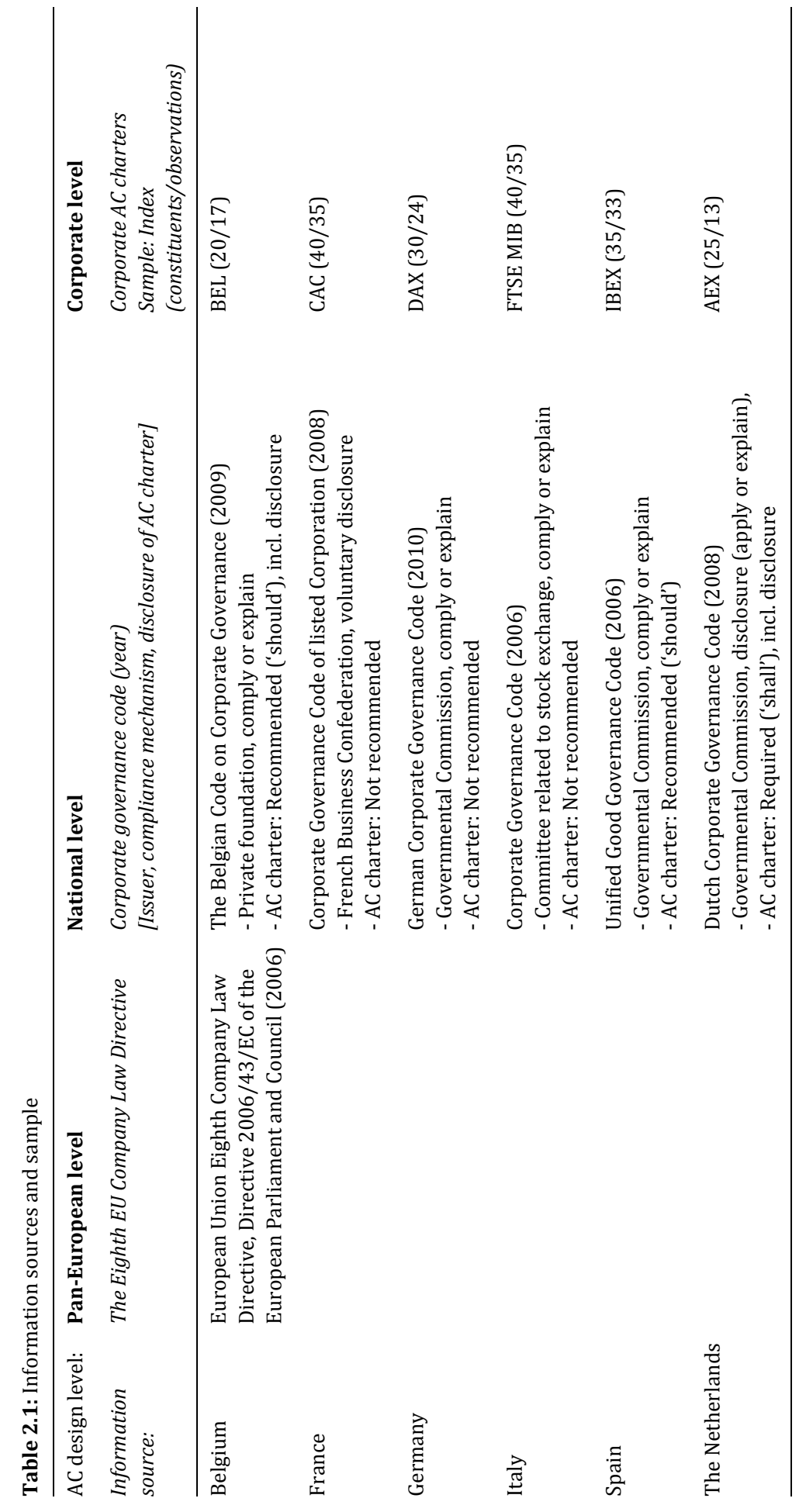




\subsection{Empirical findings}

The following discussion of the empirical results is based on the five AC characteristics that have been studied predominantly by prior research about audit committee effectiveness (DeZoort et al., 2002; Bédard and Gendron, 2010). For each characteristic, we provide a comparative discussion about the requirements of the EU Eighth Directive, the recommendations of national corporate governance codes, and the contents of the sample AC charters. At the end of each sub-section we briefly summarize the main findings.

\subsubsection{Audit committee responsibilities}

When it comes to AC design, it is important to decide what scope of responsibilities should be delegated from the board to the AC, and which tasks the AC should perform to effectively discharge these responsibilities. Defining the responsibilities of the AC in the form of a charter is viewed as being important, because AC members demand clarity about the scope of responsibilities they need to address and the power to carry out these responsibilities (Kalbers and Fogarty, 1993; DeZoort, 1997). Bédard et al. (2004) and Abbott et al. (2007) provide empirical evidence that inscribing responsibilities in $\mathrm{AC}$ charters can contribute to $\mathrm{AC}$ effectiveness. Besides contributing to committee effectiveness, accurate AC charters enable the public to form expectations about what the AC can accomplish (Greene and Falk, 1979).

Table 2.2 summarizes the contents of the EU Eighth Directive, continental European corporate governance codes and AC charters regarding the responsibilities to be addressed by ACs. First, we list a total of seven responsibilities that, according to the Eighth Directive should be addressed by every AC in the EU. For each country featured in this research we indicate whether the latest corporate governance code recommends that ACs assume the respective responsibility (demarcated by ' $\mathrm{X}$ ') and the percentage of AC charters that were analyzed stating that the AC addresses the respective responsibility (noted by '\%').

By analyzing the contents of the governance codes and AC charters in our sample, we identified an extended number of AC responsibilities that were not explicitly mentioned by the EU Eighth Directive, but in one or more corporate governance codes and AC charters. For illustrative purposes we classified these responsibilities into the more general fields of activity 'external audit and reporting', 'internal audit', and 'compliance and governance related'. These categorisation schemes follow prior clustering of AC responsibilities used in audit committee literature (e.g., Wolnizer; 1995; DeZoort, 1997; Carcello et al., 2002).

We show additional descriptive figures at the bottom of Table 2.2. First, we outline per country the total number of AC responsibilities recommended by the respective corporate governance code as well as the average number of responsi- 
bilities disclosed in the AC charters studied. We also show the average disclosure rate in $\mathrm{AC}$ charters for the responsibilities required by the Eighth Directive and for those responsibilities recommended by the applicable governance code. These figures indicate the scope of responsibility assigned to ACs in the respective countries as well as the degree of implementation of the Eighth Directive and of national corporate governance provisions in AC charters.

A number of key findings can be derived from the results presented in Table 2.2. First, when comparing these responsibilities with prior research on $\mathrm{AC}$ responsibilities conducted in an Anglo-Saxon context (Green, 1994; Carcello et al., 2002; Walker, 2004), we find that the responsibilities assigned to continental European ACs closely resemble those identified by prior studies focusing on the Anglo-Saxon context. We can also confirm the observation of prior research that the scope of AC oversight has expanded well beyond oversight over external reporting and the external auditing process, towards more oversight responsibilities in the area of internal governance of corporations (e.g., Beasley et al., 2009).

Second, the scope of responsibilities assigned to ACs in continental European differs substantially between the countries studied. Our results indicate that ACs of Belgian, Spanish and Dutch-listed corporations are directed to address significantly more responsibilities than their French, German and Italian counterparts. The differences in the scope of responsibilities assigned to ACs between the six countries are most evident when contrasting the findings of the German with the Dutch sub-sample. We identify a total of 20 separate AC responsibilities in the Dutch code and the average number of responsibilities disclosed in the AC charters is 17.5. For Germany, in turn, we find that the German code recommends 11 separate AC responsibilities and the average number of disclosed responsibilities in AC charters is 7.4. 


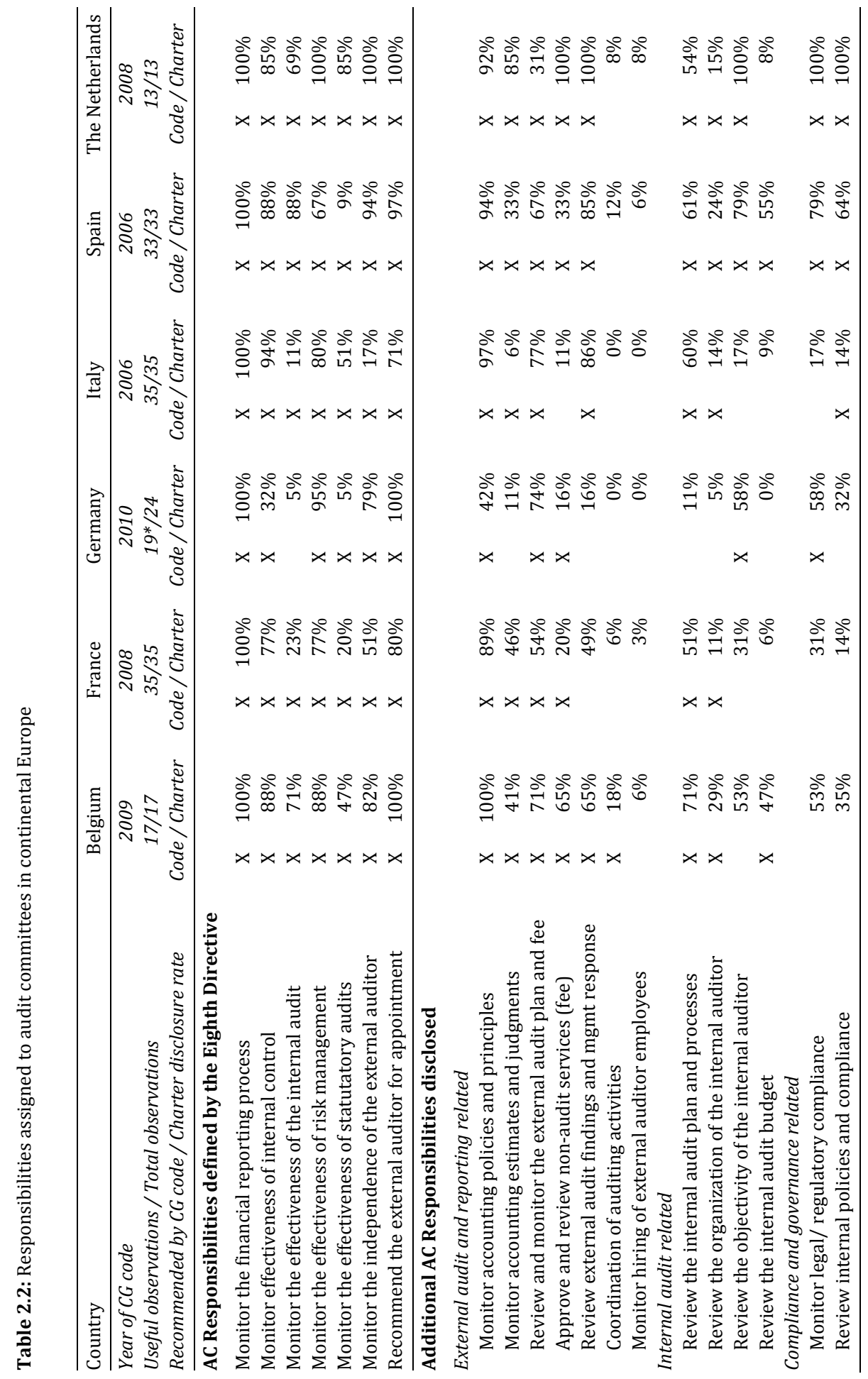




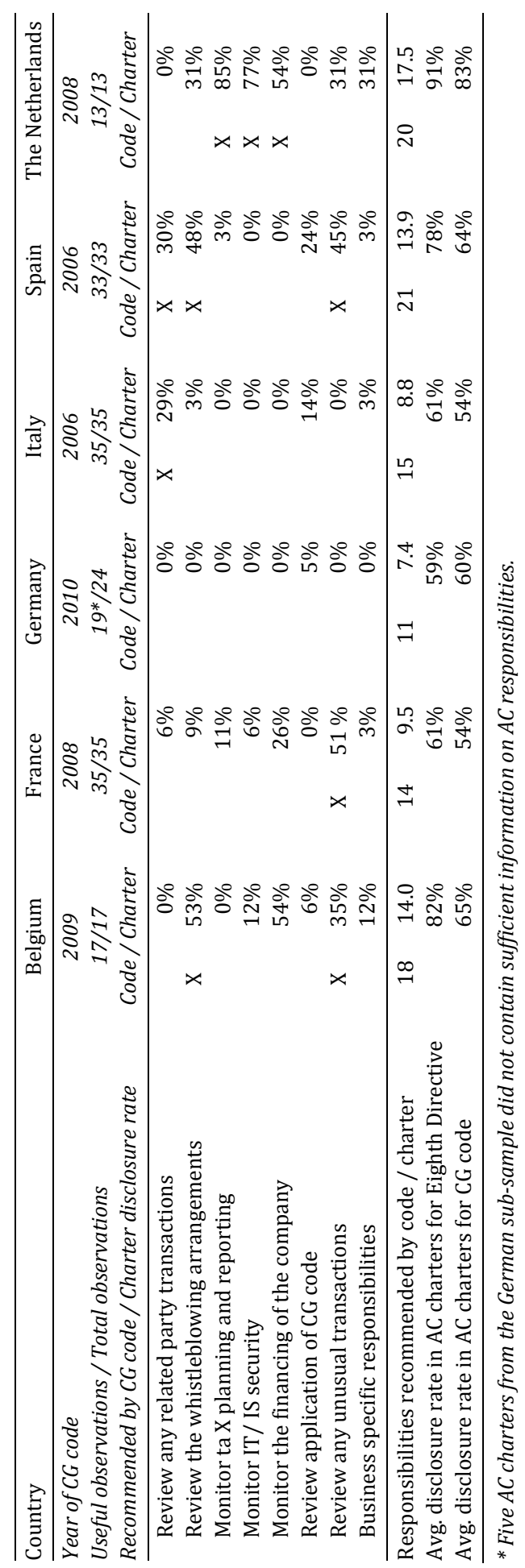


The differences in AC scope between the two groups of countries is primarily driven by the fact that ACs of Belgian, Spanish and Dutch-listed corporations are expected to address more responsibilities in the areas of internal auditor oversight as well as compliance and governance related responsibilities. More specifically, the Spanish and Dutch corporate governance codes recommend an extended set of $\mathrm{AC}$ responsibilities, including for example oversight over compliance with internal policies, whistleblowing arrangements, IT/IS security and corporate tax planning. From the content analysis data presented in Table 2.2 we conclude that four years after the EU Eighth Directive came into effect, authoritative opinion about the scope of responsibilities to be addressed by ACs differs throughout Europe. The differences in the recommended scope of AC responsibilities given by the national codes are reflected in the responsibilities formally assigned to ACs by means of their charter.

Third, we can compare the required responsibilities as stated in the EU Eighth Directive and the recommended responsibilities of the corporate governance codes with the disclosure rate in $\mathrm{AC}$ charters. By comparing the average disclosure rates in AC charters with the respective governance code and the Eighth Directive we analyse the effectiveness of the coercive pressures for isomorphism in AC design enacted by pan-European and national standards. We find comparatively high average disclosure rates for the seven responsibilities stipulated by the Eighth Directive for AC charters from the Netherlands (91\%), Belgium (82\%) and Spain (78\%). For the German, French and Italian charters we find lower average disclosure rates of $59 \%$ to $61 \%$. The disclosure rates of the $\mathrm{AC}$ responsibilities recommended by the national corporate governance codes featured in this research in corporate AC charter range from $83 \%$ for the Netherlands to $54 \%$ for the French and Italian sub-samples.

To summarize, we find that the scope of responsibilities formally assigned to audit committees varies substantially in continental Europe, at both the national and corporate level. Corporate governance codes issued in Spain and the Netherlands recommend that audit committees address a relatively broad scope of responsibilities. Codes recently issued in France, Italy and in particular Germany, in turn, indicate fewer responsibilities that should be addressed by audit committees. The average number of responsibilities disclosed in the charters show that inter country differences in AC scope also hold at the corporate level. The requirements given by the EU Eighth Directive regarding the responsibilities to be addressed by audit committees have been implemented in the corporate governance codes. However, the average disclosure rates in the audit committee charters for the responsibilities required by the Eighth Directive and for those recommended by the respective codes are, with the exception of the Netherlands, fairly low in most of the countries. This holds in particular for the French, German and Italian subsamples, with disclosure rates ranging from $54 \%$ to $61 \%$. 


\subsubsection{Competences required of audit committee members}

The qualifications of AC members should follow logically from their assigned responsibilities (Pomeranz, 1997). In light of the expanding scope of responsibilities to be addressed by ACs, it is interesting to see which competences are required from AC members. Regulation and research on AC competences differentiates between AC members having sufficient knowledge in terms of financial literacy vs. AC members who are financial experts (Bédard et al., 2004). Furthermore, prior research shows that not only functional knowledge of financial reporting or accounting, but also corporate governance experience as well as firm-specific knowledge can contribute to AC effectiveness (e.g., DeZoort and Salterio, 2001; Carcello and Neal, 2003; Bédard et al., 2004).

We have analysed the EU Eighth Directive, the governance codes and the AC charters in our sample regarding the level of competence required from AC members, the area in which the competence should be, as well as the proportion of AC members who should hold the respective competence. When studying the level of competence we differentiate between financial literacy vs. being a financial expert and the proportion of AC members who should possess the respective competence level (all; majority; minority). Concerning the scope of competence required from AC members, we distinguish between AC charters indicating that the AC should possess functional competence in finance, accounting or auditing and those requiring additional competences in compliance, risk management or internal control, governance experience, and industry/firm-specific knowledge.

The EU Eighth Directive states that at least one member of the AC should have competence in accounting and/or auditing. Table 2.3 outlines the recommendations of the corporate governance codes we have analyzed. Continental European corporate governance codes define AC competence as expertise in financial matters (Belgium); competence in finance or accounting (France); specialist knowledge and experience in the application of financial accounting principles and internal control processes (Germany); relevant experience in accounting and finance (Italy); knowledge and background in accounting, auditing and risk management (Spain); and being a financial expert (the Netherlands).

As expected, the recommendations of the different national codes are not completely different from each other. However, when taking a closer look it becomes clear that both level of competence (background, knowledge, experience, expertise or being an expert) as well as the competence subject (accounting, auditing, finance, internal control, and risk management) differ among the six corporate governance codes. The recommendations given by the codes also differ on another dimension, namely the number of AC members who should possess the relevant competence. The German, Italian and Dutch corporate governance codes recommend that at least one member possesses the relevant competence. According to 
the German code, this should be the chairman. The French and Spanish codes, in turn, recommend that all members bring with them the indicated competences.

We also analysed the contents of the AC charters in our sample regarding the competences that committee members should possess. As outlined in Table 2.4, the number of charters that require AC members to possess additional competences, on top of finance, accounting and auditing is limited. $30 \%$ of the Spanish and $13 \%$ of the German charters we analyzed require competence in risk management and in internal control processes, respectively. Experience in corporate governance or firm-specific knowledge is mentioned in only three of the 157 charters we have analyzed as a prerequisite for serving on the AC.

Table 2.4 shows that a large percentage of the charters studied here do not disclose any competence requirements. This is striking given the requirement of the EU Eighth Directive and the recommendations of national codes that one or more AC members need to possess certain competences, and evidence from prior research about the importance of AC competences for AC effectiveness (Bédard and Gendron, 2010; Lin and Hwang, 2010).

In summary, we find that the requirement of the EU Eighth Directive that one AC member should possess relevant competences has been implemented in the six corporate governance codes studied. However, the codes differ in content when it comes to spelling out the required competences to serve on the AC and how many members should posses the respective competences. Most striking, we find that an elevated percentage of the corporate charters studied do not disclose any competence specifications for AC members at the time of this study. This holds in particular for the French and German sub-samples.

\subsubsection{Audit committee independence}

When AC members are independent, chances are higher that they will carry out their responsibilities in an unbiased manner and critically review results presented to them (Zattoni and Cuomo, 2010). In line with prior studies we analyse the degree of independence of individual AC members and the proportion of independent members on the AC (see Bédard and Gendron, 2010). We differentiate between non-executive directors (NEDs) and independent non-executive directors (INEDs). Concerning the proportion of NEDs/INEDs, we distinguish between 'all members', 'the majority' or the 'minority' being independent. Due to the specific role of the chairman of the $\mathrm{AC}$, we also analyse whether the chairman of the $\mathrm{AC}$ should be a non-executive or an independent non-executive director. 


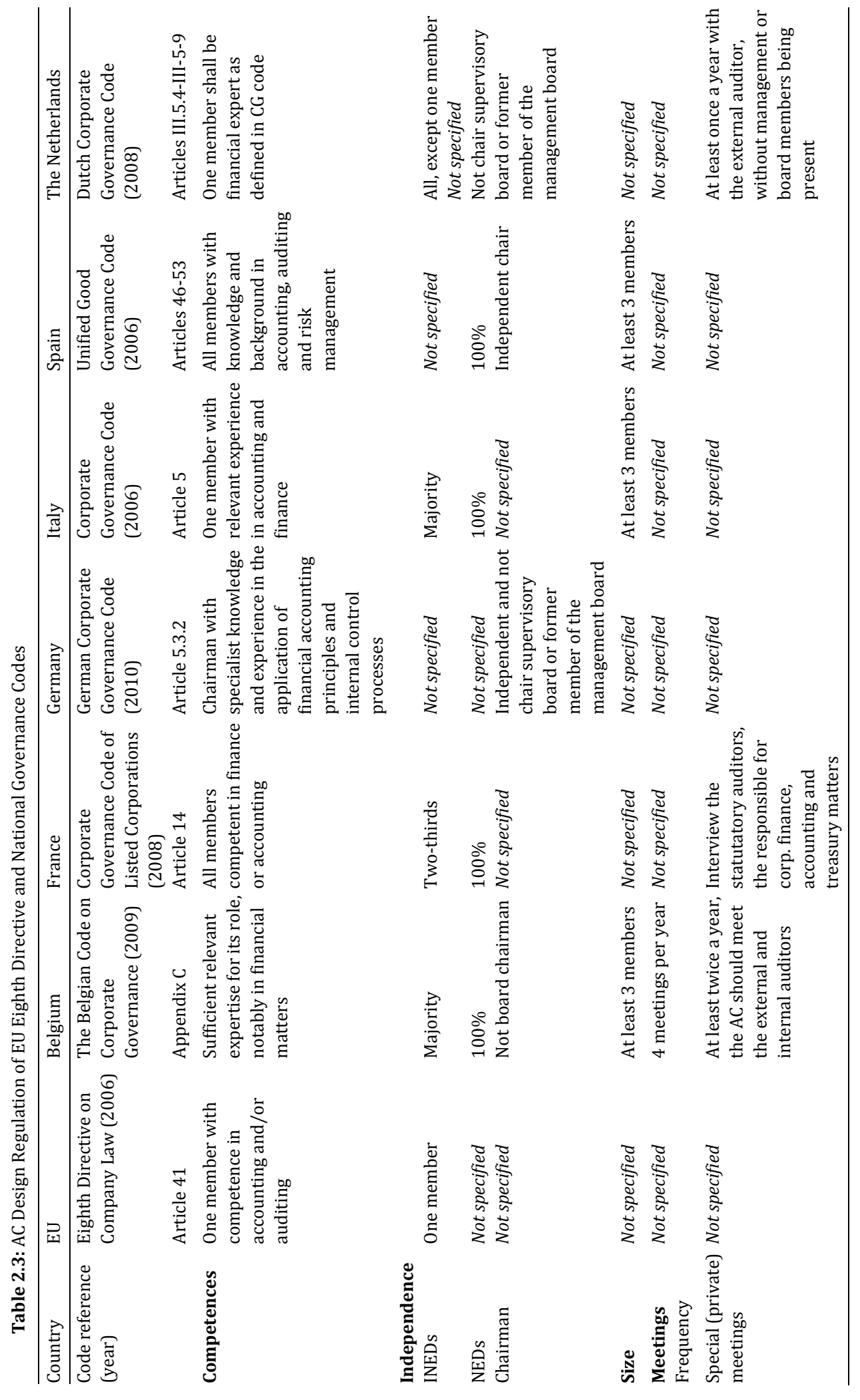


Table 2.4: AC charter analysis

\begin{tabular}{|c|c|c|c|c|c|c|}
\hline $\begin{array}{l}\text { Country } \\
\text { Observations }\end{array}$ & $\begin{array}{c}\text { Belgium } \\
17\end{array}$ & $\begin{array}{c}\text { France } \\
35\end{array}$ & $\begin{array}{c}\text { Germany } \\
24\end{array}$ & $\begin{array}{c}\text { Italy } \\
35\end{array}$ & $\begin{array}{c}\text { Spain } \\
33\end{array}$ & $\begin{array}{c}\text { Netherlands } \\
13\end{array}$ \\
\hline \multicolumn{7}{|l|}{ Competences } \\
\hline \multicolumn{7}{|l|}{ Expert } \\
\hline All members & $18 \%$ & $0 \%$ & $0 \%$ & $0 \%$ & $0 \%$ & $0 \%$ \\
\hline Majority & $6 \%$ & $0 \%$ & $0 \%$ & $6 \%$ & $0 \%$ & $0 \%$ \\
\hline One member & $18 \%$ & $9 \%$ & $29 \%$ & $20 \%$ & $30 \%$ & $42 \%$ \\
\hline Not disclosed & $59 \%$ & $91 \%$ & $71 \%$ & $74 \%$ & $70 \%$ & $58 \%$ \\
\hline \multicolumn{7}{|l|}{ Knowledge/experience } \\
\hline All members & $47 \%$ & $31 \%$ & $25 \%$ & $40 \%$ & $55 \%$ & $100 \%$ \\
\hline Majority & $18 \%$ & $3 \%$ & $0 \%$ & $3 \%$ & $0 \%$ & $0 \%$ \\
\hline One member & $12 \%$ & $0 \%$ & $0 \%$ & $14 \%$ & $12 \%$ & $0 \%$ \\
\hline Not disclosed & $24 \%$ & $66 \%$ & $75 \%$ & $43 \%$ & $33 \%$ & $0 \%$ \\
\hline \multicolumn{7}{|l|}{ Competence domain } \\
\hline Finance, accounting, auditing & $82 \%$ & $23 \%$ & $21 \%$ & $37 \%$ & $52 \%$ & $100 \%$ \\
\hline and additional competences* & $12 \%$ & $0 \%$ & $13 \%$ & $3 \%$ & $30 \%$ & $8 \%$ \\
\hline and governance expertise & $6 \%$ & $0 \%$ & $0 \%$ & $3 \%$ & $0 \%$ & $0 \%$ \\
\hline and firm-specific knowledge & $0 \%$ & $0 \%$ & $0 \%$ & $0 \%$ & $3 \%$ & $0 \%$ \\
\hline Not disclosed & $18 \%$ & $77 \%$ & $79 \%$ & $63 \%$ & $48 \%$ & $0 \%$ \\
\hline \multicolumn{7}{|l|}{ Independence } \\
\hline \multicolumn{7}{|l|}{ INEDs } \\
\hline All members INEDs & $12 \%$ & $0 \%$ & $4 \%$ & $17 \%$ & $12 \%$ & $38 \%$ \\
\hline Majority INEDs & $41 \%$ & $46 \%$ & $4 \%$ & $34 \%$ & $27 \%$ & $62 \%$ \\
\hline Minority INEDs & $29 \%$ & $0 \%$ & $0 \%$ & $0 \%$ & $33 \%$ & $0 \%$ \\
\hline Not disclosed & $18 \%$ & $54 \%$ & $92 \%$ & $49 \%$ & $28 \%$ & $0 \%$ \\
\hline \multicolumn{7}{|l|}{$N E D s$} \\
\hline All members NEDs & $82 \%$ & $6 \%$ & $4 \%$ & $54 \%$ & $79 \%$ & $38 \%$ \\
\hline Majority NEDs & $0 \%$ & $0 \%$ & $0 \%$ & $9 \%$ & $21 \%$ & $62 \%$ \\
\hline Not disclosed & $18 \%$ & $94 \%$ & $96 \%$ & $37 \%$ & $0 \%$ & $0 \%$ \\
\hline \multicolumn{7}{|l|}{ Chairman } \\
\hline Independent & $29 \%$ & $6 \%$ & $8 \%$ & $34 \%$ & $67 \%$ & $0 \%$ \\
\hline Non-executive chairman & $53 \%$ & $0 \%$ & $4 \%$ & $26 \%$ & $33 \%$ & $100 \%$ \\
\hline Not disclosed & $18 \%$ & $94 \%$ & $88 \%$ & $40 \%$ & $0 \%$ & $0 \%$ \\
\hline \multicolumn{7}{|l|}{ Size } \\
\hline Min. 2 members & $0 \%$ & $0 \%$ & $0 \%$ & $0 \%$ & $0 \%$ & $31 \%$ \\
\hline Min. 3 members & $65 \%$ & $29 \%$ & $0 \%$ & $43 \%$ & $91 \%$ & $69 \%$ \\
\hline Min. 4 members & $18 \%$ & $11 \%$ & $17 \%$ & $6 \%$ & $9 \%$ & $0 \%$ \\
\hline Min. 5 members & $0 \%$ & $3 \%$ & $25 \%$ & $6 \%$ & $0 \%$ & $0 \%$ \\
\hline Min. 6 or more & $0 \%$ & $0 \%$ & $17 \%$ & $3 \%$ & $0 \%$ & $0 \%$ \\
\hline Min. not disclosed & $18 \%$ & $57 \%$ & $42 \%$ & $43 \%$ & $0 \%$ & $0 \%$ \\
\hline Max. 5 members & $0 \%$ & $0 \%$ & $0 \%$ & $0 \%$ & $55 \%$ & $0 \%$ \\
\hline Max. 6 or 7 members & $0 \%$ & $6 \%$ & $0 \%$ & $0 \%$ & $24 \%$ & $0 \%$ \\
\hline Max. not disclosed & $100 \%$ & $94 \%$ & $100 \%$ & $100 \%$ & $21 \%$ & $100 \%$ \\
\hline
\end{tabular}




\begin{tabular}{lcccrrc}
\hline Country & Belgium & France & Germany & Italy & Spain & Netherlands \\
Observations & 17 & \multicolumn{1}{c}{35} & 24 & 35 & \multicolumn{1}{c}{33} & \multicolumn{1}{c}{13} \\
\hline Meeting & & & & & & \\
$\quad$ Frequency & & & & & & \\
Min. of 2 meetings & $0 \%$ & $9 \%$ & $0 \%$ & $6 \%$ & $3 \%$ & $23 \%$ \\
Min. of 3 meetings & $24 \%$ & $3 \%$ & $0 \%$ & $3 \%$ & $3 \%$ & $15 \%$ \\
Min. of 4 meetings & $65 \%$ & $20 \%$ & $13 \%$ & $23 \%$ & $70 \%$ & $62 \%$ \\
Min. of 5 or 6 meetings & $0 \%$ & $3 \%$ & $0 \%$ & $9 \%$ & $0 \%$ & $0 \%$ \\
Not disclosed & $12 \%$ & $65 \%$ & $87 \%$ & $59 \%$ & $24 \%$ & $0 \%$ \\
& & & & & & \\
Private meetings & $77 \%^{* *}$ & $80 \% * *$ & $11 \% * *$ & $49 \%^{* *}$ & $0 \%$ & $100 \%$ \\
External/ internal auditor & $23 \%$ & $20 \%$ & $89 \%$ & $51 \%$ & $100 \%$ & $0 \%$ \\
$\quad$ Not disclosed & & & & & \\
\hline
\end{tabular}

* Compliance, or internal control, or risk management.

** AC may hold private meetings with the external or internal auditor if deemed necessary.

According to the EU Eighth Directive, at least one member of the AC must be independent. The corporate governance codes studied here have adopted this panEuropean requirement, but differ in their recommendations on how many AC members should be non-executives and how many independent. The German code specifies that the chairman of the audit committee should be independent and not chair the supervisory board. All other codes give more stringent recommendations regarding AC independence. The Belgian and French codes state that all AC members should be non-executive and the majority of them independent. The Spanish code gives the same recommendations regarding the number of non-executives on the $\mathrm{AC}$ and notes that at least the chairman of the audit committee should be independent. The Dutch code states that one member may not be independent. The recommendations given on the matter of AC independence by European codes, thus, can be contrasted with the NYSE listing rules (2003) and the UK Combined Code (2003), which require and recommend that all AC members be independent directors.

Regarding the AC charters analyzed, a large percentage do not contain any requirements regarding the independence of $\mathrm{AC}$ members. This holds in particular for the sample firms from Germany ( $92 \%$ non-disclosure), France (54\% nondisclosure) and Italy (49\% non-disclosure). Non-disclosure rates for Spanish and Belgian charters are considerably lower, with $28 \%$ and $18 \%$, respectively. Only the sub-sample from the Netherlands stands out with a $100 \%$ disclosure rate regarding AC independence. $38 \%$ of the Dutch charters stated that all AC members should be INEDs, while the remaining $62 \%$ required that the majority of the $\mathrm{AC}$ should be INEDs. In the other countries, fewer or no charters indicate that all AC members should be independent $(<20 \%$ in Italy, Belgium, Spain; $4 \%$ in Germany; $0 \%$ in France). In addition to the large proportion of charters with non-disclosure on the issue of independence of $\mathrm{AC}$ members, we find that most charters (except those from France and Germany) require that the majority of AC members are NEDs. 
To summarize, we find substantial variation in the stipulations given by the six corporate governance codes on how many AC members should be independent. The same holds for the AC charters studied. Dutch corporations require that either the majority or all AC members are independent. Approximately one-third of the Belgian and Spanish-listed corporations studied only require the minority of AC members to be independent. Once again, it is most striking that the requirements of the EU Eighth Directive have effectively been implemented in corporate governance codes, but not in the AC charters for some of the countries studied. Specifically, we find an elevated percentage of charters from German, French and Italian firms not disclosing any independence requirements for AC members.

\subsubsection{Audit committee size}

The benefits of larger ACs in terms of additional expertise and manpower should be weighed against the incremental costs of poorer communication, coordination, and decision-making associated with larger groups (Bédard and Gendron, 2010). Consequently, the answer to the question of how many members should serve on an AC is dependent on a trade-off between more resources and poorer coordination. After all, one of the primary advantages behind forming specialized board sub-committees is that certain issues can be addressed more effectively and efficiently in smaller, more specialized teams. Board sub-committees can act more swiftly than an entire board of directors or supervisory board (McMullen, 1974).

Prior research indicates that regulators should be careful in specifying stringent AC size standards, due to empirical evidence for a negative relation between AC size and measures of AC effectiveness (e.g., Karamanou and Vafeas. 2005). Consequently, regulators typically set a minimum AC size, instead of determining exactly how many members should serve on the AC. The benchmark seems to be three members, which is the minimum AC size recommended by most European codes studied by Collier and Zaman (2005).

Our content analysis shows that neither the Eighth Directive nor the German, French or Dutch corporate governance codes specify or recommend how many members should serve on an AC. The Belgian, Italian and Spanish governance codes, in turn, recommend that the AC should be composed of at least three members. Most AC charters in our sample do not set an exact AC size, but set a minimum of three or four members. Interestingly, we find $31 \%$ of the Dutch AC charters in our sample set the minimum AC size at two members, while $42 \%$ of the German AC charters stipulate that the minimum AC size should be five or six members, which is clearly above what is generally considered to the norm, but related to the German system of co-determination and the requirement of having employee representatives on the AC. Furthermore, we find that $79 \%$ of Spanish AC charters set a maximum size of five to seven AC members, which reflects research evi- 
dence about an inverted U-shaped relations between group size and effectiveness (Cohen and Bailey, 1997).

\subsubsection{Audit committee meetings}

Even though prior research indicates that the frequency of AC meetings can be associated with AC effectiveness (Abbott et al., 2004), it is not clear how often ACs should meet (Sharma et al., 2009). Sharma et al. observe that corporate governance guidelines are by and large silent on the issue of AC meeting frequency. As Collier and Zaman (2005) point out in their study of European governance codes, $75 \%$ of the codes they analyzed did not give any guidance on how often the AC should meet per year. Our analysis shows that this situation has not changed. The EU Eighth Directive does not state how often ACs should meet. The only corporate governance code in our sample that does specify the number of AC meetings is the Belgian corporate governance code, which recommends that the AC should meet at least four times per year. The content analysis of the AC charters in our sample shows that a minimum of four meetings per year is set in most Belgian, Spanish and Dutch AC charters. As outlined in Table 2.4, we find a high percentage of nondisclosure in the German, French and Italian AC charters - 87\%, 65\% and 59\%, respectively.

In addition to meeting frequency, we have also analyzed whether the AC should hold any private or special meetings with the external auditor. Meetings between the AC and the external and internal auditor without management being present are increasingly seen as 'best practice', at least in the US (e.g., Raghunandan et al., 2001; Carcello et al., 2002). Table 2.3 outlines that three of the six governance codes studied recommend some sort of private AC meetings. However, the Dutch code is the only governance code, which explicitly states that the AC meets privately with the external auditors. The Belgian code recommends that the AC meet at least twice a year with the external and internal auditors, but does not explicitly state that these meeting should take place without management.

The codes' recommendations (or absence of recommendations) are reflected in the AC charters we studied. All Dutch charters state that private meetings between the AC and the external auditor must take place at least once a year. We also find a high percentage of Belgian and French ACs, which may hold private meetings with the external or internal auditor without the management being present. Most German and Spanish AC charters do not disclose whether the AC should meet with the external or internal auditor in private meetings.

\subsubsection{Mimetic isomorphism in audit committee charters}

To provide evidence for mimetic isomorphism in AC charters we study the percentage of unoriginal content in AC charters. Table 2.5 shows the percentage of 
unoriginal content in a sample of 78 European $\mathrm{AC}$ charters as detected by the program SafeAssign. ${ }^{14}$ A number of key findings can be derived from Table 2.5.

Table 2.5: Percentage of AC charters composed of boilerplate

\begin{tabular}{|c|c|c|c|c|c|c|c|}
\hline Observations & $\begin{array}{c}\text { Total sample } \\
78\end{array}$ & $\begin{array}{c}\text { Belgium } \\
13\end{array}$ & $\begin{array}{c}\text { France } \\
13\end{array}$ & $\begin{array}{c}\text { Germany } \\
13\end{array}$ & $\begin{array}{c}\text { Italy } \\
13\end{array}$ & $\begin{array}{c}\text { Spain } \\
13\end{array}$ & $\begin{array}{c}\text { Netherlands } \\
13\end{array}$ \\
\hline Mean & $41 \%$ & $33 \%$ & $37 \%$ & $39 \%$ & $29 \%$ & $38 \%$ & $69 \%$ \\
\hline Median & $31 \%$ & $26 \%$ & $23 \%$ & $40 \%$ & $28 \%$ & $35 \%$ & $72 \%$ \\
\hline Minimum & $8 \%$ & $19 \%$ & $8 \%$ & $12 \%$ & $10 \%$ & $12 \%$ & $20 \%$ \\
\hline Maximum & $100 \%$ & $100 \%$ & $100 \%$ & $88 \%$ & $62 \%$ & $87 \%$ & $100 \%$ \\
\hline $66 \%-100 \%$ & 15 & 1 & 2 & 3 & 0 & 2 & 7 \\
\hline
\end{tabular}

First, the average percentage of unoriginal content in $78 \mathrm{AC}$ charters detected by the program SafeAssign is $41 \% .{ }^{15}$ However, the AC charters in our sample exhibit high variability in unoriginal content, ranging from just $8 \%$ to $100 \%$. Table 2.5 outlines that $15 \mathrm{AC}$ charters display high levels of boilerplate language $(66 \%$ $100 \%)$. Of these, seven are from the Dutch sub-sample. When comparing the average percentage of boilerplate language in AC charters among the six countries studied, it can be seen that the Dutch sub-sample shows significantly more evidence for convergence in language than do the other five countries featured in this research. The average percentage of unoriginal language in the charters from the Netherlands is $69 \%$, compared with $29 \%$ to $39 \%$ in the other countries studied.

Thus, AC charters from the Dutch sub-sample display the highest level of implementation of AC design standards given by the Eighth Directive and the respective national code, while also containing the most unoriginal content. In fact, the Dutch corporate governance code is the only code studied that requires companies to publish an AC charter on their corporate website on a 'comply or explain' basis. This implies that firms listed in the Netherlands need to justify in public when they do not publish an AC charter. As shown in Table 2.1, the Belgian and Spanish codes recommend the disclosure of an $\mathrm{AC}$ charter without requiring an explanation for non-disclosure. The German, French, and Italian codes, in turn, do not provide a recommendation for the public disclosure of AC charters.

Collectively, our findings indicate that mandatory disclosure increases the level of compliance and coercive isomorphism in AC charters (Weil, Gotshal \& Manges, 2002), but also the amount of unoriginal boilerplate language and the degree of mimetic isomorphism. These findings confirm empirical evidence and

\footnotetext{
${ }^{14}$ For comparability reasons we limited the analysis with SafeAssign to $78 \mathrm{AC}$ charters. We passed 13 random charters through the software for each country in order to prevent inflating the results.

${ }^{15}$ At first sight, this is a surprisingly low result given that Holder-Webb and Cohen (2012) detect around $90 \%$ of unoriginal content in a sample of 66 codes of ethics. The reason may be that, in contrast to the codes of ethics studied by Holder-Webb and Cohen, the disclosure of AC charters is voluntary for most firms in our sample.
} 
theoretical reasoning that unoriginal content of corporate codes and charters is a predicted and rational response to regulation (e.g., Edelman, 1999; Holder-Webb and Cohen, 2012). In particular, moving from a state where companies can deviate from code recommendations without disclosure (Belgium, Spain) to a state where companies are required to publicly disclose non-compliance (the Netherlands), seems to elevate the degree of unoriginal language in AC charters.

\subsection{Discussion and conclusions}

In this study we shed light on the way ACs are designed in continental Europe by applying content analysis methods to the EU Eighth Directive, national codes of governance and corporate AC charters. We systematically analyse the extent to which different regulatory regimes in continental Europe have established AC design standards that are generally thought to contribute to AC effectiveness. In this manner, we address three related research questions about the degree of isomorphism and differentiation in AC design standards (RQ1); whether coercive pressures for isomorphism enacted by the Eighth Directive and national codes have been implemented effectively in AC charters (RQ2); and whether the AC charters contain significant boilerplate language as a proxy for mimetic isomorphism (RQ3).

The results presented in this paper show that AC design standards set in corporate governance codes and $\mathrm{AC}$ charters are mostly differentiated, rather than being isomorphic throughout continental Europe (RQ1). Differences in AC design standards between countries and companies primarily concern the scope of responsibilities assigned to ACs, the competences that AC members should possess, and the proportion of independent members. Standards relating to committee size and meeting frequency, in turn, are fairly isomorphic across our sample. Interestingly, the AC standards that remain differentiated are precisely those that have been found to be frequently associated with AC effectiveness. We conclude that four years after the Eighth EU Company Law Directive came into effect, authoritative opinions about the way ACs should be designed differ between EU member states. The extent of differentiation in AC design at the institutional and firm level comes as a surprise in light of antecedents for coercive and mimetic isomorphism in AC design across the EU.

According to the results presented here, coercive pressures for isomorphism in AC design enacted by the EU Eighth Directive and national codes of governance have been only partly successful in ironing out inconsistencies in AC design standards between EU member states. We show that AC design standards provided by the Eighth Directive have been effectively implemented on the level of national codes (RQ2a), but not on the level of individual firms' AC charters (RQ2b). The reason is that to a large extent, the contents of the $157 \mathrm{AC}$ charters studied here do 
not resemble the recommendations given by the respective national codes (RQ2c). This holds for most of the AC responsibilities, which are required by the Eighth Directive. Similarly, we find an extensive number of AC charters that do not contain any specifications about the competences that AC members should possess, nor about the percentage of independent members to serve on the AC.

However, substantial differences can be observed between the six countries studied. We find high levels of implementation of the EU Eighth Directive and the national code for Dutch-listed firms, intermediate levels for Belgian and Spanishlisted firms, and low levels for French, German and Italian-listed firms. We attribute these differences primarily to the fact that the governance codes in the latter group of countries do not recommend or require the disclosure of AC charters. The Dutch code (2008), in contrast, states that supervisory boards shall establish a terms of reference for the AC and post it on the company's website, or provide an explanation for its absence. Consequently, pressures for coercive isomorphism in AC charters are stronger in the Netherlands than in Belgium or Spain, where disclosure of AC charters is recommended, but companies do not have to publicly explain reasons for non-disclosure.

These findings indicate that one possible way to eliminate inconsistencies in $\mathrm{AC}$ design standards at the corporate level is to establish compulsory disclosure of complete AC charters throughout the EU. The content analyses of AC charters from firms listed on the Amsterdam Exchange Index suggests that mandatory disclosure can lead to high levels of implementation of the stipulations given by the EU Eighth Directive and the national code. Yet our findings with respect to mimetic isomorphism in AC charters (RQ3) should caution regulators before taking this step. The percentage of unoriginal language in $\mathrm{AC}$ charters detected by the software SafeAssign reveals that AC charters from AEX-listed firms contain considerable unoriginal language, both in absolute and relative terms. In line with prior evidence, this suggests that regulation can lead to 'copy-and-paste' or 'box-ticking' approaches when developing publicly available corporate narrative information (Baginski et al., 2002; Carcello et al., 2006; Forster et al., 2009; Holder-Webb and Cohen, 2012).

Comparing the degree of coercive and mimetic isomorphism in AC charters of Belgian and Spanish-listed firms with French, German and Italian firms on the one hand, and Dutch-listed firms on the other hand, conveys two important messages. First, including a "should" type recommendation to disclose an AC charter in national codes can increase the effectiveness of coercive pressures for isomorphism in AC design standards without significantly raising the level of mimetic isomorphism and unoriginal content in publicly available AC charters. Second, moving from a "should" to a "shall" type recommendation can further increase the effectiveness of coercive isomorphism, but also the level of mimetic isomorphism and as a result the share of unoriginal content in $\mathrm{AC}$ charters. Thus, the choice between 
the two types of recommendations when it comes to AC charters may ultimately depend on preferences between conformity in content and originality in language.

While prior research indicates that $\mathrm{AC}$ charters can have a positive impact on AC effectiveness (Kalbers and Fogarty, 1993; Bédard et al., 2004; Abbott et al., 2007), the need for mandating public disclosure of AC charters is, according to the best of our knowledge, not supported by empirical evidence, but is primarily driven by the intention of regulators to restore legitimacy in corporate governance and financial markets. After all, conventional reasoning suggests that current and potential shareholders have a genuine interest in knowing who is watching over their property or stakes (AC competences, $\mathrm{AC}$ independence, $\mathrm{AC}$ size) and what these guardians are doing to protect it (AC responsibilities, $\mathrm{AC}$ meetings).

However, mandating the public disclosure of $\mathrm{AC}$ charters may lead to mimetic isomorphism, up to the point where AC charters of firm listed within one country are hardly distinguishable from each other. Two (potential) negative consequences can arise from this form of institutionally driven convergence in the content and language of AC charters. ${ }^{16}$ First, given that the organizational and operational approach followed by an $\mathrm{AC}$ should take into account the unique aspects of the organizational and governance structure of the company that the AC serves on (VeraMuñoz, 2005), 'copy-and-paste' type AC charters may lack firm- or industryspecific content. Second, the degree of unoriginal content and boilerplate language in AC charters might be an indication that these documents are developed primarily to gain institutional legitimacy via cosmetic compliance, and not necessarily to direct the actual composition and work program of the AC (Krawiec, 2003; Forster et al., 2009). We would argue, in line Holder-Webb and Cohen (2012), that this is not in the interest of investors and other stakeholders, who may take comfort in the knowledge that the board of their company has written an AC charter targeted to the firms purposes, without arriving at the awareness of the limitations of the content of these charters.

In this context, the US Securities and Exchange Commission (SEC, 2000) outlined that: "While it is inevitable that some of the same provisions will appear in charters of different ACs, we encourage companies to tailor their charters to their specific circumstances". However, extant research and the results presented in this study, indicate that coercive pressures to publicly disclose corporate documents, which fulfil the dual purpose of internal organizational direction provision and external organizational information provision (e.g., codes of ethics, compliance programs, or board committee charters), can led to high levels of unoriginal content and language in these types of documents, which might not be in the best interest of regulators (Holder-Webb and Cohen 2012).

\footnotetext{
${ }^{16}$ DiMaggio and Powell (1983) point out two types of isomorphism - competitive and institutional. The (potential) negative consequences of unoriginal content in AC charters discussed in the conclusion section are related to institutional isomorphism.
} 
The EU Eighth Directive aims to establish minimum auditing standards across the EU without dictating how these standards have to be implemented at the national level. The European Commission has also stressed that the composition and operation of the board and its committees should be made transparent. The reduction of information barriers regarding the composition and operation of board committees was one of the primary objectives of the 2003 action plan to improve corporate governance in the European Union (European Commission, 2003: 12). The empirical evidence provided in this study, indicate deficiencies in both the implementation as well as the transparency of AC design standards in continental Europe, particularly in France, Germany and Italy.

We see three primary avenues to address these deficiencies. First, the European Commission could consider recommending the disclosure of AC charters, but leave it up to national standard setters to decide whether this will be implemented by introducing a "should" or "shall" type recommendation in the national code. Second, the choice between mandating compulsory disclosure or not is - according to extant literature and our results - related to preferences for the effectiveness of coercive isomorphism and the originality of AC charters. The cases of Belgium and Spain indicate that recommending disclosure of AC charters without legal enforcement can improve the implementation of AC design standards without turning them into boilerplate documents. Third, our results suggest that at least some form of standard-setting resistance at the corporate level. To improve the level of institutional isomorphism and corporate acceptance of AC design standards, national expert committees and standard setters could make use of strategies for dealing with standard-setting resistance (e.g., Jeppesen, 2010), especially when following the route of voluntary disclosure. ${ }^{17}$

For future research on ACs in continental Europe, the question emerges, which factors impede convergence of AC design standards throughout continental Europe. Yoshikawa and Rasheed (2009: 392) outline a number of impediments to cross-national convergence in the governance practices of public corporations, including, multiple optima, complementarities, path dependence (i.e. different AC design standards before the EU Eighth Directive came into effect), rent seeking by national interest groups, and lack of consensus on an ideal. Given our results, it should be of particular interest to further explore the causes and economic consequences of AC design standards and the lack thereof in France, Germany and Italy.

Our findings contribute to academic literature about ACs outside the AngloSaxon domain and inform practice about the effectiveness of the EU Eighth Directive and national codes in ironing out inconsistencies in AC standards throughout continental Europe. Thereby, we add to prior research in the field of comparative corporate governance by providing evidence for limited convergence in AC standards between continental Europe countries, both at the institutional and firm

${ }^{17}$ Jeppesen (2010) discusses five strategies for dealing with standard-setting resistance: alignment of interests, representation, due process, soft texts, and reference to ideology. 
level. As such, we corroborate extant literature pointing to the difficulties involved in bringing about convergence in corporate governance practices (Bebchuk and Roe, 1999; Gordon and Roe, 2004; Yoshikawa and Rasheed, 2009).

Our results should be interpreted with caution, though, given that we have merely studied six continental European countries. Furthermore, we see two primary limitations of this study. First, actual AC activity and design might differ from the contents of the charters and corporate governance codes we have analyzed. For example, Carcello et al. (2002) find that what ACs say they are doing in their reports differs from what their charters say they should be doing. Therefore, we encourage future research to assess whether continental European ACs actually follow the AC design specifications as outlined in the respective governance code and their charter. Second, further input factors to AC effectiveness beyond the five $\mathrm{AC}$ design factors we have studied surely exist. Externally definable and verifiable $\mathrm{AC}$ characteristics provide only a partial guide to AC activity and effectiveness. They cannot account for informal processes and behavioural effects (Turley and Zaman, 2007). Due to the key role that the reflections of individual audit committee members play in configuring meanings of effectiveness (Gendron and Bédard, 2006), future studies on AC design in continental Europe should therefore be complemented by qualitative research on the processes that play a role in constructing AC effectiveness. 


\section{Appendix: Eight EU Directive on Company Law}

\section{Excerpts from:}

DIRECTIVE 2006/43/EC OF THE EUROPEAN PARLIAMENT AND OF THE COUNCIL

of 17 May 2006 on statutory audits of annual accounts and consolidated accounts

Background on the EU $8^{\text {th }}$ Directive:

(5) This Directive aims at high-level - though not full - harmonisation of statutory audit requirements. A Member State requiring statutory audit may impose more stringent requirements, unless otherwise provided for by this Directive.

Article 41 on Audit Committees:

1. Each public-interest entity shall have an audit committee. The Member State shall determine whether audit committees are to be composed of non-executive members of the administrative body and/or members of the supervisory body of the audited entity and/or members appointed by the general meeting of shareholders of the audited entity. At least one member of the audit committee shall be independent and shall have competence in accounting and/or auditing.

In public-interest entities Member States may permit the functions assigned to the audit committee to be performed by the administrative or supervisory body as a whole, provided at least that when the chairman of such a body is an executive member, he or she is not the chairman of the audit committee.

2. Without prejudice to the responsibility of the members of the administrative, management or supervisory bodies, or of other members who are appointed by the general meeting of shareholders of the audited entity, the audit committee shall, inter alia:

(a) monitor the financial reporting process;

(b) monitor the effectiveness of the company's internal control, internal audit where applicable, and risk management systems;

(c) monitor the statutory audit of the annual and consolidated accounts;

(d) review and monitor the independence of the statutory auditor or audit firm, and in particular the provision of additional services to the audited entity.

3. In a public-interest entity, the proposal of the administrative or supervisory body for the appointment of a statutory auditor or audit firm shall be based on a recommendation made by the audit committee.

4. The statutory auditor or audit firm shall report to the audit committee on key matters arising from the statutory audit, and in particular on material weaknesses in internal control in relation to the financial reporting process.

5. Member States may allow or decide that provisions laid down in paragraphs 1 to 4 shall not apply to any public-interest entity that has a body performing equivalent functions to an audit committee, established and functioning according to provisions in place in the Member State in which the entity to be audited is registered. In such a case the entity shall disclose which body carries out these functions and how it is composed. 


\title{
CHAPTER 3 The Role of Audit Committee Charters 18,19
}

\begin{abstract}
In general, it is either required or recommended that listed firms adopt, periodically update and publicly disclose a written charter for their audit committee. The ostensible purpose of audit committee charters is to inform the investing public about the role and responsibilities of the audit committee of a given firm and to provide authority, direction and discipline for audit committee members. However, evidence has indicated that the audit committee charters of different firms may be boilerplate copies of each other and that firms deliberately decouple actual committee practices from the content of their charters, perversely in those institutional settings characterized by a stringent disclosure regime regarding audit committee charters. This chapter, on the other hand, provides empirical evidence for a significant relation between the nominal scope of responsibilities set forth in audit committee charters and measures of actual audit committee activity in institutional settings characterized by stringent disclosure regimes, and an absence thereof in voluntary disclosure settings. This suggests that in countries where the regulatory setting is more stringent, the professed activities of audit committees are more closely related to their actual work, relative to voluntary disclosure settings.
\end{abstract}

\footnotetext{
18 This chapter is based on a paper co-authored with Laury Bollen and Harold Hassink.

${ }^{19}$ I would like to thank the participants of the 8th Workshop on Corporate Governance of the European Institute for Advanced Studies in Management (Brussels, May 30-31, 2011), and 33rd Annual Congress of the European Accounting Association (Istanbul, May 19-21, 2010) for their valuable comments.
} 


\subsection{Introduction}

When the US Securities and Exchange Commission (SEC) and the New York Stock Exchange (NYSE) originally endorsed the audit committee concept in 1940, the responsibilities envisioned for these committees were quite narrow, basically being limited to the nomination of the external auditor and to setting some parameters for the auditor engagement (Verschoor, 2008). More recently, though, the role and responsibilities of the audit committee have expanded substantially (Beasley et al., 2009) - not only in the US, but also in all of the 30 largest economies. The following excerpts from a contemporaneous audit committee charter exemplify the range of responsibilities that audit committees are expected to address today.

"To fulfill its responsibilities the [audit] committee shall: Review with management and the external auditor the Group's financial statements, stock exchange and media releases; Review with the external auditor the planned scope of their audits and subsequently their audit findings; Review the qualifications, organization, strategic focus and resourcing of internal audit; Ensure that the company has an effective risk management system and that macro risks are reported at least annually to the Board; Address the effectiveness of the Company's internal control system; Review the Group's insurance cover; Review the Group's tax planning and compliance; Review the Group's whistle-blowing procedures..." (Excerpts from the 2010 audit committee charter of Rio Tinto Plc.).

In spite of the substantial expansion of the role and responsibilities of the corporate audit committee, empirical evidence is scant on the existence, causes, and consequences of cross-sectional variation in the scope of responsibilities set forth in audit committee charters (DeZoort et al., 2002; Bédard and Gendron, 2010). ${ }^{20}$ It is surprising that academic research on this matter has been limited, given the importance that regulators and corporate governance experts attribute to audit committee charters as key instruments for providing authority, direction and discipline to audit committee members and for informing legitimate interest groups i.e. shareholders, creditors, regulatory authorities - about the committees' role and responsibilities at the firm level. According to the SEC (1999), the disclosure of audit committee charters should strengthen investor confidence in the integrity of financial reporting and contribute to the effectiveness of audit committees.

However appealing these benefits may sound, practitioners and scholars alike have expressed concerns that placing coercive pressure on firms to publicly disclose their audit committee charter may not lead to the desired benefits for two reasons. First, institutional pressure to disclose corporate narrative documents

${ }^{20}$ Merely seven out of 103 studies published between 1994 and 2008 and reviewed by Bédard and Gendron include the responsibilities addressed by the audit committees under study into their analysis. 
which fulfill the dual purpose of providing external organizational information as well as internal organizational direction can led to high levels of isomorphism in the content and language of these documents (Forster et al., 2009; Holder-Webb and Cohen, 2012; Böhm et al., 2013). Second, given that it is virtually impossible for external parties to observe consistencies between the responsibilities disclosed in audit committee charters (the front-stage) and the actual activities of audit committees (the back-stage), firms may deliberately decouple actual committee practices from the charters content (Osma and Guillamón-Saorín, 2011).

To investigate the extent to which the two aforementioned concerns are justified - i.e. the isomorphism and the decoupling concern - we empirically address three research questions in the course of this chapter. First, we investigate whether the scope of responsibilities disclosed in audit committee charters differs significantly and systematically across firms. If so, we want to test in a second step if measures of actual audit committee activity can be associated with the scope of responsibilities set forth in audit committee charters, suggesting that the internal work program of audit committees is coupled to the charters' content. ${ }^{21}$ Finally, we examine to what extent the answers to the aforementioned questions depend on the level of institutional pressure to publicly disclose an audit committee charter.

We find that the scope of responsibilities disclosed in 202 publicly available audit committee charters from large-cap firms listed on Anglo-Saxon and continental European exchanges differs significantly and systematically from one firm to another. Further, our analysis suggests that in institutional settings with high levels of coercive pressure to disclose an audit committee charter (Anglosphere), measures of actual audit committee activity are significantly and positively related to cross-sectional variation in the scope of responsibilities set forth in audit committee charters. In institutional settings characterized by low levels of coercive pressure to disclose an audit committee charter (continental Europe), we find no association between proxies for actual audit committee activity and the nominal scope of duties disclosed in audit committee charters.

This study contributes to the literature on audit committees, disclosure and the effectiveness of regulation in three distinct ways. First, we extend Carcello et al. (2002), which compared the disclosures in audit committee charters and reports and thereby found that what audit committees say they are doing differs from what the charters say the committees should be doing. More specifically, Carcello et al. show evidence that audit committees are more likely to disclose in their charters what they will do rather than report what they actually did. This raises the question whether responsibilities disclosed in audit committee charters are not being addressed. By using meeting frequency as a proxy for actual audit committee

${ }^{21}$ Thereby, we directly address the call of Kalbers and Fogarty (1993: 45) to investigate the relation between organizational types of power (charters) and audit committee diligence. 
activity, we provide evidence that what audit committees are actually doing may well be in line with what the charters say the committees should be doing. ${ }^{22}$

Second, by linking audit committee meeting frequency to the scope of responsibilities set out in audit committee charters, we also extend the literature on the determinants of audit committee meeting frequency (Raghunandan and Rama, 2007; Sharma et al., 2009). Third, we provide novel insights into the interplay between audit committee disclosure and actual activity across geographic regions that vary in regulatory structure. Thereby, we aim to inform policymakers and investors about the effectiveness of regulation and the informativeness and value relevance of audit committee charters, respectively.

The reminder of this chapter is organized as follows. First, we discuss the promise and peril of publicly available audit committee charters in light of extant literature. Next, we develop hypotheses regarding firm-level determinants of audit committee scope, its relation to actual audit committee activity and the role of institutional pressure in this context. Thereafter, we present the research design and the empirical results of the study at hand. In the concluding section, we discuss to what extent audit committee charters should matter to the investing public insofar as these documents contain substantive rather than symbolic content and whether they constitute effective instruments from a regulatory point of view.

\subsection{The promise and peril of audit committee charters}

One of the central recommendations given by the Blue Ribbon Committee on Improving the Effectiveness of Corporate Audit Committees (BRC, 1999), is that each listed firm should be required to adopt a formal written charter that is approved by the full board and that specifies the scope of the audit committee's responsibilities. Based on this recommendation, the SEC (1999) issued a rule that companies disclose in their proxy statements whether their board has adopted an audit committee charter, and if so, include a copy of the charter as an appendix to the company's proxy statements at least once every three years. Ever since, it has become a common practice not only for firms listed in the US, but also internationally, to disclose an audit committee charter, either directly via their corporate website or attached to the annual reporting documents (Walker, 2004; Jiang et al., 2009).

With this background, what benefits can the corporate governance community in general and the investing public in particular expect from the public disclosure

22 Due to reputation and liability concerns, audit committee members may be reluctant to disclose details about activities actually performed during the year (Cohen et al., 2002; Rowland, 2002). As a result, activities disclosed in audit committee reports may not reflect the actual level of committee activity. The number of committee meetings, in turn, is considered the only publicly available quantitative signal about the diligence of audit committees (Raghunandan and Rama, 2007). The measure has been frequently used in audit committee research and is arguably less susceptible to be distorted by liability concerns. 
of written charters detailing the role and responsibilities of corporate audit committees? The response of the BRC and the SEC is that if a corporation is to be a viable attraction of capital, it must ensure disclosure and transparency concerning its governance practices including the role and responsibilities of its audit committee. After all, if audit committees represent most reliable guardians of the public interest, as suggested by Levitt (1998), then it is easy to see why investors would have a genuine and legitimate interest in the authority and duties of these guardians. Thus, one benefit expected from the disclosure of audit committee charters is to strengthen investor confidence and corporate legitimacy by offering investors transparency about the role and responsibilities of the audit committee (Carcello et al., 2002). Furthermore, the BRC formulated a second benefit, namely that audit committee charters contribute to the role effectiveness of audit committees:

\begin{abstract}
"Further, the audit committee should self-disclose its self-determined role, structure, and practices. Such transparency is at the heart of good governance, serves to inform investors, and also acts as a disciplinary measure on the committee. It will encourage committees to think about their important role, to articulate a clear mission, and then to establish appropriate practices and follow them. Disclosure will guide the committee to responsible practices, as sunlight generally does" (BRC, 1999: 27).
\end{abstract}

In addition to this, a number of studies conclude that written charters play a key role in equipping audit committees with the necessary internal organizational legitimization, authority and power to effectively carry out their designated responsibilities (Kalbers and Fogarty, 1993; Golden and Zajac, 2001; Ng and Tan, 2003). In this context, Bédard et al. (2004) show a positive relation between the quality of financial information released by US firms and the presence of a clear mandate defining the responsibilities of the audit committee. In a similar vein, Abbott et al. (2007) find that formal designation of authority is a prerequisite for the audit committee to evaluate internal audit outsourcing options.

In summary, the promise of audit committee charters is to inform external parties about the role and concrete responsibilities of the audit committee of a given firm, and at the same time to provide authority, direction, and discipline to that committee (Carcello et al., 2002). The intended purpose of publicly available audit committee charters, then, is to strengthen investor confidence in financial information and markets, either directly by signaling to shareholders that audit committees are responsible for important oversight matters, or indirectly by contributing to the role effectiveness of audit committees.

However promising as these benefits sound, there is empirical and anecdotal evidence to question their validity, suggesting that in the long run publicly available charters might constitute more peril than promise for investor confidence and audit committee effectiveness (Ashforth and Gibbs, 1990; Harvard Law Review, 
2003; Krawiec, 2003; Forster et al., 2009; Holder-Webb and Cohen, 2012). The aforementioned studies point out two reasons why publicly available audit committee charters might constitute a meaningless or even perilous tool towards building investor confidence and audit committee effectiveness: isomorphism in the content of audit committee charters up to a point where the charters of different firms become indistinguishable from each other, and, second, the deliberate decoupling of actual committee practices from the content of these charters. ${ }^{23}$

Regarding the isomorphism concern, the SEC (1999) has pointed out that "even though it is inevitable that some of the same provisions will appear in charters of different audit committees, we encourage companies to tailor the charters to their specific circumstances". In other words, audit committee charters should contain firm- and industry-specific content. Notwithstanding this call, though, theoretical reasoning provided by DiMaggio and Powell $(1983,1991)$ on isomorphism in organizational fields has more recently been matched with empirical evidence documenting high levels of isomorphism in corporate documents that fulfill the dual purpose of providing both external organizational information and internal organizational direction, i.e. codes of ethics and audit committee charters (Forster et al., 2009; Holder-Webb and Cohen, 2012; Böhm et al., 2013). As pointed out by Suchman (1995) and Westphal et al. (1997), one reason why audit committee charters might lack firm- and industry-specific content is that concerns for institutional legitimacy supersede considerations of firm-level efficiency. ${ }^{24}$

Without discarding the desirability of a certain degree of overlap in the role and responsibilities between audit committees of different firms, we argue that at some degree of isomorphism in the contents of audit committee charters "form" will triumph over "substance" and these documents will become so generic in nature that they become a meaningless or at best ineffective tool for informing the public about the committees' role and responsibilities and for contributing to the committees' effectiveness, respectively (cf. Cohen et al., 2008).

However, even in case of significant cross-sectional differences in the scope of responsibilities disclosed in audit committee charters, the intuitive question emerges whether these differences are substantial or merely a result of impression management (Goffman, 1959). Existing research demonstrates that organizations engage in impression management by creating and maintaining deliberate gaps between formal policies and actual organizational practices - a phenomenon called decoupling (Meyer and Rowan, 1977; Weaver et al., 1999; Westphal and Zajac,

\footnotetext{
${ }^{23}$ Decoupling refers to the deliberate manufacture of gaps between actual organizational practices and formal policies regarding those practices (Meyer and Rowan, 1977). In the context of this study, we focus on gaps between audit committee charters and actual committee practices.

24 The literature on organizational legitimacy differentiates between strategic legitimacy and institutional legitimacy (DiMaggio and Powell, 1983). Isomorphism in audit committee charters among firms from similar institutional settings should be attributable to institutional legitimacy.
} 
2001; Lamertz and Martens, 2011).25 In the context of audit committee charters this form of decoupling would imply that firms systematically over-promise on the designated role and responsibilities of their audit committee.

A number of audit committee studies find affirmative evidence for this proposition, suggesting that the responsibilities disclosed in audit committee charters do not reflect actual committee practices (DeZoort, 1997; Carcello et al., 2002; Beasley et al., 2009). DeZoort (1997) conducted a survey among US audit committee members about their assigned and perceived responsibilities. He finds that audit committee members were not able to recognize their assigned responsibilities as detailed in proxy statements and that much of the audit committees' work was performed in areas not formally assigned to the committee. Carcello et al. (2002), in turn, find substantial inconsistencies between the responsibilities disclosed in audit committee charters and those reported in audit committee reports.

Against this background, it is important to further investigate the relation between actual audit committee practices and the contents of audit committee charters. When the responsibilities set forth in audit committee charters are primarily the outcome of impression management to gain legitimacy and remain decoupled from actual audit committee practices, then these charters would constitute perilous and ineffective tools for strengthening investor confidence and audit committee effectiveness, respectively (MacLean and Bahnam, 2010).26

Interestingly, the Harvard Law Review (HLR), has pointed out that institutional pressure in the form of disclosure rules will lead firms to make different decision about the information their codes and charters will generate than the decisions they would have made before the rules (Oliver, 1991; Goodstein, 1994). The HLR (2003: 2140) suggests that when pressured to publicly disclose corporate codes and charters, "companies will likely seek to protect themselves [from the risk of litigation] by creating nebulous documents that are not illuminating to their own management or the public... then the public filing of codes [or charters] will not matter because investors will be unable to distinguish one vague, boilerplate code from another". In a nutshell, the HLR suggests that the audit committee charters of different firms may be boilerplate copies of each other and that firms deliberately decouple actual committee practices from the content of their charters, perversely in those institutional settings characterized by a stringent disclosure regime.

\footnotetext{
${ }^{25}$ Decoupling enables organizations to maintain standardized, legitimating, formal structures while their activities can vary in response to practical considerations (Meyer and Rowan, 1977). Decoupling is attractive to listed firms, because it is virtually impossible for investors or creditors to directly observe consistencies between formal policies and actual organizational activities (MacLean and Behnam, 2010).

${ }^{26}$ In this scenario, audit committee charters might constitute a perilous tool because legitimacy is a social judgement that is ultimately accorded to an organization by its constituents. As pointed out by Suchman (1995), when legitimacy is achieved by means of symbolic instead of substantive practices, organizations run the risk of "protesting too much", leading to long-term loss of external legitimacy.
} 
The next section develops hypotheses about firm level determinants of the scope of authority disclosed in audit committee charters (audit committee scope), its relation to actual committee practices (audit committee activity), and the impact of institutional pressure to disclose an audit committee charter (disclosure regime).

\subsection{Development of hypotheses}

\subsubsection{Firm level determinants of audit committee scope}

Legitimacy considerations aside, there are two potential advantages of assigning additional responsibilities to the audit committee - independent oversight and board efficiency (Menon and Williams, 1994). However, audit committees are monitoring devices that do not come "for free", but lead to direct and indirect costs for organizations (Eichenseher and Shields, 1985). ${ }^{27}$ Given that cross-sectional differences exist in the benefits and costs associated with audit committee oversight, it is important to better understand these differences. For this purpose, the first generation of audit committee research investigated firm-level determinants of voluntary audit committee formation (Pincus et al., 1989; Bradbury, 1990). Since audit committee formation has become a listing requirement on major stock exchanges, a number of studies have been published that explore variations in audit committee meeting frequency (Raghunandan and Rama, 2007; Sharma et al., 2009). Based on the aforementioned literature, we will in turn summarize the variables that may help to explain inter-firm differences in the responsibilities set forth in audit committee charters. These factors are: firm size, industry, profitability, ownership, and board characteristics.

H1: $\quad$ The scope of responsibilities disclosed in audit committee charters is related to firm size, industry, profitability, ownership and board characteristics.

Empirical evidence that firm size is positively related to the demand for audit committee oversight is generally explained by agency theory (Fama and Jensen, 1983 ) and/or economies of scale (Mautz and Neumann, 1977). Since agency problems are expected to increase with firm complexity and greater dispersion of stockholdings, larger organizations are expected to make more extensive use of the audit committee (Sharma et al., 2009). The economies of scale argument, in turn, is based on the premise that the net monitoring benefits of audit committees increase with firm size, since monitoring costs are to a certain extent fixed (Pincus et

\footnotetext{
${ }^{27}$ These costs could include, for example, the expenses incurred per audit committee meeting and the preparatory time spend by audit and non-audit committee members outside the official meetings or the costs incurred by the audit committee for hiring outside experts.
} 
al., 1989). Overall, evidence shows that the demand for audit committee oversight increases with firm size (Deli and Gillan, 2000; Fernandéz and Arrondo, 2007).

In addition to firm size, audit committee scope might also depend on the type of industry in which the firm operates. The demand for audit committee oversight seems comparatively high in financial institutions, as a result of the concentration of fraud cases and excessive risk-taking in this sector (Beasley et al., 2000). Due to the importance attributed to internal auditing and risk management in financial institutions, there should be a greater demand for audit committee oversight in these areas. Further, it is reasonable to assume that boards of financial institutions have expanded the scope of their audit committees as a direct result of the 2008 financial crisis, which resulted in the collapse of large financial institutions and the bailout of banks by national governments (see e.g., Sikka, 2009).

Further, firm profitability could impact the demand for audit committee oversight. In particular, loss-making firms might place greater demands on internal monitoring and consequently also on audit committee oversight (Beasley, 1996; Sharma et al., 2009). By increasing the scope of the audit committee, unprofitable firms could signal to investors that corrective actions are being taken (Bédard et al., 2008).

Regarding ownership characteristics, we focus on the degree of leverage and ownership concentration. Jensen and Meckling (1976) argue that agency cost of debt increases with leverage due to higher probabilities of wealth transfer from debtholders to shareholders. Given the costliness of monitoring compliance with covenants written into debt contracts, more extensive audit committee oversight is generally viewed as a means to mitigate the cost of debt financing (Collier and Gregory, 1999). A broader scope of audit committee oversight might be warranted in particular in the areas of internal control and risk management, because highly levered firms tend to engage in earnings and asset manipulation (Raghunandan and Raman, 2007) and run higher risks of defaulting (Piot, 2004).

Berle and Means (1932) vividly describe how diffuse stock ownership creates a wide gap between corporate ownership and control and that substantial effort is required to bridge that gap and align the interests of principals and agents. In theory, investors with a substantial equity stake in a firm have sufficient financial incentives and voting power to bridge the gap and exert pressure to delegate more responsibilities to the audit committee (Connelly et al., 2010). Raghunandan and Rama (2007) provide empirical evidence suggesting that large shareholders of US listed firms pressure boards of directors to raise the level of audit committee activity. On the other hand, it has been suggested, based on Shleifer and Vishny (1997), that large shareholders with a great deal of power might decrease the level of audit committee oversight, since an intensive monitoring environment could raise the cost associated with extracting private benefits (Greco, 2011). In line with this proposition, Fernándz-Mendéz and Arrondo-García (2007) find negative associations between shareholder concentration and audit committee meetings frequency 
for a sample of Spanish listed firms. Sharma et al. (2009) and García-Sánchez et al. (2012), in turn, fail to provide evidence for an association between shareholder concentration and audit committee diligence.

Extant literature also shows that characteristics of the entire board impact the formation and activity of board committees (Menon and Williams, 1994; Beasley and Salterio, 2001). Interdependencies between the board and its committees might be considered inevitable, given the fact that committee members are drawn from the board and that it is common practice to hold board committee meetings immediately before or after a meeting of the entire board (Sharma et al., 2009). Consequently, we expect that audit committee scope is related to characteristics of the entire board, or what has been termed supply factors (Rainsbury et al., 2008). It has also been shown that the chairman of the board impact agenda and composition of the board and its committees. Based on agency theory, Laux and Laux (2009) convincingly argue that CEOs have strong interests in the work of audit committees, in particular in the area of financial reporting, and thus might try to influence the way responsibilities are allocated between the board and the audit committee. Since CEOs are generally prohibited from sitting on the audit committee, we argue that a CEO serving as chairman of the board will try to limit the scope of authority assigned to the audit committee.

\subsubsection{Nominal audit committee scope and actual audit committee activity}

Conventional reasoning and literature from the field of management as well as organizational studies indicate that - all other things being equal - workgroups facing additional duties need to increase their meeting frequency and/or manpower to discharge them effectively (Marks et al., 2001; Christian et al., 2011). Thus, if audit committee charters serve as a means for determining the 'actual' work program of audit committees and not purely as a means of gaining external legitimacy, we expect to find a positive relation between the 'nominal' scope of responsibilities professed in charters and measures of actual audit committee activity:

H2: $\quad$ There is a positive relation between the scope of responsibilities disclosed in audit committee charter and measures of actual audit committee activity.

If we find no association between audit committee scope, on the one hand, and audit committee meeting frequency, on the other hand, this could be an indication that cross-sectional differences in audit committee scope result from impression management, whereupon actual committee activities remain decoupled from the charters' content. 


\subsubsection{The impact of institutional pressure on isomorphism and decoupling}

According to literature on organizational responses to institutional pressure (DiMaggio and Powell, 1983; Oliver, 1991; Goodstein, 1994; HLR, 2003; Okhmatovskiy and David, 2012), the level of institutional pressure exerted on firms to publicly disclose an audit committee charter will have an impact on the level of isomorphism in the content of these charters and the probability that firms decouple actual committee practices from the charters' content.

In fact, empirical evidence has been found that since US listed firms were required to disclose a code of ethics according to Section 406 of the Sarbanes-Oxley Act (2002), most of these codes of ethics have turned into boilerplate copies of one another (Murphy, 2005, Forster et al., 2009; Holder-Webb and Cohen, 2012). In their paper titled "The Cut and Paste Society", Holder-Webb and Cohen (2012: 504) emphasize that "codes of ethics that are ostensibly provided to guide the daily decision-making activities of employees are instead generic carbon-copies of one another, with little or no attempt by most firms to provide any sort of guidance tailored to the ethical pressures unique to their organization or industry".

If this is also the case for audit committee charters, then the "good intent" of regulators to help shareholders assess the role and responsibilities of audit committees and to contribute to audit committee effectiveness by recommending or even requiring firms to place an audit committee charter on public record might have backfired (Arya et al., 2005; Jamal, 2012). Since isomorphism and decoupling may constitute predictable and rational responses to a stringent disclosure regime (HLR; 2003), we expect that:

H3: Institutional pressure for the public disclosure of audit committee charters irons out inter-firm differences in audit committee scope and fuels the decoupling of actual audit committee practices from the nominal responsibilities set out in the charters.

\subsection{Research design}

\subsubsection{Sample selection and data collection}

In order to test whether audit committee charters exhibit systematic differences in content and whether these differences are related to measures of actual activity, we study a sample of firms listed on the Anglo-Saxon and continental European exchanges. Both institutional setting require listed firms to establish an audit committee. Anglo-Saxon firms are chosen for analysis, because audit committees are a mature corporate governance mechanism (Vanasco, 1994; Carson, 2002). Moreover, Anglo-Saxon countries represent an institutional context with high lev- 
els of coercive pressure to disclose an audit committee charter. In continental Europe, in turn, establishing audit committees was not a standard board practice until the Eight EU Company Law Directive came into effect in 2006. In addition, most firms with a primary listing in continental Europe, can decide whether to place an audit committee charter on the public record, or not. Hence, our sample allows to study the interplay between the scope of responsibilities disclosed in audit committee charters and actual activity across geographic regions that vary in regulatory structure and in maturity of the audit committee concept.

By carrying out our study in an international context, we also aim to address the numerous calls that have been raised by the academic community to study audit committees not only in jurisdictions which follow the Anglo-Saxon model of corporate governance (e.g., Bédard and Gendron, 2010; Carcello et al., 2011). Assuming that interdependencies between firms and diverse environments can lead to variations in the effectiveness of different governance practices, it is important to test our hypotheses in corporate governance domains portrayed as fairly dichotomous by extant literature (Letza et al., 2004; Aguilera et al., 2008).

To address our research question and hypotheses in a continental European context, we initially chose the constituents of the FTSE EURO 100 index. For our Anglo-Saxon sample, we selected the largest corporations in terms of market capitalization from Australia, the UK, and US. We selected the ASX20 constituents, the 30 largest companies in terms of market capitalization on the LSE and the 50 largest companies on the NYSE. However, a considerable number of firms in the FTSE EURO 100 index did not disclose a complete audit committee charter at the time of this study (January 2010).

In order to increase the number of useful observations from continental Europe, we subsequently chose the following six country indices: BEL20 (Belgium), CAC40 (France), DAX30 (Germany), FTSE MIB40 (Italy), IBEX35 (Spain), and AEX25 (The Netherlands). Thus, our final sample includes 202 observations, thereof 102 from continental Europe. ${ }^{28}$ Out of the 190 observations from the six indices, we subsequently excluded six firms with dual listings in the abovementioned country indices. All remaining 184 continental European sample firms had established an audit committee as required by the Eight EU Directive on Company Law (2006). However, merely 102 (55\%) disclosed an audit committee charter by January 2010. Thus, our final sample includes 202 observations, thereof 102 from continental Europe. Table 3.1 summarizes the final sample per country, whether the respective country has enforced an audit committee charter disclosure regime, the level of coercive pressure, and the corresponding percentage of firms disclosing an audit committee charter.

\footnotetext{
${ }^{28}$ We limit this study to this sample size due to: (1) the labor intensiveness of analyzing audit committee charters (2) the difficulty of obtaining information about board of directors/supervisory boards of European firms, which was not readily available in a canned dataset and needed to be hand-collected.
} 
Table 3.1: Sample overview

\begin{tabular}{|c|c|c|c|c|c|c|c|c|c|}
\hline \multirow[b]{2}{*}{ Country } & \multicolumn{3}{|c|}{ Anglosphere } & \multicolumn{6}{|c|}{ Continental Europe } \\
\hline & $\mathrm{AU}$ & UK & US & $\mathrm{BE}$ & $\mathrm{DE}$ & ES & FR & IT & NL \\
\hline $\begin{array}{l}\text { Disclosure regime for AC } \\
\text { chartera }(\text { disclosure } \\
\text { required or } \\
\text { recommended) }\end{array}$ & $\sqrt{ }$ & $\sqrt{ }$ & $\sqrt{ }$ & $\sqrt{ }$ & & $\sqrt{ }$ & & & $\sqrt{ }$ \\
\hline $\begin{array}{l}\text { Level of coercive } \\
\text { pressure }^{b}\end{array}$ & 2 & 2 & 3 & 1 & 0 & 1 & 0 & 0 & 2 \\
\hline $\begin{array}{l}\text { Sample (stock exchange / } \\
\text { index) }\end{array}$ & ASX & LSE & NYSE & BEL & DAX & IBEX & CAC & MIB & AEX \\
\hline Initial sample & 20 & 30 & 50 & 20 & 30 & 35 & 40 & 40 & 25 \\
\hline $\begin{array}{l}\text { Less dual-listed companies } \\
\text { (DLCs) }\end{array}$ & & & & (1) & & & $(1)$ & $(1)$ & (4) \\
\hline $\begin{array}{l}\text { Less firms not disclosing an } \\
\qquad \text { AC charter }\end{array}$ & $(0)$ & $(0)$ & $(0)$ & $(2)$ & $(26)$ & $(6)$ & $(22)$ & $(22)$ & (3) \\
\hline $\begin{array}{l}\% \text { of firms disclosing an } \\
\text { AC charter }\end{array}$ & $100 \%$ & $100 \%$ & $100 \%$ & $90 \%$ & $13 \%$ & $83 \%$ & $44 \%$ & $44 \%$ & $86 \%$ \\
\hline $\begin{array}{l}\text { Effective final sample per } \\
\text { country }\end{array}$ & 20 & 30 & 50 & 17 & 4 & 29 & 17 & 17 & 18 \\
\hline $\begin{array}{l}\text { Effective final sample per } \\
\text { CG domain }\end{array}$ & & & 100 & & & & & & 102 \\
\hline
\end{tabular}

Notes: This table summarizes the sample per country and corporate governance domain.

a $\mathrm{AC}=$ audit committee

b $0=$ no requirement or recommendation; 1 = recommended (no explanation), 2 = comply or explain, 3

= required.

c For the purpose of this study, we only include firms that disclosed a separate document called audit committee 'charter', 'bylaws', 'terms of reference', 'regulations', or 'rules' on their corporate Web site or attached to the annual reporting documents by January 2010.

d Final sample/disclosure rate per level of coercive pressure: $0=38 / 35 \%$ (DE, FR, IT); $1=46 / 85 \%$ (BE, ES); 2 = 68/96\% (AU, NL, UK); 3 = 50/100\% (US)

\subsubsection{Content analysis of audit committee charters}

In order to study the determinants of audit committee scope and its impact on audit committee activity, we apply content analysis techniques to audit committee charters. ${ }^{29}$ Thereby, we aim to assign a numerical value to audit committee scope and subsequently test the hypotheses outlined in the previous section. The analysis of the charters followed the standard protocols of the content analysis method of formal coding based on a codebook and inter-rater agreement (Krippendorff, 2004). Two raters independently coded the responsibilities disclosed in the 202

\footnotetext{
${ }^{29}$ The objective of content analysis is to reduce the amount of data in a text by classifying words, sentences, and paragraphs into a smaller number of 'content categories' (Weber, 1990). Content analysis is a research method suited to elaborate theories of organizations (Sonpar and Golden-Biddle, 2008).
} 
sample charters. For this purpose, both followed a deductive-inductive procedure by adding new responsibilities to the list established by Wolnizer (1995). As suggested by Gaumnitz and Lere (2004), the raters selected audit committee tasks as their unit of analysis, and subsequently categorized individual tasks along broader responsibility schemes. The coding scheme was pre-tested on two sub-samples of 30 charters, after which the raters came to an agreement about the final set of items (see also Pugliese et al., 2009). Before coming up with the final codebook, two experts from the practitioner field - i.e. an audit committee member of an AEX constituent and a senior manager of a Big 4 audit firm - checked the set of items on the basis of exhaustive and mutually exclusive categories. In total, over 100 separate audit committee tasks were identified and subsequently categorized among 33 responsibilities. The Appendix outlines the final categorization scheme.

For readability purposes, we assigned the 33 responsibilities to five fields of activity: (1) financial reporting and disclosure; (2) external audit matters; (3) internal audit matters; (4) business control environment; (5) corporate governance, compliance, and other matters. Regarding the reliability of our coding, a twoperson inter-rater agreement statistic (K, Kappa) is calculated with a $95 \%$ confidence interval (Fleiss et al., 2003). The value obtained for $\mathrm{K}$ is 0.85 . Thus, the strength of the inter-rater agreement can be considered very good (Altman, 1991).

\subsubsection{Analytical approach}

Our dependent variable ACSCOPE is calculated as the number of responsibilities set forth in audit committee charters (Eaton and Nocinero, 2000). To test the determinants of ACSCOPE, we use the following Negative Binomial count model. We employ this procedure instead of OLS, because our dependent variable is nonnegative count data. Our choice for a binomial instead of a Poisson model is due to overdispersion in ACSCOPE (Prob > chi2 $=.01$ ). ${ }^{30}$

ACSCOPE $=\quad$ fSSIZE, INDUSTRY, LOSS, LEVRG, BLOCK, BSTRENGTH, DUALITY, DREGIME, COMMITTEES, ACROLE, MULTLIST, TWOTIER\}. (1) (2)

Based on this equation and in order to test $\mathrm{H} 1$, we establish two slightly different count models with essentially the same independent variables, but taking different approaches to calculating the dependent variable. In Model 1, we calculate ACSCOPE as the number of distinct responsibilities set forth in audit committee charters. In Model 2, we calculate ACSCOPE as the difference between the number of responsibilities disclosed in the audit committee charter of a given firm, and the minimum number of responsibilities disclosed in the respective country sample. Due to this modification, we eliminate the effect of inter-country differences in the

${ }^{30}$ The binomial count model is suitable for a discrete dependent variable that takes small values and has a variance that is higher than its average value (Cameron and Trivedi, 1990). 
number of "baseline" responsibilities - i.e. those responsibilities to be addressed by all audit committees in a certain country due to country-specific regulation within the Anglo-Saxon and continental European sample. Thus, in Model 2, our dependent variable ACSCOPE is a count of the responsibilities disclosed above a minimum threshold in the respective country.

To test H2, i.e. the association between ACSCOPE and actual audit committee activity, we use the number of audit committee meetings held in 2010 as our dependent variable (ACMEET). Audit committee meeting frequency is commonly used as a proxy for audit committee diligence in empirical research (Xie et al., 2003), also because it is the only publicly available quantitative signal about the diligence of audit committees (Raghunandan and Rama, 2007).

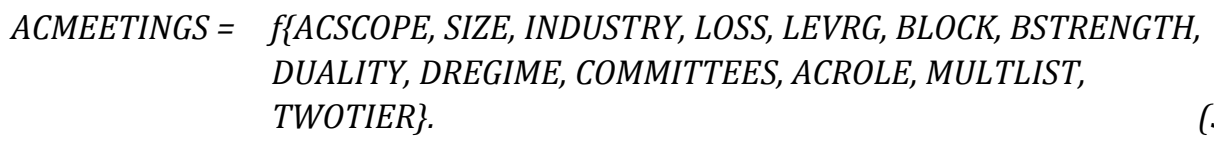

The next section reports our empirical results. Given that the objective of this study is to investigate the determinants and implications of the scope of responsibilities set forth in audit committee charters in institutional settings characterized by different audit committee charter disclosure regimes, we report descriptive statistics for the Anglo-Saxon and for the continental European sample firms. Further, we run all models separately for the Anglo-Saxon (Model 1A-3A) and for the continental European sample (Model 1B-3B).

\subsection{Empirical results}

\subsubsection{Descriptive statistics}

Table 3.2 shows that in countries without a disclosure regime (France, Germany, Italy), we find that merely $35 \%$ of the sample firms voluntarily disclosed a charter at the time of this study. Once disclosing an audit committee charter is recommended (Belgium, Spain), this figure jumps to $85 \%$, and in countries with a comply-or-explain provision (Australia, Netherlands, UK), to 96\%. As expected, all US listed firms in our sample disclosed an audit committee charter.

Panel C shows the Pearson correlation coefficients among our dependent and explanatory variables for the Anglo-Saxon and continental European sample firms. Both tables show significant correlations between ACSCOPE and several explanatory and control variables. Panel $C$ of Table 3.2 also reveals significant and positive correlations between ACSCOPE and ACMEET in the Anglo-Saxon context $(\mathrm{p}<0.01)$ and an absence thereof in the continental European sample. Further, a positive correlation between DREGIME and ACSCOPE is reported for both corporate gov- 
ernance domains $(\mathrm{p}<0.01) .{ }^{31}$ In the continental European context, ACSCOPE is also positively related to BSTRENGTH and MULTILIST (both $\mathrm{p}<0.01$ ).

Table 3.2: Descriptive statistics, variable definitions, and correlations

Panel A: Descriptive statistics

\begin{tabular}{|c|c|c|c|c|c|c|c|c|c|}
\hline & \multicolumn{3}{|c|}{ Total sample } & \multicolumn{3}{|c|}{ Anglo-Saxon sample } & \multicolumn{3}{|c|}{ Cont. European sample } \\
\hline & Mean & Median & St. dev. & Mean & Median & St. dev. & Mean & Median & St. dev \\
\hline ACSCOPE & 18.75 & 20 & 5.84 & $22.26^{* * *}$ & 23 & 3.60 & 15.30 & 15 & 5.56 \\
\hline ACSIZE & 4.24 & 4 & 1.16 & $4.45^{* * *}$ & 4 & 1.19 & 4.03 & 4 & 1.09 \\
\hline ACMEET & 7.25 & 7 & 3.07 & $7.87^{* * *}$ & 8 & 3.21 & 6.65 & 6 & 2.82 \\
\hline$S I Z E$ & 23.43 & 23.56 & 1.45 & $4.37^{* * *}$ & 24.40 & 1.04 & 22.51 & 22.30 & 1.18 \\
\hline INDUSTRY & 0.22 & 0 & 0.41 & 0.24 & 0 & 0.43 & 0.20 & 0 & 0.40 \\
\hline LOSS & 0.19 & 0 & 0.39 & 0.15 & 0 & 0.36 & 0.23 & 0 & 0.42 \\
\hline$L E V R G$ & 0.65 & 0.64 & 0.20 & 0.64 & 0.6 & 0.21 & 0.66 & 0.70 & 0.19 \\
\hline$B L O C K$ & 23.70 & 16.27 & 23.57 & 15.19 & 6.3 & 20.57 & $32.04^{* * *}$ & 30.7 & 23.43 \\
\hline BSTRENGTH & 2.40 & 2 & 1.08 & 2.36 & 2 & 1.11 & 2.26 & 2 & 1.00 \\
\hline DUALITY & 0.43 & 0 & 0.50 & 0.40 & 0 & 0.49 & 0.45 & 0 & 0.50 \\
\hline COMMITTEES & 3.86 & 4 & 1.33 & $4.58^{* * *}$ & 5.0 & 1.11 & 3.16 & 3.0 & 1.14 \\
\hline DREGIME 2 & 0.25 & 0 & 0.43 & 0.50 & 0.5 & 0.50 & - & - & - \\
\hline DREGIME 1 & 0.56 & 1 & 0.50 & 0.50 & 0.5 & 0.50 & 0.63 & 1 & 0.49 \\
\hline$A C R O L E$ & 0.19 & 0 & 0.39 & 0.15 & 0 & 0.36 & 0.23 & 0 & 0.42 \\
\hline MULTLIST & 0.26 & 0 & 0.44 & 0.30 & 0 & 0.46 & 0.23 & 0 & 0.42 \\
\hline TWOTIER & 0.12 & 0 & 0.32 & - & - & - & 0.24 & 0 & 0.43 \\
\hline
\end{tabular}

${ }^{31}$ None of the VIF values exceeds three, which indicates that multicollinearity is not expected to pose a material problem in the estimation of our models (Maddala, 1992). 
Panel B: Variable definitions

ACSCOPE The number of distinct responsibilities set forth in a firms' audit committee charter (January 2010).

ACSIZE The number of directors serving on the audit committee (financial year 2010-2011).

ACMEET The number of meetings held by the audit committee (financial year 2010-2011).

SIZE The natural logarithm of market capitalization.

INDUSTRY A binary variable equal to one for firms from the financial sector (GICS 40), zero otherwise.

LOSS A binary variable equal to one if a firm reported consecutive losses in 2008-2010, zero otherwise.

LEVRG The ratio of total liabilities to total assets.

BLOCK The cumulative percentage of shareholders with more than $5 \%$ ownership.

BSTRENGTH A composite score comprising board size, proportion of independent board members, board tenure, board meetings, and outside board membership: range $=0$ (weak) to 5 (strong).

DUALITY A binary variable coded one if the roles of $\mathrm{CEO}$ and $\mathrm{COB}$ are combined, zero otherwise. COMMITTEES The number of board committees established.

DREGIME 2 Coded one if a firm is required to disclose an audit committee charter, zero otherwise.

DREGIME 1 Coded one if a firm is recommended to disclose an audit committee charter, zero otherwise.

ACROLE A binary variables equal to one if the audit committee has a dual name, zero otherwise.

MULTLIST A binary variable equal to one if a firm is listed in two or more countries, zero otherwise.

TWOTIER A binary variable equal to one if a firm has a two-tier board system, zero otherwise.

*** indicates significant effects of a two-tailed test at the $1 \%$ level. The differences in means are calculated between the Anglo-Saxon and continental European sample firms. If not otherwise indicated, all firm-specific variables are taken from the respective 2010 annual reports. 


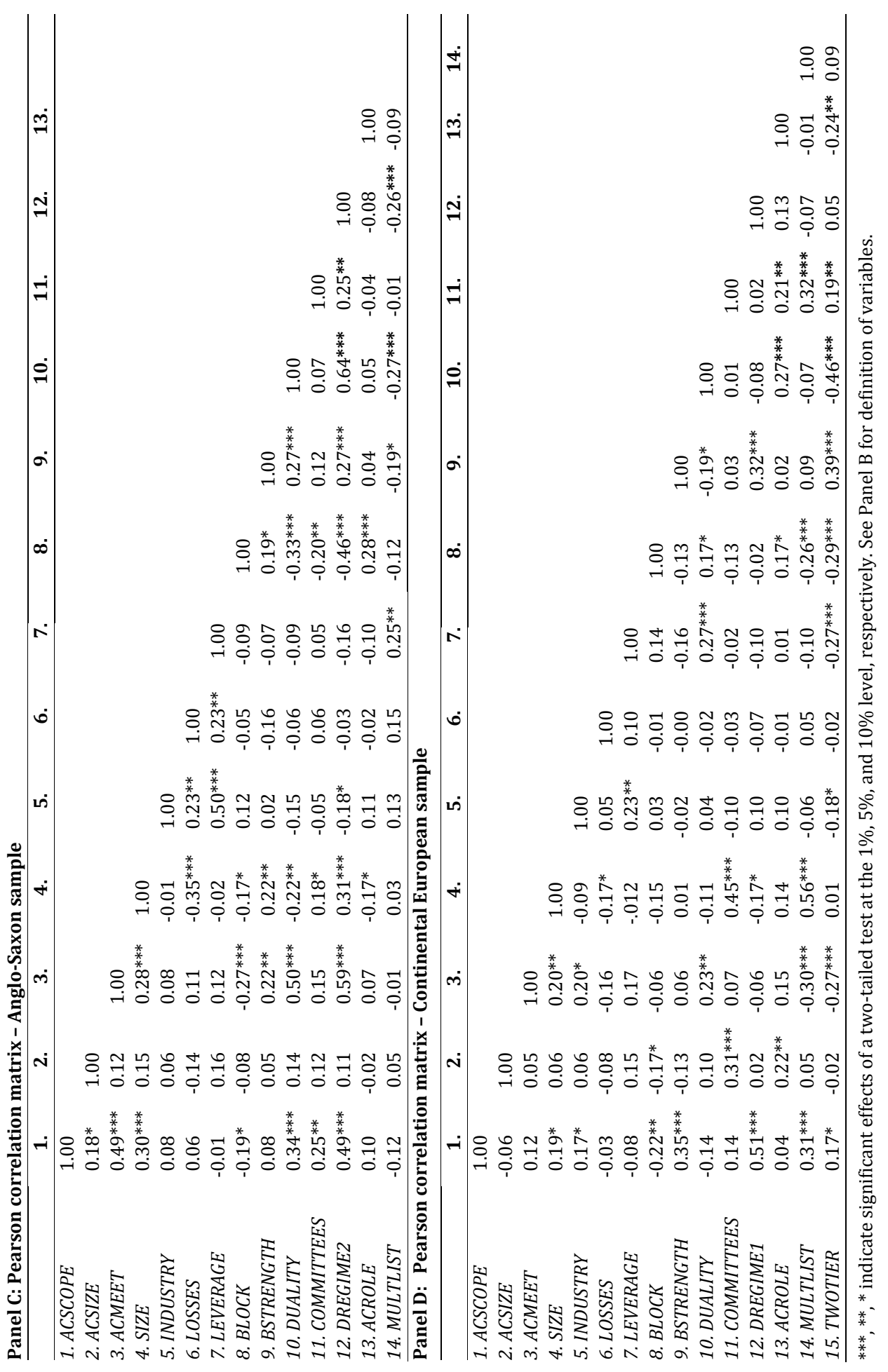




\subsubsection{Determinants of audit committee scope}

Table 3.3 presents the results of Models $1 \mathrm{~A}-2 \mathrm{~B}$ that test the hypothesized determinants of ACSCOPE for the Anglo-Saxon and continental European sample firms. In both institutional settings we document significant relations between ACSCOPE and explanatory variables. For the Anglo-Saxon sample and Model 1A, we find positive associations between the scope of responsibilities set forth in audit committee charters (ACSCOPE) and the variables SIZE $(\mathrm{p}<0.01)$, INDUSTRY $(\mathrm{p}<0.10)$, and LOSSES ( $\mathrm{p}<0.05)$. We also document a positive impact of the coercive pressure enacted by the prevalent disclosure regime DREGIME $(\mathrm{p}<0.01)$.

For Model 2A, we find once more a robust and positive association between $A C S C O P E$ and SIZE as well as LOSSES (both, $\mathrm{p}<0.05$ ). Table 4 also shows a marginally significant association to INDUSTRY as well as BSTRENGTH (both, p < 0.10). The significance of DISREGIME in Model 1A indicates that firms listed on US exchanges set forth more responsibilities in their audit committee charters than Australian and UK listed firms. When controlling for country effects in Model 2A, moving from a comply-or-explain to a mandatory disclosure regime has no impact on cross-sectional variation in audit committee scope. This suggests that the impact of DISREGIME on ACSCOPE in Model 1 is driven by cross-country differences in the scope of responsibilities to be addressed by audit committees and not by a disclosure regime effect.

In the continental European context and Model 1B, we also document a positive association between ACSCOPE and SIZE ( $\mathrm{p}<0.05)$, INDUSTRY $(\mathrm{p}<0.05)$ as well as DREGIME ( $\mathrm{p}<0.01)$. Further, Table 3.3 shows that even after controlling for country effects DREGIME is still positively related to ACSCOPE in Model 2B (p < 0.01), which suggests that cross-sectional differences in ACSCOPE across continental Europe are not only related to different national recommendations on the number of responsibilities to be addressed by audit committees, but also to a disclosure regime effect. The positive coefficient of DREGIME in Model 2B indicates that, against our expectation, coercive pressure to disclose an audit committee charter had a positive impact on cross-sectional differences in ACSCOPE.

Collectively, these results show that there are significant and systematic differences in the scope of responsibilities disclosed in audit committee charters and that this holds in settings with comparatively low levels of institutional pressure to disclose an audit committee charter (continental Europe), but also in settings with more stringent disclosure regimes (Anglosphere). More specifically, our results indicate that the demand for audit committee scope may be related to firm size, the type of industry, and firm profitability (all H1). In contrast to H3 and what has been predicted by the HLR, the absence of a negative coefficient for the variable DREGIME in Models 2A and 2B, as well as the overall results obtained for the Anglo-Saxon and the continental European samples do not support H3 - i.e. that high- 
er levels of institutional pressure to disclose an audit committee charter iron out cross-sectional differences in audit committee scope. ${ }^{32}$

\subsubsection{Audit committee scope and audit committee activity}

Table 3.4 presents the results of OLS regressions with the number of audit committee meetings (ACMEET) as the dependent variable. Based on the premise that publicly available audit committee charters are also used to determine the internal work programs of audit committees, $\mathrm{H} 2$ suggests that the number of audit committee meetings is positively related to ACSCOPE. In line with this prediction and in the Anglo-Saxon sample, we find that the coefficients of ACSCOPE are positive and significant in Model 3A as well as in Model 4A (both, $\mathrm{p}<0.05$ ). Furthermore, we document a positive relation between our proxies for audit committee activity and LEVERAGE as well as for the DREGIME $(\mathrm{p}<0.01)$.

In contrast, for the continental European sample firms, we find no association between the scope of responsibilities disclosed in audit committee charters and our proxies for the level of actual audit committee diligence. Instead, we document a negative relation to the reporting of consecutive losses $(\mathrm{p}<0.05)$ and a positive association between ACMEET and BSTRENGTH ( $\mathrm{p}<0.05)$. Finally, as expected, our analysis shows a positive and negative association between the variables MULTLIST and TWOTIER, on the one hand, and the level of audit committee activity, on the other hand ( $\mathrm{p}<0.01$ and $\mathrm{p}<0.05$, respectively).

Overall, the results provided in Table 3.4 give evidence to support $\mathrm{H} 2$ and to refute $\mathrm{H} 3$. In contrast to our expectations formulated by $\mathrm{H} 3$ and prior literature (HLR, 2003; Forster et al., 2009; Holder-Webb and Cohen, 2012), we document positive associations between the nominal scope of responsibilities set forth in audit committee charters and measures of actual committee activity precisely in institutional settings characterized by more stringent disclosure regimes concerning audit committee charters, and an absence thereof in voluntary settings. We will next summarize our main findings and discuss implications for policy makers and researchers in the concluding section of this chapter.

32 If the disclosure regime and level of coercive pressure would lead to isomorphism in ACSCOPE, then we would expect to observe a negative coefficient of the explanatory variable DREGIME in Model 2A and 2B. Additionally, we would expect to find more significant explanatory variables in Model 2B than in 2A. 
Table 3.3: Binomial count model for audit committee scope

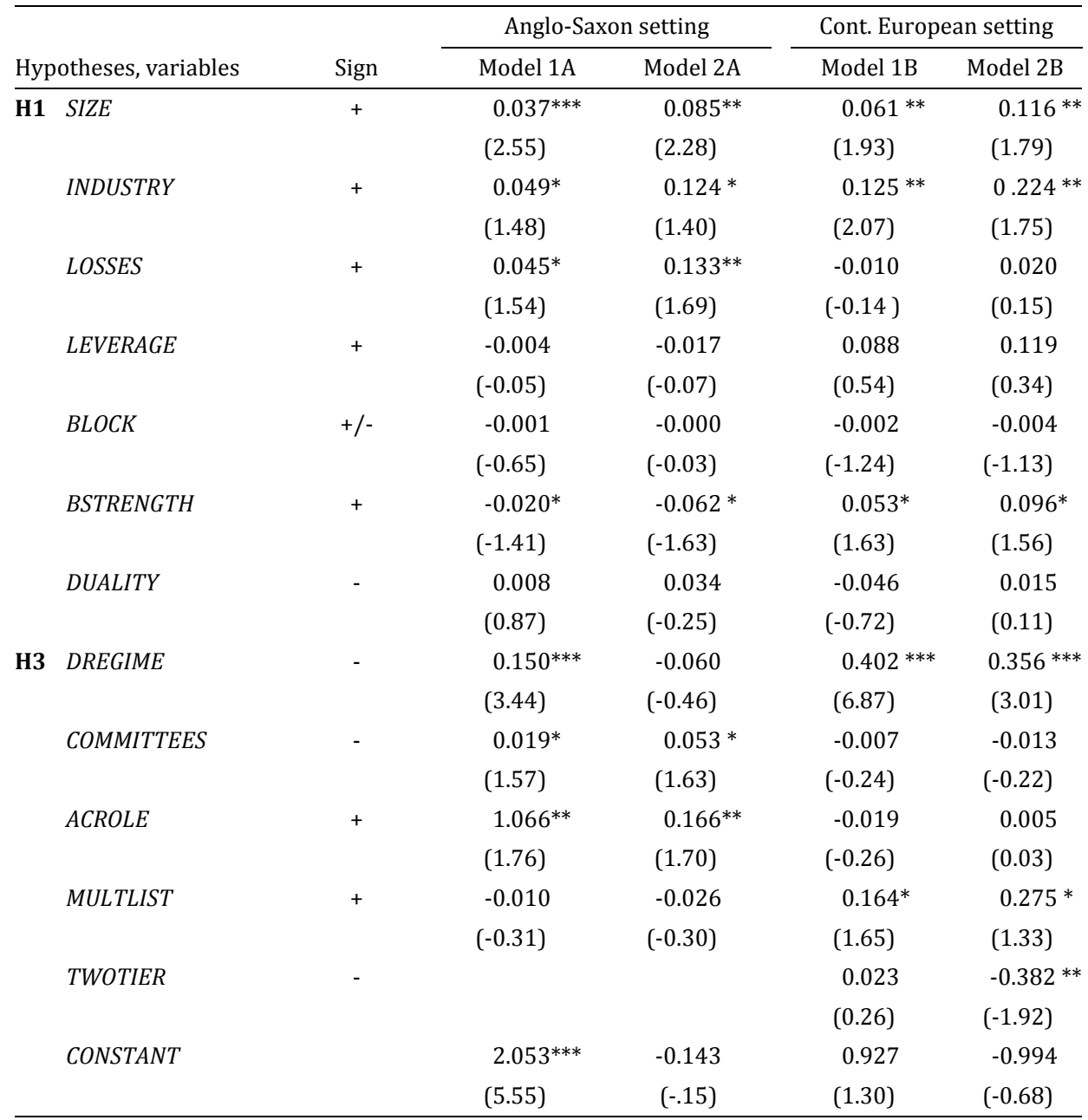

Prob > chi2: $(1 \mathrm{~A})=.00,(2 \mathrm{~A})=.03,(1 \mathrm{~B})=.00,(2 \mathrm{~B})=.00$

Log-likelihood: $(1 \mathrm{~A})=-268.91,(2 \mathrm{~A})=-252.60 ;(1 \mathrm{~B})=-306.02(2 \mathrm{~B})=-294.28$

Number of observations: Anglo-Saxon sample ( $\mathrm{N}=100)$, continental European sample $(\mathrm{N}=102)$

This table reports the binomial count models that test determinants of the number of distinct responsibilities disclosed in audit committee charters (ACSCOPE). The following model is used: ACSCOPE = f(SIZE, INDUSTRY, LOSSES, LEVERAGE, BLOCK, BSTRENGTH, DUALITY, DREGIME, COMMITTEES, ACROLE, MULTILIST, TWOTIER). The difference between model 1 and 2 is the calculation of the dependent variable ACSCOPE. In model 2, we adjust for country effects within the Anglo-Saxon and continental European setting by calculating AC Scope as the difference from the minimum value obtained for ACSCOPE within each country. The table shows the coefficients (z-value). The variables are defined in Panel B of Table 3.2. We also ran each model using the five factors comprising BSTRENGTH, however, we do not document significant results between individual board measures and ACSCOPE. ***, **, *indicate significance at the $0.01,0.05$ and 0.10 level, respectively (one-tailed for predictions, two-tailed otherwise). 
Table 3.4: OLS regression for audit committee activity

\begin{tabular}{|c|c|c|c|c|}
\hline \multicolumn{2}{|c|}{ Hypotheses, variables } & Sign & $\begin{array}{l}\text { Anglo-Saxon setting } \\
\text { Model 3A } \\
\text { (ACMEET) }\end{array}$ & $\begin{array}{c}\text { Cont. European setting } \\
\text { Model 3B } \\
\text { (ACMEET) }\end{array}$ \\
\hline \multirow{2}{*}{\multicolumn{2}{|c|}{ H2 ACSCOPE }} & + & $0.127^{* *}$ & 0.025 \\
\hline & & & $(2.03)$ & $(0.42)$ \\
\hline \multirow{2}{*}{\multicolumn{2}{|c|}{ SIZE }} & + & -0.043 & -0.201 \\
\hline & & & $(-0.20)$ & $(-0.66)$ \\
\hline \multirow{2}{*}{\multicolumn{2}{|c|}{ INDUSTRY }} & + & 0.253 & $0.942^{*}$ \\
\hline & & & $(0.46)$ & $(1.48)$ \\
\hline \multirow{2}{*}{\multicolumn{2}{|c|}{ LOSSES }} & + & 0.727 & $-1.454^{* *}$ \\
\hline & & & $(1.04)$ & $(-2.28)$ \\
\hline \multirow{2}{*}{\multicolumn{2}{|c|}{ LEVERAGE }} & + & $3.054^{* * *}$ & 1.538 \\
\hline & & & $(2.84)$ & $(0.92)$ \\
\hline \multirow{2}{*}{\multicolumn{2}{|c|}{ BLOCK }} & $+/-$ & 0.015 & -0.008 \\
\hline & & & $(1.15)$ & $(-0.69)$ \\
\hline \multirow{2}{*}{\multicolumn{2}{|c|}{ BSTRENGTH }} & + & 0.087 & $0.570^{* *}$ \\
\hline & & & $(0.40)$ & $(1.96)$ \\
\hline \multirow{2}{*}{\multicolumn{2}{|c|}{ DUALITY }} & - & -0.026 & 0.729 \\
\hline & & & $(-0.04)$ & $(1.25)$ \\
\hline \multirow[t]{12}{*}{ H3 } & \multirow[t]{2}{*}{ DREGIME } & + & $4.764^{* * *}$ & -0.844 \\
\hline & & & $(6.61)$ & $(-1.15)$ \\
\hline & \multirow[t]{2}{*}{ COMMITTEES } & - & -0.222 & 0.080 \\
\hline & & & $(-1.16)$ & $(0.31)$ \\
\hline & \multirow[t]{2}{*}{ ACROLE } & + & $1.193^{* *}$ & 0.426 \\
\hline & & & $(2.12)$ & $(0.58)$ \\
\hline & \multirow[t]{2}{*}{ MULTLIST } & + & $1.152^{* *}$ & $2.282^{* * *}$ \\
\hline & & & $(2.08)$ & $(2.58)$ \\
\hline & \multirow[t]{2}{*}{ TWOTIER } & - & & $-1.852^{* *}$ \\
\hline & & & & $(-2.63)$ \\
\hline & \multirow[t]{2}{*}{ CONSTANT } & & -5.114 & 8.664 \\
\hline & & & $(-0.99)$ & $(1.26)$ \\
\hline \multicolumn{2}{|l|}{$\mathrm{N}$} & & 100 & 102 \\
\hline \multicolumn{2}{|c|}{ Adjusted R ${ }^{2}$} & & $55.28 \%$ & $20.54 \%$ \\
\hline \multicolumn{2}{|c|}{ F-statistic } & & $7.89^{* * *}$ & $3.05^{* * *}$ \\
\hline
\end{tabular}

This table reports determinants of audit committee meeting frequency for 2010. The following model is used: ACMEET = f(ACSCOPE, SIZE, INDUSTRY, LOSSES, LEVERAGE, BLOCK, BSTRENGTH, DUALITY, DREGIME, ACROLE, MULTILIST, TWOTIER). We also ran an OLS regressions using ACSIZE as the dependent variable with insignificant results and low model fit (Adjusted $\mathrm{R}^{2}<5 \%$ ). Further, we performed additional tests by disentangling BSTRENGTH into its five components. We find no significant results for Model 3B (Adjusted $\mathrm{R}^{2}$ stays constant). For Model 3A, we find significant results for board size $(t=1.84$, $\mathrm{p}<0.10)$ and board meetings $(\mathrm{t}=3.03, \mathrm{p}<0.01) .{ }^{* *},{ }^{* *},{ }^{*}$ indicate significance at the $0.01,0.05$ and 0.10 levels, respectively (one-tailed for predictions, two-tailed otherwise). 


\subsection{Discussion and conclusion}

Regulators and standard setters across different counties have embraced the concept of publicly available charters as a means for informing legitimate interest groups about the audit committees' role and responsibilities and for improving audit committee effectiveness at the firm level. However, theoretical reasoning and empirical evidence has been provided suggesting that audit committee charters of different firms are boilerplate copies of each other, and that firms deliberately decouple actual committee practices from the content of their charters (HolderWebb and Cohen, 2012). Further, it has been argued that the level of isomorphism and decoupling related to corporate narrative documents that fulfill the dual purpose of external organizational information provision and internal direction provision will increase with the level of institutional pressure exerted on firms to disclose such documents (Harvard Law Review, 2003). If these concerns were justified, publicly available audit committee charters would constitute perilous or at best meaningless documents perversely in those institutional settings characterized by a stringent disclosure regime, such as the US..$^{33}$

The empirical evidence presented in this chapter shows, however, that audit committee charters differ systematically in content from one firm to another and that this holds in institutional settings characterized by low as well as by high levels of coercive pressure exerted on firms to publicly disclose an audit committee charter. Thus, our results do not corroborate previously raised concerns that publicly available audit committee charters are boilerplate copies of each other and that a disclosure regime fuels isomorphism in charter content across firms vis-àvis voluntary disclosure settings (HLR, 2003; Holder-Webb and Cohen, 2012).

Further, we do not find empirical evidence in favor of the supposition that institutional pressure exerted on firms to place an audit committee charter on the public record will increase the probability that firms decouple actual audit committee practices from the charters content. On the contrary, we show evidence suggesting that in countries where the regulatory setting is more stringent (AngloSaxon countries), the professed activities of audit committees are more closely related to their actual work, relative to voluntary disclosure settings (continental Europe). This also indicates that audit committee charters are adopted for efficiency and not purely for legitimacy reasons and that it might well be worthwhile for legitimate interest groups (e.g., investors) to read and compare audit committee charters of firms listed in countries with a stringent disclosure regime.

\footnotetext{
${ }^{33}$ If investors would become aware of elevated isomorphism in audit committee charters, they would be unlikely to compare charters between firms or even read them (Holder-Webb and Cohen, 2012). In this scenario, these charters would constitute meaningless documents. In case audit committee charters differ in content, but remain decoupled from actual practice, on the other hand, investors might form unreasonable expectations about what audit committees can be expected to accomplish.
} 
The intended purpose of audit committee charters is not only to inform investors, but also to provide authority, direction and discipline to audit committee members (BRC, 1999). Kalbers and Fogarty (1998) point out that effective audit committees require a strong organizational charter, institutional support and diligence. According to Cohen et al. (2010; 2012) and DeZoort et al. (2008), audit committees have become more active, diligent, and powerful in the US following the SarbanesOxley Act. We partly attribute this development to the requirement to formalize the responsibilities of the audit committee in a written charter, which is disclosed to the outside world. Beasley et al. (2009), for example, found that agendas of US audit committees are often tailored to the audit committee charter.

On the other hand, our study casts doubt on whether audit committee charters that are being voluntarily disclosed should matter to investors. The presented results show that - in voluntary disclosure settings - publicly available audit committee charters may not hold in store substantive information about actual audit committee practices. Hence, in this context, audit committee charters may function primarily as vehicles to gain external legitimacy via front-stage impression management, but not as a means for informing legitimate interest groups about the committees' actual responsibilities, nor as an instrument for providing authority, direction, and discipline to audit committee members. Voluntary disclosure may serve as a symbol of legitimacy, which allows companies to gain access to resources (Spira, 1999; Chen and Li, 2013). However, audit committee charters that are being voluntarily disclosed do not appear to strengthen the effectiveness of audit committees from an agency theory perspective.

The findings of this study are subject to the following limitations that may provide opportunities for future research. First, we gathered our data on audit committee scope and audit committee activity from archival sources of information, which cannot proxy for the manner by which audit committee members construct meanings of effectiveness (Gendron and Bédard, 2006). Accordingly, our dependent variables do not capture the relative importance and effort that audit committee members devote to individual responsibilities inside and outside of formal meetings. They do also not capture the individual behaviors of audit committee members. As pointed out by Higgs (2003) and Spira and Bender (2004), the effectiveness of board committees in their assigned roles depends as much on their individual behaviors and relationships as the prescribed framework in which they operate.

Second, we have gathered data on audit committee scope using human-scored schemes. Even though this method typically scores high on validity in comparison with word-count systems and computerized methods, its labor intensity severely limits our sample size (Martson and Shrives, 1991). Future studies could use more cost-effective and sophisticated mixed-method techniques to study the content of audit committee charters (e.g., Grüning, 2011; Lewis et al., 2013). Third, this study is restricted to a subset of the largest economies by GDP, to large-cap firms and to a short period of observation, which may limit the generalizability of our findings. 
While keeping in mind the aforementioned limitations, different policy implications emerge from this study for the Anglo-Saxon and continental European context. One of the central measures for modernizing corporate governance in the European Union, set forth by the European Commission in 2003, was to reduce barriers to shareholders' ability to evaluate the corporate governance practices of public interest entities in the EU. However, the presented results suggest that - as far as audit committees are concerned - the European Commission has not achieved this objective. Rather, our findings suggest that, introducing a more stringent disclosure regime on audit committee charters in the EU should be considered.

In the Anglo-Saxon context, in turn, the question emerges whether crosssectional differences in the scope of responsibilities set forth in audit committee charters actually lead to economic benefits for investors and financial markets. Recent first hand insights from audit committee members in North America point out adverse consequences of increasing the scope of responsibilities assigned to the audit committee (Beasley et al., 2009; ICAA, FRC and ICAS, 2012). Specifically, audit committee members warned of creating unrealistic expectations about what audit committees can achieve, and noted that assigning ever more responsibilities to the audit committee creates the risk of it becoming so burdened that it is unable to carry out its core functions effectively. ${ }^{34}$ Another potential unintended consequences of a disclosure regime on audit committee charter is that this could deter potential audit committee members due to liability concerns (Rowland, 2002).

Against this background, future research could study the relationship between the scope of responsibilities inscribed in audit committee charters and measures of audit committee performance in institutional settings characterized by a stringent disclosure regime. Given that audit committees face constraints in terms of, inter alia, expertise, resources and diligence when faced with an increasing number of responsibilities (Whiteoak, 2007) an important avenue for future research is to examine the impact of increasing audit committee scope on composite and individual measures of audit committee effectiveness.

In turn, in situations where organizations seem to decouple audit committee charters from actual audit committee activity to gain external legitimacy, longitudinal studies can explore how investors react to this form of impression management (Merkl-Davies and Brennan, 2011), and whether, as predicted by Suchman (1995), such a legitimacy façade leads to a loss of external legitimacy in the long run. Affirmative evidence in conjunction with the findings presented here could encourage firms to couple actual organizational practices to the content of their charters and vice versa.

\footnotetext{
${ }^{34}$ According to Olson (1999: 1102), overloading audit committee members with too many responsibilities can have three adverse impacts: (1) committee effort and energy may be dissipated in so many directions that audit committees become ever more busy but ever less effective; (2) good directors may decline to take on the burden of serving on the committee (3) those who do serve may face the risk of personal liability or a greater chance of being named as defendants in shareholder lawsuits.
} 


\section{Appendix: Audit committee scope categorization scheme}

\section{Theme: \\ Oversight responsibilities \\ 1. Financial disclosure \\ 1.1 Financial statements \\ 1.2 Accounting policies \\ 1.3 Accounting practices \\ 1.4 Press releases \\ 1.5 Financial reporting process \\ 2. External auditing}

2.1 Appointment

2.2 External audit findings

2.3 Independence

2.4 Audit plan and fees

2.5 Performance review

2.6 Service provision

\subsection{Non-audit services}

2.8 Hiring former employees

\section{Internal auditing}

3.1 Internal audit findings

3.2 Internal audit plan

3.3 Performance review

3.4 Organisational set-up

3.5 Budget

3.6 Service provision

3.7 Objectivity

4. Business control

4.1 Internal control

4.2 Risk management

4.3 Whistleblowing

4.4 Fraud

4.5 Related-party transactions

4.6 IT/IS security

4.7 Officer expenses

\section{Corporate governance}

5.1 Regulatory compliance

5.2 Internal compliance

5.3 Financial management

5.4 Tax matters

5.5 CG guidelines \& policies 5.6 Other responsibilities
Statement:

Frequency counts

Corresponding tasks set out in audit committee charters

$(\mathrm{n}=202)$

Review integrity of financial statements, audit adjustments, going-concern

$100 \%$ assumption, Recommend financial statement for board approval

Review compliance with accounting standards and policies, Recommend changes

$97 \%$

in accounting policies, Advise board on emerging practices

Review accounting estimates and management judgments, the accounting

\section{$70 \%$}

treatment for unusual transaction

Review earnings press releases \& analyst presentations

Review the effectiveness of the financial reporting system and processes, the

CEO/CFO certifications of financial statements

(re-)Appoint and replace the external auditor / Recommend appointment

Review the results of the external audit plan, the adequacy of corrective actions

taken by management, any audit problems and reservations

Evaluate the independence of the EA, Ensure the EA/lead auditor rotation

$88 \%$

Review and approve the annual audit plan

$86 \%$

Review the quality of the services provided by the EA, the cost effectiveness

$70 \%$

Resolve disagreements between EA, the IA and management, Coordinate the

$69 \%$

work of the EA with other parties, Monitor the progress against plan

Determine categories of non-audit services to be provided by the EA, Pre-approve $69 \%$ non-audit services, Ensure disclosure of non-audit services

Recommend a policy for hiring EA employees, Monitor the compliance

Review the internal audit findings and management response

Determine the focal points of the internal audit, Approve annual audit plan

Evaluate the quality of the services provided by the IA, the performance

of the head of IA, the possibility to outsource the IA

Review the organisational structure of the IA, Approve the IA charter

Approve the internal audit budget and that adequate resources are available

Coordinate the work of the IA with other parties, Monitor the IA progress

Review the objectivity of the IA

Review the internal control report, material weaknesses of internal control

Review risk management governance (guidelines \& policies), Oversee

the management of risks, the insurance cover and plans

Establish whistleblowing procedures, Monitor compliance therewith

Review the processes for detecting fraud, fraud report, exposure to fraud

Review IT/IS security

Review the expense report of executives and officers

Review regulatory compliance (e.g., accounting, environmental, listing rules)

Review compliance with code of conduct/ethics

Review capital raising, investment activities, treasury policies 


\title{
CHAPTER 4 Audit Committee Oversight of Enterprise Risk Management and Firm Performance during the 2007-2011 Financial Crisis
}

\begin{abstract}
Is there a relationship between firm performance during a period of economic distress and the characteristics of independent audit committees? This is an important question, given the persistence and severity of the recent financial crises and the importance attributed to audit committees in corporate governance research and practice. This study documents positive relationships between the extent of audit committee authority for overseeing enterprise risk management (ERM) and the subsequent performance of S\&P 500 firms during the 2007-2011 global financial crisis. We also find that audit committees with longer tenure directors and multiple directorships are more likely to be associated with better firm performance during a financial crisis. To substantiate these findings, we provide further evidence which indicates that those firms where substantial authority for overseeing risk management rests with an independent audit committee are more likely to exhibit lower performance variability during a crisis period. The study at hand contributes to research and practice in two major ways. First, our results suggest that independent audit committees are well positioned in the corporate governance mosaic to assume substantial authority for overseeing risk management. Second, formal designation of authority for overseeing ERM and the degree of firm-specific and governance expertise that audit committee members bring to the table seem to be important determinants for audit committee effectiveness in terms of safeguarding firm performance in periods of economic distress.
\end{abstract}




\subsection{Introduction}

The first decade of the $21^{\text {st }}$ century marked a comparatively volatile economic environment with two periods of severe economic distress - namely, the early 2000s recession (2001-2003) and the global financial crisis that took hold in 2007 (2007-2012). At the same time, the role of audit committees in the US corporate governance system expanded substantially as a direct result of the recommendations given by the Blue Ribbon Committee (1999) and the Sarbanes-Oxley Act (2002). Interestingly, a number of studies now report affirmative evidence for systematic associations between the characteristics of US audit committees and firm performance during the early 2000s recession and the subsequent global financial crisis (Chan and Li, 2008; Yeh et al., 2011; Aldamen et al., 2012).

A closer look at existing audit committee literature reveals that the aforementioned studies have one thing in common that differentiates them from prior research which reported no relationship between audit committees and firm performance outcomes (Daily 1996; Ellstand et al., 1998; Klein, 1998). All of them rely on empirical data gathered in times of economic distress. This suggests that systematic associations between audit committees and firm performance indicators tend to surface during significant adverse economic events. In line with this proposition, Yeh et al. (2011) find significant associations between audit committee characteristics and firm performance proxies during a period of economic distress (2007-2008) and an absence thereof in an ordinary period (2005-2006).

The factor which is seemingly driving the audit committees-firm performance association during a period of economic distress, according to agency theory (Jensen and Meckling, 1976; Fama and Jensen, 1983) and existing literature (Chan and Li, 2008; Yeh et al., 2011) is the degree of audit committee independence from management and from the company. More specifically, it has been argued, based on agency theory and evidence from the market for outside directors (Gilson, 1990; Yermack, 2004; Fich and Shivdasani, 2007), that independent directors on audit committees have strong incentives to curb excessive risk-taking and to provide their expert prestige and monitoring power in a crisis period. Excessive risktaking may thus be prevented by increasing the independent directors on the audit committee, leading in turn to lower losses and better firm performance during a period of economic distress, such as the recent financial crisis (Yeh et al., 2011).

In the US, however, listed firms have been required to establish an audit committee made up exclusively of independent directors since 2002, in accordance with Section 301 of the Sarbanes-Oxley Act (SOX). Since the Securities and Exchange Commission (SEC) issued a rule that firms will be de-listed if they fail to comply with SOX, it is reasonable to assume that US audit committees were staffed 
with directors who possessed a sufficient degree of independence several years before and during the global financial crisis (henceforth GFC) took hold in 2007.35

However, relatively little is known about the factors that determine the effectiveness of independent audit committees to impact firm performance during a crisis period. Much of the existing literature consists of empirical research that links cross-sectional variations in audit committee independence to the quality of financial reporting and external auditing (Bédard and Gendron, 2010). While the evidence provided in this body of literature underscores the merit of setting stringent standards regarding audit committee independence, it does not offer many theoretical insights or much empirical evidence regarding factors that determine the effectiveness of fully independent audit committees to safeguard firm performance during a crisis period. It is important to address this gap because enhancing the effectiveness of independent audit committees is a central issue confronting corporate governance scholars and practitioners (Carcello et al., 2011).

To fill this void, it has been suggested to draw from the rich literature on team effectiveness published in the realm of organizational studies and social psychology (Zona and Zattoni, 2007; Payne et al., 2009). In this study, we apply a threedimensional framework established by Hollenbeck et al. (2012) to the audit committees of S\&P 500 firms during the 2007-2011 GFC. This framework encompasses three dimensions: authority differentiation, skill differentiation, and temporal stability. In light of the existing audit committee literature and for the purpose of this study we operationalize these dimensions as cross-sectional differences in (1) the degree to which audit committees are charged with authority to oversee ERM, (2) the financial, governance and firm-specific expertise of committee members, and (3) the temporal stability in audit committees. We deliberately limit this study to US listed firms in order to study audit committee effectiveness in a context where all members are supposedly independent.

This study contributes to the literature in two major ways. First, our study adds to mounting empirical evidence which suggests that independent audit committees can safeguard firm performance during periods of economic distress. Second, the main significance of our study is to show that formal designation of authority for overseeing risk management, board tenure and multiple directorships can be important determinants of audit committee effectiveness in the context of safeguarding firm performance during significant adverse economic events. Policy makers should take note of these findings, due to the increasing importance attributed to risk oversight in the wake of the GFC (OECD, 2009).

\footnotetext{
${ }^{35}$ An alternative explanation would be that non-executive directors "officially" designated as independent were in fact not free from undue influence. Given the stringent post-SOX independence requirements for audit committee members in the US, however, we assert that the vast majority of audit committee members were sufficiently independent before and during the financial crises (Rupley et al., 2011).
} 
This chapter starts with a discussion of the findings presented by Yeh et al. (2011) and the conceptual framework of Hollenbeck et al. (2012). Next, we develop hypotheses concerning the impact of audit committee authority differentiations, skill differentiation, and temporal stability on firm performance outcomes during the GFC. Subsequently, we present our research design, empirical results, and the conclusions of the study at hand.

\subsection{Research background}

\subsubsection{Audit committees and firm performance during a crisis period}

In a special issue of the journal Corporate Governance: An International Review, dedicated exclusively to the role of corporate governance in precipitating or exacerbating the 2007-2011 GFC, empirical evidence is provided by Yeh et al. (2011), which suggests that the independence of directors on audit committees affected the level of risk-taking and the subsequent performance of large financial institutions from G8 countries. The study of Yeh et al. holds in store three important findings that provide the theoretical and motivational point of departure for the study at hand. We shall discuss each of them in turn.

First, audit committees may impact firm performance outcomes. This is a noteworthy finding, because the first wave of audit committee-firm performance research carried out in the 1990s failed to provide evidence for a relationship between audit committees and firm performance (Daily et al., 1998; Ellstand et al., 1998; Klein, 1998; Vafeas and Theodorou, 1998). More recent studies, including Chan and Li (2008), Aldamen et al. (2012) and Bolton (2014), however, seem to square with the results presented by Yeh et al. Table 4.1 lists ten empirical studies of the audit committee-firm performance link published between 1996 and 2014. The table shows four papers published between 1996 and 1999 that find no association between audit committees and firm performance, whereas five out of six studies published between 2008 and 2014 document evidence for systematic relationships between firm performance and audit committee characteristics. ${ }^{36}$

Second, systematic associations between audit committee characteristics and firm performance indicators tend to surface in periods of economic distress. Yeh et al. find statistically significant associations between audit committee characteristics and firm performance proxies during a period of economic distress (20072008), and an absence thereof in a non-distress period (2005-2006). In fact, all studies depicted in Table 4.1 that document statistically significant associations

\footnotetext{
${ }^{36}$ Hence the percentage of papers reporting affirmative evidence on the audit committee-firm performance link has risen from quasi zero to over $80 \%$. We attribute this trend primarily to two factors: (1) the expanding role of audit committees in the US system of corporate governance, resulting from the BRC (1999) and SOX (2002), and (2) the contextual focus of recent research (crisis period setting).
} 
between audit committees and firm performance rely on data gathered in times of economic distress. Hence, there is evidence to suggest that audit committees can contribute to safeguarding firm performance during periods of adverse economic events. Intuitively, the question emerges: which factors determine the effectiveness of audit committees in safeguarding performance in times of economic distress? We deem this an important question to be studied in light of the persistence of periods of crisis for corporate America during the past decades. ${ }^{37}$

Third, according to Yeh et al. (2011) and as predicted by agency theory (Jensen and Meckling, 1976; Fama and Jensen, 1983), the factor seemingly driving the audit committee-firm performance relationship during a period of crisis is the proportion of independent directors serving on the audit committee. According to Yeh et al., financial institutions with more independent audit committees performed better during 2007-2008, because independent directors - supposedly due to career and reputation concerns - have incentives to curb excessive managerial risktaking and to provide their expert prestige and monitoring power during a crisis. In this context, Gilson (1990) and Fich and Shivdasani (2007) show that directors sitting on the boards of firms in trouble are less likely to receive new appointments. Yermack (2004), in turn, documents considerable wealth consequences for outside directors if the respective firm performs well. Recent reviews of the empirical audit committee literature show that independence is the factor most frequently associated with different dimensions of audit committee effectiveness (Bédard and Gendron, 2010).

${ }^{37}$ Figure 1 shows five years with a negative change in total annual return: the savings and loan crisis of $1990(-3 \%)$, the early 2000 s recession $(-9 \%,-12 \%$, and $-22 \%)$, and the late 2000 s financial crisis ($37 \%$ ). This means that five years in this 20 -year period can be considered to be within a period of crisis. 


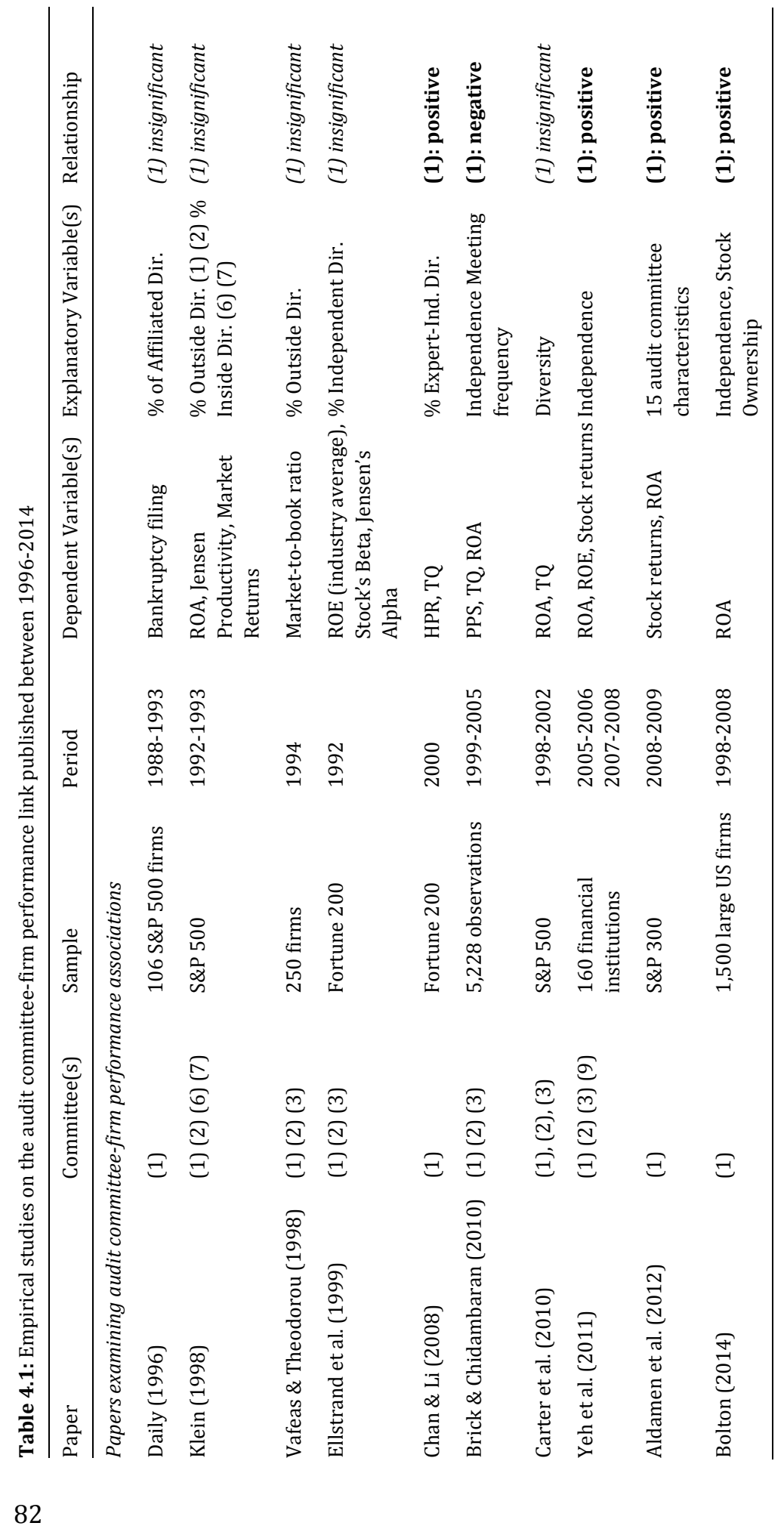




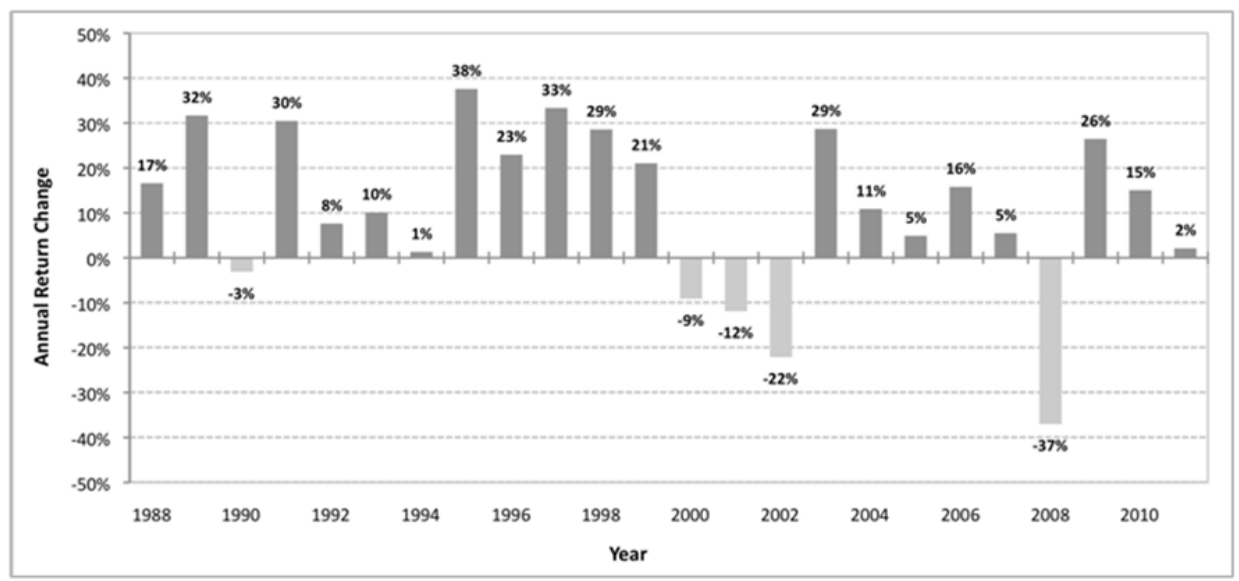

Figure 4.1 S\&P 500 total annual return changes between 1988 and 2011.

However, a closer look at the descriptive statistics on audit committee independence for the sample firms and time period studied by Yeh et al. reveals that at the outset of the GFC, approximately 97 percent of the directors serving on the audit committees of the largest financial institutions from the G8 countries were classified as being independent according to prevalent standards. In four of the eight countries featured in the study of Yeh et al., namely, Canada, Germany, the UK, and the US, the percentage of independent directors serving on the audit committees of the 20 largest financial institutions between 2005-2008 exceeded 99 percent. ${ }^{38}$ As far as the US is concerned, this does not come as a surprise, since Section 301 of the Sarbanes-Oxley-Act of 2002 mandates that US-listed firms maintain an audit committee made up entirely of independent directors. To enforce this, the SEC issued a rule that firms be delisted if they failed to comply with Section 301 of SOX.

The fact that US-listed firms were already required to maintain a fully independent audit committee according to SOX casts doubt on the finding of Yeh et al. (2011) that audit committee independence moved the needle on cross-sectional differences in firm performance outcomes during the GFC. At the same time, a number of prior studies show that not all fully independent audit committees are equally effective in their monitoring efforts (e.g. Hoitash et al., 2009; Dhaliwal et al., 2010; Carcello et al., 2011). These considerations lead us to formulate two research questions, which are the focus of the present study: First, which factors may explain cross-sectional differences in the effectiveness of fully independent audit committees in safeguarding firm performance during periods of economic distress? Second, are cross-sectional differences along these characteristics associated with better firm performance during the GFC, as suggested by recent evidence?

${ }^{38}$ When assuming that on average four directors serve on an audit committee, then the sample studied by Yeh et al. contains about 480 audit committee members, thereof circa 19 non-independent directors. 


\subsubsection{What makes fully independent audit committees effective?}

Drawing on agency theory, the empirical audit committee literature consists to a large extent of studies that link cross-sectional variations in audit committee independence to several dimensions of audit committee effectiveness, While the evidence provided in this body of literature shows positive associations between audit committee independence and effectiveness, it offers limited insights regarding the factors that enhance audit committee effectiveness in a context where firms are required to maintain fully independent audit committees. It is important to address this gap, given that most countries require listed firms to set up and maintain an audit committee composed of a majority or entirely of independent directors. Furthermore, corporate governance scholars have outlined that board of directors and audit committees cannot be understood from a single theoretical lens, and that agency theory alone may be insufficient to explain cross-sectional variations in their effectiveness (Zona and Zattoni, 2007; Carcello et al., 2011)

One field of research that could provide valuable insights is literature on the effectiveness of different types of teams that has been published outside the corporate governance and audit committee domain. After all, the main difference between the audit committee and team effectiveness literature is the focus of the former on agency theory and independence as primary dimensions of effectiveness. In a setting like the US, where all audit committee members are supposed to be independent, this difference diminishes. What remains is the question: what makes fully independent audit committees effective?

To provide an answer to this question, we first scanned seminal papers on the determinants of team effectiveness published in the realm of organizational sciences and social psychology (e.g. Sundstrom et al., 1990; Milliken and Martins, 1996; Cohen and Bailey, 1997; Mathieu et al., 2008). However, the tricky part of this exercise - i.e. applying evidence on the antecedents of team effectiveness published outside the realm of corporate governance research to audit committees - is to make sure that the dimensions studied are relevant in the context of audit committees. After all, the predominant position in academic literature seems to be that the relation between team characteristics and team performance is contingent on the type of team studied (Stewart, 2006; LePine et al., 2008).

However, Hollenbeck et al. (2012) suggest differently. In a paper published in the Academy of Management Review, the authors show that by and large the same underlying dimensions have been used in academic literature to study different kinds of teams (e.g., management teams, product development teams, project teams, or crews). According to Hollenbeck et al. (2012: 84), "the literature on teams proposes a dizzying array of different team types, even though the number of actual underlying dimensions used as building blocks to differentiate teams is limited". By reviewing 42 seminal papers published on different team types in high impact journals included in the Social Sciences Citation Index (SSCI), Hollenbeck et 
al. develop a framework to differentiate and study teams along three dimensions: (1) authority differentiation; (2) skill differentiation; and (3) temporal stability. ${ }^{39}$

When conferring the aforementioned dimensions on audit committees, they can be defined as follows: authority differentiation refers to the degree to which specific oversight responsibilities are vested in the audit committee; skill differentiation is the degree to which audit committee members have specialized knowledge or capabilities that may enhance their effectiveness; and temporal stability refers to the degree to which audit committee members have a history of working together and an expectation of working together in the future. ${ }^{40}$ In the following we shall consider each dimension and explain in what way they might contribute to the effectiveness of independent audit committees to impact firm performance during a crisis period. Thereby, we aim to enrich the existing literature on audit committees with insights provided by the team effectiveness literature and merge two strands of research that have hitherto been largely undertaken in isolation from each other.

\subsection{Hypothesis development}

\subsubsection{Audit committee authority differentiation}

Studies concerning the role of boards of directors during the GFC suggest that inter-firm differences in board oversight of enterprise risk management (ERM) may help to explain why some firms maneuver better through a financial crisis than others (Brown et al., 2009; Erkens et al., 2012; Francis et al., 2012). ${ }^{41}$ In this context, it has been argued - based on the experiences from previous periods of crisis - that a board's inability to monitor firm risk-taking is the major cause of financial crises in the first place (Greenspan, 1999; Mitton, 2002; Dobbin and Jung, 2010). Hence, it is easy to see why there is tremendous interest among regulators, practi-

\footnotetext{
${ }^{39}$ As pointed out by Hollenbeck et al., (2012: 84), these dimensions were chosen for conceptual and practical reasons. Conceptually, 38\%, 55\%, and $57 \%$ of the 42 papers reviewed by Hollenbeck et al. invoke authority differentiation, skill differentiation and temporal stability, respectively. On the practical side, they reflect the dimensions that go into the construction of organization charts in terms of the vertical dimension (authority), the horizontal dimension (skills) and names (temporal stability).

${ }^{40}$ Independence may constitute a fourth dimension in Hollenbeck et al.'s framework when studying teams in the context of corporate governance. Since the audit committees of US-listed firms are required to be staffed entirely with independent directors, we disregard this dimension in this study.

${ }^{41}$ According to the Committee of Sponsoring Organizations of the Treadway Commission (COSO), enterprise risk management deals with risks and opportunities affecting value creation or preservation and can be defined as "a process, effected by an entity's board of directors, management and personnel, applied in strategic setting and across the enterprise, designed to identify potential events that may affect the entity, and manage risks to be within its risk appetite, to provide reasonable assurance regarding achievement of objectives" (COSO, 2004: 2).
} 
tioners and academics to better understand the structural relationships between board oversight of ERM and firm performance during periods of crisis.

However, boards of directors are not the sole bodies responsible for overseeing risk management. According to US regulation, boards of directors are required to delegate authority to oversee risk matters to an independent audit committee. The following passage from the New York Stock Exchange corporate governance rules outlines the designated role of audit committees of firms listed on that stock exchange with respect to risk oversight:

"While it is the job of the CEO and senior management to assess and manage the company's exposure to risk, the audit committee must discuss guidelines and policies that govern the process by which this is handled. The audit committee should discuss the company's major financial risk exposures and the steps management has taken to monitor and control such exposures. The audit committee is not required to be the sole body responsible for risk assessment and management, but, as stated above, the committee must discuss guidelines and policies to govern the process by which risk assessment and management is undertaken. Many companies, particular financial companies, manage and assess their risks through mechanisms other than the audit committee. The process these companies have in place should be reviewed in a general manner by the audit committee, but they need not be replaced by the audit committee"

(NYSE corporate governance rules, 2003, 2011).

We draw two conclusions from the above-stated NYSE provisions. First, the boards of directors of US-listed firms were already required to assign the task of discussing guidelines and policies for risk assessment and management to their respective audit committees several years before the GFC took hold in October 2007. Second, the NSYE governance rules grant considerable leeway to boards of directors to determine whether the audit committees' role with respect to risk oversight should be strictly procedural and indirect (limited to oversight of guidelines and policies) or more substantial and direct (more extensive oversight of ERM, e.g. levels of risk exposure and processes for managing risk).

With this as a background, it does not come as a surprise that a survey among 281 US audit committee members conducted between January 2007 and November 2008 by the audit firm KPMG shows substantial differences in the level of risk oversight assumed by audit committees in the US at the outset of the GFC. ${ }^{42}$ This intuitively raises the question of whether there is an association between the extent of audit committee authority to oversee ERM and firm performance during the

${ }^{42}$ According to KPMG (2008: 6), merely 17 percent indicated that their audit committee has primary responsibility for the oversight of significant nonfinancial reporting risks, while 56 percent said such responsibility rests with the full board, and 18 percent said it rests with various board committees. 
GFC. In other words: are audit committees charged with substantial oversight of ERM more likely to prevent firm performance dips related to unexpected and significant adverse economic events, such as the GFC, than those charged with limited oversight of ERM? In the academic literature, the aforementioned research questions remain largely unexplored (Turley and Zaman, 2004). The professional literature, on the other hand, provides some arguments against, but even more in favor of delegating substantial authority for overseeing risk management to the audit committee.

On the one hand, it has been argued that due to the already lengthy list of audit committee responsibilities related to financial reporting and the external/internal audit function, adding oversight of risk exposure and the management thereof to the committee agenda will lead to audit committee overload (Beasley et al., 2008). In a rather critical paper, Burton (2008: 3) stresses that "audit committees are constantly being charged with ever greater responsibilities and that authoritative bodies seem to think that the audit committee is the appropriate entity for whatever additional responsibility it wishes to place on listed firms". Burton further outlines that the traditional role of audit committees, namely, to oversee financial reporting and auditing, is neither prospective nor managerial, and therefore largely incompatible with oversight of ERM. Based on this line of reasoning, it has been suggested that separate standing committees of the board, exclusively responsible for ERM oversight, be formed, instead of placing additional duties on already overworked audit committees (Fraser and Henry, 2007; Burton, 2008).

In direct response to the aforementioned concerns, several papers advocate that audit committees are ideally positioned in the corporate governance mosaic to oversee the assessment and management of risk exposure and financial matters and that audit committee effectiveness is also a matter of setting priorities and therefore not threatened by "crowded agendas" per se (e.g., KPMG, 2009; Sherman et al., 2009; NACD, 2010; IIA, 2011). First, audit committees may be in a good position to assume substantial authority related to risk and financial oversight, given their involvement in many of a firm's core governance activities and interaction with the major players in the corporate governance mosaic (NACD, 2010; IIA, 2011). Second, and in direct response to the "crowded agenda argument", Sherman et al. (2009) argue that audit committees should move more critical business issues like overseeing strategy, risk management, and financial management, to the top of their agenda, instead of focusing primarily on compliance and financial reporting matters (KPMG, 2011).43

\footnotetext{
${ }^{43} \mathrm{~A}$ survey among US audit committee members by the audit firm KPMG and the NACD (2011) reinforces this proposition. When asked to which areas of oversight audit committees would like to devote the most time, "risk management" and "corporate strategy" ranked among the top three answers. The survey further shows that in order to enhance audit committee effectiveness, audit committee members plan to better link strategy and risk and prioritize the committee's agenda to focus on the most important issues.
} 
The global financial crisis constitutes an interesting natural experiment for testing the economic consequences of charging audit committees with substantial authority to oversee ERM on firm performance outcomes. Due to the empirical evidence provided by Yeh et al. (2011), Aldamen et al. (2012), and Bolton (2014), and the importance attributed to ERM for safeguarding firm performance during periods of economic distress, such as the GFC (Erkens et al., 2012; Ferrero-Ferrero et al., 2012), we formulate the following hypothesis:

H1: The effectiveness of independent audit committees to impact firm performance during a period of crisis is contingent on the extent of audit committee authority to oversee risk management.

\subsubsection{Audit committee skill differentiation}

We define audit committee skill differentiation as the degree to which audit committees are composed of directors who have specialized knowledge and/or capabilities which may contribute to their effectiveness. In contrast to authority differentiation, there is no shortage of empirical and experimental evidence for an association between the skills and capabilities of audit committee members and audit committee effectiveness (e.g., DeZoort, 1998; Hoitash et al., 2009; Dhaliwal et al., 2010). Reviews of the empirical audit committee literature even show that, next to independence, audit committee skill differentiation constitutes the factor that has been found to be most frequently correlated with different proxies of audit committee effectiveness (Bédard and Gendron, 2010; Lin and Hwang, 2010).

Regarding the implementation of the expertise required of audit committee members, US policymakers have focused primarily on financial competencies in their attempts to improve audit committee effectiveness (Krishnan and Lee, 2009). US stock exchange rules and the SOX have institutionalized a minimum threshold of financial competencies for the audit committees of US-listed firms by requiring every audit committee member to be "financially literate" and that firms disclose whether at least one audit committee member can be classified as an "audit committee financial expert" (SEC, 2003).44 Despite this stringent requirement of the SEC, it has been pointed out that audit committee effectiveness may be further enhanced along the dimension of skill differentiation in at least three distinct ways (DeZoort and Salterio, 2001; Bédard and Gendron, 2010; Dhaliwal et al., 2010).

First, prior research demonstrates that financial expert directors differ from financially literate directors in terms of their oversight judgments (McDaniel et al., 2002). Even though the audit committee literature reveals some controversy regarding the desirability of financial expertise over financial literacy (Kirk, 2000), it

${ }^{44} \mathrm{~A}$ discussion of the requirements for designating an audit committee member a 'financial expert' is beyond the scope of this study. For further information, please refer to: http://www.sec.gov/rules/ final/33-8177.htm. 
is generally hypothesized in extant studies that increasing the number or proportion of audit committee members who can be classified as financial experts beyond the minimum threshold of one member will contribute to audit committee effectiveness (see e.g., Krishnan, 2005; Zhang et al., 2007; Krishnan and Visvanathan, 2008). Bédard and Gendron (2010) show that this hypothesis is confirmed by the majority of empirical audit committee studies published between 1994 and 2008.

Second, prior research drawing from the resource-based view of the firm (Pfeffer and Salancik, 1978) asserts that a main asset that outside directors bring to the board of a given firm - in addition to an independent view - is their body of knowledge and experiences gained at other firms, e.g., in the form of holding additional directorships (Hillman and Dalziel, 2003). Several studies confirm that holding additional directorships may contribute to audit committee effectiveness. Bédard et al. (2004) and Yang and Krishnan (2005), for example, find that the likelihood of aggressive earnings management is negatively related to the governance expertise of audit committee members. Hoitash et al. (2009), in turn, document a significant and positive relation between the supervisory expertise of audit committee members and the quality of internal control. Hence, we posit that expertise in governance may also be an important precursor for the audit committee-firm performance link in a period of crisis.

Third, it has been suggested that the effectiveness of independent directors is also contingent on their knowledge of the respective firm and industry (e.g., Beasley, 1996; Yang and Krishnan, 2005; Ghosh et al. 2010; Cohen et al., 2014). Audit committees staffed exclusively with recently appointed outside directors are likely to know little about the industry dynamics and the underlying business model of the respective firm. It is intuitive that a lack of firm- and industry-specific knowledge may create difficulties when carrying out complex tasks that require a solid understanding of the respective firms and industry, such as overseeing the way risks and financial matters are being managed (Zattoni and Cuomo, 2010). Accordingly, newly appointed independent directors might not be able to oversee and appraise managerial decisions - let alone stand up to management in case of disputes on risk management topics (Mueller-Kahle and Lewellyn, 2011). In this context, Bacon and Brown (1973) and Kesner (1998) argue that it takes at least three to five years for independent directors to gain a solid understanding of large and complex firms.

In sum, the existing corporate governance and audit committee literature provide theoretical reasoning and empirical evidence that the degree to which an audit committee is composed of members possessing financial competencies, governance expertise and firm-specific knowledge can make a difference in audit committee effectiveness. More recently, Aldamen et al. (2012) provide evidence that audit committees with more experience and financial expertise were more likely to be associated with the positive firm performance of S\&P 300 firms during the 2008-2009 GFC period. With this as a background, we hypothesize that firm 
performance during a crisis period is positively related to increasing levels of audit committee skill differentiation in terms of financial, governance and firm-specific expertise:

H2: The effectiveness of independent audit committees in impacting firm performance during a crisis period is contingent on the skill differentiation of committee members in terms of financial, governance and firm-specific expertise.

\subsubsection{The Temporal (in)stability of audit committees}

The third dimension in Hollenbeck et al.'s framework is that of the temporal stability of a team. At the time of this writing, there is no requirement in the US regarding the temporal stability or instability of audit committees in terms of the minimum-maximum period that directors should serve on the audit committee of a given firm. It also remains unclear in the literature, whether and how the stability of board committees may impact their effectiveness.

On the one hand, it has been argued in corporate governance literature that temporal stability in teams that perform a monitoring role vis-à-vis management may lead presumably independent directors to entrench management due to the development of social ties, and that this may impair their monitoring effectiveness (Vafeas, 2003). The organizational literature presents additional benefits associated with unstable teams, including: more frequent displacement of poor performing team members; frequent infusion of new knowledge; and higher levels of intragroup communication and motivation (e.g., Katz, 1982; Staw, 1980).

In contrast, several studies show that stable teams outperform unstable ones in several kinds of settings (Ton and Huckman, 2008; Van der Vegt et al., 2010), and that high turnover among groups may be harmful for organizations (Glebbeck and Bax, 2004). Staw (1980) points out that operational disruption and the demoralization of team membership are drawbacks associated with high turnover groups. Van der Vegt et al. (2010), in turn, motivates that social integration, team learning behavior, and task flexibility suffer when team membership is unstable. In a similar vein, it has been pointed out that the frequent assimilation of newcomers can negatively impact team performance and prevent groups from reaching higher levels of social identity and performance (Guzzo and Dickson, 1996). Due to different perspectives on the impact of temporal stability on audit committee effectiveness we test the following non-directional hypothesis in this study:

H3: $\quad$ The effectiveness of independent audit committees in safeguarding firm performance during a crisis period is related to their temporal stability. 


\subsection{Research design}

\subsubsection{Sample and timeline}

In order to test the hypothesized relationships between the authority, expertise and temporal stability of fully independent audit committees, on the one hand, and firm performance during a crisis period, on the other hand, we select the constituents of the S\&P 500 index as our sample. ${ }^{45}$ Furthermore, we focus our study on the time period between 2007 and 2011, which has been considered by leading economists to be the worst financial crisis since the Great Depression of the 1930s (Reuters, 2009). The GFC provides an interesting natural experiment for the purpose of this research, due to: (1) the importance attributed to the effective oversight of enterprise risk management and the financial policies for firm performance during this period; (2) the involvement of audit committees in the aforementioned oversight areas; and (3) existing evidence that the magnitude of the audit committee-firm performance association should be amplified during periods of exogenous shocks (Mangena et al., 2012; Ferrero-Ferrero et al., 2012).

One of the main considerations in firm performance studies is the appropriate time lag for properly evaluating the influence of corporate initiatives on firm performance outcomes (Day and Lord, 1988). As pointed out by Ellstrand et al. (1999) choosing an appropriate time lag between firm performance and explanatory variables is especially relevant to corporate governance studies, since director influence on corporate decisions take time to be realized. In order to take into account (i.e. empirically examine) potentially time lagged effects between audit committee characteristics and firm performance outcomes, we constrain our analysis to those S\&P 500 firms for which complete firm performance and audit committee data is available for the entire period of observation, i.e. from 2007 to 2011 (Baysinger and Butler, 1985). Even though this implies that an elevated number of firms have to be excluded from our final sample, the possibility of accounting for time lagged effects and two further aspects favor using balanced panel data sets for this study.

First, from the average yearly stock returns of the S\&P 500 firms shown in Figure 4.1, it can be derived that the magnitude of the exogenous shocks differed significantly during the individual years of the GFC. While it is commonly recognized that the GFC started in the latter part of 2007 (Allen and Staff, 2012), firm performance as measured by yearly stock returns really dipped in $2008(-37.00$ percent), before bouncing back 26.46 percent in 2009 and dropping to 2.05 percent in 2011. This suggests that the GFC can be separated into an early stage crisis period (2007-2008), followed by a period of recovery (2009), and a less severe late stage crisis period (2010-2011). Accordingly, it is interesting to study the hypothe-

45 Although this implies that our study is focused purely on large publicly traded firms, choosing the S\&P 500 offers several advantages, including comparability of results, data availability, and selection of firms that have received the greatest scrutiny in term of governance practices (Ellstrand et al., 1999). 
sized audit committee-firm performance linkages for the same set of firms over the entire GFC period, separately for the early and late stages of the crisis period, as well as for individual years. Second, data on audit committee authority, competencies and temporal stability was not readily available in a canned data set at the time of this study. Hence, we constrain our study to those firms that were included in the S\&P 500 index all the way from 2007 until 2011.

Table 4.2 presents an overview of our initial and final sample. From the 500 firms that were listed in the S\&P 500 index at year-end 2011 we dropped 28 firms that were not included in the S\&P 500 during the entire period of observation. Next, we excluded 25 firms from our sample due to incomplete data on the directors serving on the audit committee, which we gathered from the RiskMetrics (ISS) Directors database. Since our measure of temporal stability draws on audit committee membership information before the outset of the GFC, we also excluded firms that were not listed in the S\&P 500 and firms with incomplete data in the RiskMetrics Director database between 2004 and 2007. After accounting for a number of mergers and acquisitions between S\&P 500 firms and other missing data, we arrive at a final effective sample of 351 firms and 1,755 firm-year observations. 
Table 4.2: Sample overview

\begin{tabular}{|c|c|c|}
\hline & $\mathrm{N}$ of firms dropped & Remaining firms \\
\hline \multicolumn{3}{|l|}{ Panel A: Sample Selection } \\
\hline S\&P 500 (year-end 2011) thereof: & & 500 \\
\hline Firms not included in S\&P 500 from 2007-2011 & $(28)$ & 472 \\
\hline Firms with missing director data 2007-2011 & $(25)$ & 447 \\
\hline Firms not included in S\&P 500 from 2004-2007 & $(31)$ & 416 \\
\hline Firms with missing director data 2004-2007 & $(42)$ & 374 \\
\hline Missing data (other) & $(11)$ & 363 \\
\hline Mergers and Acquisitions & $(12)$ & 351 \\
\hline Effective final sample & $(149)$ & 351 \\
\hline \multicolumn{3}{|l|}{ Panel B: Samples by Industry Sector (GICS) } \\
\hline Sector 10: Energy & $(12)$ & 26 \\
\hline Sector 15: Materials & $(6)$ & 23 \\
\hline Sector 20: Industrials & $(10)$ & 48 \\
\hline Sector 25: Consumer Discretionary & $(24)$ & 54 \\
\hline Sector 30: Consumer Staples & $(12)$ & 29 \\
\hline Sector 35: Health Care & (19) & 37 \\
\hline Sector 40: Financials & $(35)$ & 47 \\
\hline Sector 45: Information Technology & (19) & 53 \\
\hline Sector 50: Telecommunications Services & (7) & 5 \\
\hline Sector 55: Utilities & $(5)$ & 29 \\
\hline
\end{tabular}

The next paragraph presents the empirical models that were used to test the audit committee-firm performance link during the GFC along the dimensions of audit committee authority differentiation, skill differentiation and temporal stability. We also delineate in more detail the way we measure the variables of interest and the data collection procedures.

\subsubsection{Model specifications}

In line with prior studies on the associations between board committees and firm performance outcomes (Klein, 1998; Vafeas and Theodorou, 1999; Jackling and Johl, 2009), we use the following OLS regression estimation to gauge whether audit committee authority differentiation, audit committee skill differentiation, and audit committee temporal stability can explain cross-sectional variation in S\&P 500 firm performance during the GFC:

$$
\begin{aligned}
& \text { Performance Measure }=\quad \text { AC Authority }+ \text { AC Expertise }+ \text { AC Stability }+ \text { other Board } \\
& \text { of Director Controls + other Control Variables + error } \\
& \text { term. } \\
& \text { (1), (2), (3) }
\end{aligned}
$$


Model (1) and Model (2) analyze the audit committee-firm performance link during the early (2007-2008) and late stage period of the GFC (2010-2011), respectively. Model (3) covers the entire period of observation (2007-2011).

\subsubsection{Firm performance measures}

In this study, we use multiple firm performance measures to study associations between audit committee characteristics and firm performance outcomes during the GFC. In line with prior research (e.g., Klein, 1998; Yeh et al., 2011), we make use of both accounting- and market-based performance measures. It is commonly recognized in the firm performance literature that individual accounting- and market-based measures are imperfect in the sense that they entail unique problems and deficiencies and that they in fact measure different aspects or dimensions of firm performance (Venkatraman and Ramanujam, 1986; Dalton et al., 1998). Sambarhya (2011) outlines that accounting measures are ex-post and internally oriented and therefore reflect realized strategies and management performance, whereas market measures are future-oriented, reflecting investor expectations.

Following Premuroso and Bhattacharya (2007) and Yeh et al. (2011), among others, we use two accounting-based measures of firm performance, namely, return on assets (ROA) and return on equity (ROE). ROA is measured by the ratio of net income to total assets, whereas ROE is measured by the ratio of net income to shareholders' equity. In order to study the impact of audit committees on firm performance over multiple years (early stage, late stage, entire GFC period), we calculate average yearly figures for both performance measures, which we denote $R O A / R O E_{0708}, R O A / R O E_{1011}$, and $R O A / R O E_{0711}$, respectively. $R O A / R O E_{0711}$ captures firm performance from 2007 to 2011 with annual average ROE and ROE over this five-year period. Our performance measures for the early and late stage period are based on 2007-2008 and 2010-2011 firm performance data, respectively. All accounting-based measures are obtained from the COMPUSTAT database.

We also employ market-based measures of firm performance, namely, stock returns $(S R)$, which we calculate as the percentile change in share price over a specific time period. ${ }^{46}$ In line with the accounting-based performance measures, we calculate $S R_{0708}, S R_{1011}$ and $S R_{0711}$ as the early, late and entire crisis period stock returns, using the same time horizons as outlined above. Hence, $S R_{0708}$ is calculated as the difference in share price between January 2007 and December 2008, scaled to the share price in January 2007. We retrieved all share price data from the Center for Research in Security Prices (CRSP).

For the purpose of the empirical analysis to be presented in Section 4.5.2, all performance measures are industry-adjusted by calculating the difference between a firm's performance measure and the respective industry average, using the Global Industry Classification Standard (GICS) coding system.

${ }^{46}$ We use the following formula: stock returns $=\left(\right.$ Price $_{\text {end }}-$ Price $\left._{\text {begin }}\right) /$ Price $_{\text {begin }}$. 


\subsubsection{Measuring audit committee authority differentiation}

A major challenge for every study about boards of directors and board committees is that information about the backstage (actual) activities of these governance bodies is not publicly available. At the same time, few researchers have the opportunity to attend board or board committee meetings to directly observe actual practices (e.g., Gendron et al., 2004). Instead, researchers rely primarily on interviews with audit committee members (Spira, 1998; Beasley et al., 2009) and content analyses of audit committee charters (Carcello et al., 2002) when gathering information on what audit committees are responsible for and do. Bédard and Gendron (2010:20) outline that "written [audit committee] charters constitute relevant data for researchers since they provide a way of assessing whether responsibilities conferred to the audit committee beyond regulation are related positively with effectiveness".

In this study we use publicly available audit committee charters of S\&P 500 firms in order to assess whether the respective audit committees had substantial authority to oversee risk management. More specifically, we conduct a content analysis of audit committee charters of the 351 firms in our sample at two points in time, namely, at the outset of the GFC (in 2007) as well as at a late stage crisis period (in 2010). Further, we measure audit committee authority differentiation in a binary way - 1 being substantial authority for risk oversight and 0 , otherwise.

Audit committee charters delineate the authority of a firm's audit committee in written form. These charters typically set forth: the main purposes or oversight areas of the audit committee; the scope of responsibilities delegated to the audit committee within the distinct oversight areas; and the concrete tasks addressed by the audit committee in carrying out their assigned responsibilities. We designate an audit committee as having substantial authority to oversee the management of risk and financial matters if one of the following two cases applies: (1) the committee is called audit \& risk committee and/or (2) the audit committee charter and report delineate that one of the primary objectives of the committee is to oversee the management of risk matters. For the sake of clarity, the Appendix gives three textual examples from audit committee charters corresponding to the aforementioned cases (substantial authority) as well as an example of an audit committee without substantial authority to oversee the management of risk and financial matters.

\subsubsection{Measuring audit committee skill differentiation}

We measure audit committee skill differentiation along three dimensions. First, we use the proportion of audit committee members who are classified as financial experts to measure the degree of financial expertise resting with the audit committee of a given firm. Second, we proxy governance expertise by the average number 
of other directorships held by audit committee members. Third, we measure firm expertise by the average number of years of board service of audit committee members (see Bédard et al., 2004).

We collected information on the number of financial experts on audit committees, the number of other directorships held by audit committee members and the number of years of board service from the RiskMetrics (ISS) Director database and its predecessor, the RiskMetrics - Directors Legacy Database. ${ }^{47}$ Both databases are part of Wharton Research Data Service (WRDS). The RiskMetrics Director database in WRDS contains director data on S\&P 500 firms and provides three types of data for the present study: beginning year of board service, financial expert yes/no, and other directorships. With this information we are able to perform the calculations for our skill differentiation proxies. Alas, the WRDS database did not contain the required data for all S\&P 500 firms and each year of observation. Consequently, we hand-collected the missing information from annual reports and proxy statements. Given the effort required to compile data on all three dimensions of audit committee skill differentiation, we gathered the respective data at two points in time and not for every year of the GFC. Specifically and in line with our measurement points for authority differentiation, we measure audit committee skill differentiation at the outset of the GFC (2007) and then again at a later stage (2010).

\subsubsection{Measuring audit committee temporal stability}

Team stability has been studied widely and different measures of team stability used in extant research include, inter alia, the proportion of team members no longer on a team after a certain time period (Wiersema and Bantel, 1983), the number of team entries and exits (Ton and Hackman, 2008), and team turnover, i.e. the number of team members who left the team during a certain period scaled by team size (Arrow and McGrath, 1995; Chang, 2011). In organizational literature, team turnover is generally considered the conventional way to measure team stability (Glebbeek and Bax, 2004). We follow this approach and use the number of directors leaving the committee between $\mathrm{t} 1$ and $\mathrm{t} 2$, scaled by committee size in $\mathrm{t} 1$, to measure the temporal stability of audit committees.

In accordance with the measurement points defined for authority and skill differentiation, we measure the temporal stability of S\&P 500 audit committees at two points in time, namely in 2007 and in 2010 . Audit committee stability at the outset of the GFC (temporal stability ${ }_{0407}$ ) is calculated by audit committee turnover between 2004 and 2007, whereas late stage audit committee stability (temporal stability $_{0710}$ ) is calculated as audit committee turnover between 2007 and 2010. Thus,

\footnotetext{
${ }^{47}$ The RiskMetrics Directors database includes a range of variables related to individual board directors (e.g., name, age, tenure, gender, committee memberships, independence classification, primary employer and title, number of other public company boards serving on, shares owned, etc.). This data collection began in 1996 and is updated annually (see http://www.lib.utexas.edu/).
} 
we measure audit committee turnover over a four-year period. This time horizon is in line with prior empirical research about team turnover in business and organizational studies (e.g., Jackson et al., 1991). Our implicit assumption here is that a four-year window represents a long enough period for sufficient turnover to occur within the audit committee, yet is short enough to see the effects of audit committee turnover on committee effectiveness (Wiersema and Bantel, 1983).

We gathered data on audit committee size and directors' exits from audit committees during 2004-2007 and 2007-2010 by using the RiskMetrics Director database. After downloading the names for all directors serving on the boards of directors of S\&P 500 firms between 2004 and 2010, we filtered for audit committee members and then programmed Microsoft Excel in such a way as to compute the number of audit committee members who left the committee of a given sample firm during the indicated time periods.

\subsubsection{Control variables}

Our choice for control variables is motivated by their relevance as documented in extant literature (Klein, 1998; Vafeas, 1999; Brick and Chidambaram, 2010). As shown in Model (1), we use two types of control variables, namely, board and other firm-specific control variables. Regarding the former, we control for board size, board diligence, the percentage of outside directors on the board, director ownership, and the formation of a dedicated risk committee of the board of directors.

Regarding board size a number of studies suggest that larger boards face coordination and communication problems and document a negative relation between board size and firm performance (Yermack, 1996). To control for a possible relation between board diligence and firm performance (Vafeas, 1999), we use the total sum of yearly board and board committee meetings (Brick and Chidambaram, 2010). Further, we control for board independence by the proportion of outside directors and for director ownership (Klein, 1998). Finally, we include the variable risk committee to take account of firms that establish a dedicated risk committee.

Other control variables included in this study are firm size measured by total assets, the debt to total assets ratio (leverage), sales growth in the preceding threeyear period (growth), and the volatility of monthly stock returns over the preceding five years as a proxy for firm risk (volatility). Firm size is included as a standard control variable and leverage because the GFC is more likely to impact firms which are highly leveraged (Aldamen et al., 2012). Even though the GFC constitutes an unexpected exogenous force on the performance of S\&P 500 firms, we include the variables growth and volatility to capture the impact of a firms' past performance and risk profile on the dependent variables (see Wintoki et al., 2012). We also control for industry fixed effects with $\mathrm{n}-1$ dummy variables, since prior studies show that the GFC impacted some sectors more than others (Aldamen et al., 2012). 


\subsection{Empirical results}

\subsubsection{Descriptive statistics}

Table 4.3 presents the descriptive statistics and variable definitions for our final sample. As expected, the minimum and maximum values reported for the firm performance measures used in this study indicate substantial variation in firm performance across our sample, both for the early as well as late stages of the GFC. The mean values for ROE and ROA remain pretty constant. In line with Figure 4.1, we find a sizeable dip in $S R$ during the early GFC.

As far as the explanatory variables are concerned, Table 4.3 presents a number of interesting insights on the cross-sectional audit committee differences of S\&P 500 firms during the GFC along the dimensions of authority differentiation, skill differentiation and temporal stability. In 2007, 42 out of the 351 sample firms studied (ca. 12\%) had established an audit committee with substantial authority to oversee risk management. By 2010, this number had increased substantially to 148 out of 351 sample firms studied (around 42\%). In line with Dellaportas et al. (2012) we interpret this development as an indication that the role of independent audit committees with respect to overseeing risk management has expanded as a direct result of the 2007-2008 plunge in firm performance attributable to the GFC.

Table 4.3 also shows some interesting insights regarding the skill differentiation of audit committee members in the S\&P 500. Both in 2007 and in 2010, slightly more than half of the audit committee members in our sample were designated financial experts. We do find some variation between firms when it comes to financial expertise. Although this is not shown in Table 4.3, we find that 171 firms had established an audit committee where only one audit committee member classified as a financial expert by 2007.48 Three out of those firms had formed an audit committee with seven members; thus the reported minimum percentage of financial experts is reported as 14 percent. At the same time, we find 87 firms with an audit committee composed only of financial experts. We find that on average audit committee members held slightly more than one other directorship. Here again, cross-sectional differences are reported by the range of governance expertise (ranging from an average of zero to around three other directorships per committee member). On average the audit committee members in our sample had served on the respective board for nearly eight years. The statistics on audit committee expertise presented here are in accord with those reported in previous studies (e.g., Bédard et al., 2004).

Next to authority and skill differentiation, we also gathered data on audit committee turnover over a four-year pre-GFC period (stability ${ }_{407}$ ), and again before the late stage GFC period (stability 0710 ). For stability 407 we find mean, minimum and maximum values of 50, zero, and 175 percent, respectively. For stability ${ }_{710}$ we find

48 The average audit committee size in our sample is 4.1 in 2007 and 4.3 in 2010. 
values of 34, zero, and 200 percent, respectively. This implies that our sample contains both stable audit committees (no turnover before and during the GFC) and unstable audit committees (those that renewed themselves twice during a period of four years).

Collectively, these descriptive statistics indicate sufficient cross-sectional differences in firm performance as well as explanatory variables, calling for further investigation of the hypothesized associations between inter-firm differences in audit committee design and firm performance during the GFC. The full correlation matrixes are not reported here, given the large number of variables employed across all regression models. ${ }^{49}$ The next section starts with a recap of the empirical models and main variables featured in this study, followed by the empirical results.

\subsubsection{Audit committees and firm performance during the GFC}

In order to analyze the audit committee-firm performance association during the financial crisis, we establish three empirical models. Model 1 analyses the relationship between audit committee characteristics and firm performance during the early years of the financial crisis (2007-2008). Model 2 looks into the aforementioned relationship during the late stage of the crisis (2010-2011), and model 3 covers the entire period of observation (2007-2011). Ordinary least square results are presented in Table 4.4. The key variables of interest are the degree of audit committee authority for risk oversight, the skill differentiation of audit committee members as measured by financial expertise, governance expertise, and firm expertise, and the temporal stability of the audit committees under observation.

We find significant and positive associations between the extent of audit committee authority to oversee risk management and firm performance during the financial crisis. More specifically, we document marginally significant results between risk oversight at the outset of the crisis and firm performance between 2007 and 2008 (model 1 , all $\mathrm{p}<.10$ ). We also show positive associations between the extent of audit committee risk oversight going into 2010 and subsequent firm performance measured by $R O E_{1011}$ and $R O A_{101}$. Finally, the coefficients for risk oversight are significant when using $R O E_{0711}$ and $R O A_{0711}$ as dependent variables (model 3 , both $\mathrm{p}<.05$ ). Collectively, these results provide support for hypothesis 1 predicting that the effectiveness of audit committees in safeguarding firm performance in a crisis is contingent on their authority to oversee risk management.

Regarding audit committee skill differentiation, we document positive and significant relationships between firm expertise of independent audit committees and firm performance during the financial crisis. As shown in Table 4.4, we find significant associations between average board tenure of audit committee members at the outset of the crisis and $R O A_{0708}$ and $R O A_{0711}$. Marginally significant re-

${ }^{49}$ All correlations are below 0.50 . Accordingly, the correlations among explanatory variables are not large enough to prohibit the use of multivariate regression analysis. The highest VIF score is 3.01. 
sults are obtained for firm expertise when using ROE and Stock Returns as explanatory variables. Furthermore, we show positive and significant coefficients for governance expertise when measuring firm performance by $R O A_{0711}$ and $R O E_{1011}$. Finally, we find a positive association between financial expertise and Stock Returns 0711 . These results seem to confirm hypothesis 2 predicting that the effectiveness of independent audit committees in safeguarding firm performance during is contingent on the degree to which independent audit committee members have specialized knowledge or capabilities that may enhance their effectiveness.

With one exception, the models presented in Table 4.4 have considerable explanatory power for a study using firm performance as the dependent variable in a crisis period setting. The obtained adjusted $\mathrm{R}^{2}$ statistic ranges between 10 and 30 percent. In the case of the models using ROA, we obtain adjusted $\mathrm{R}^{2}$ statistics ranging from 22 to 27 percent for the three time periods studied. These results are comparable to prior firm performance studies (Carter et al., 2010; Yeh et al., 2011).

\subsubsection{Audit committees and firm performance variability}

To substantiate our analysis of the relationship between audit committee authority to oversee enterprise risk management and firm performance during the GFC, we ran an additional analysis looking into the performance variability of our sample firms from 2007-2011. In the literature, business risk is commonly defined in terms of uncertainty in firm outcomes as reflected in the variability of firm performance indicators (Boubaker et al., 2012). Prior literature, including Pathan (2009), Minton et al. (2010) and Yeh et al. (2011), provide theoretical reasoning and empirical evidence for a negative relation between corporate risk-taking behavior and the degree of board (committee) independence. Accordingly, we reason that fully independent audit committees charged with substantial oversight of risk management limit firm performance variability (risk) in a crisis period.

H4: Firm performance variability during a period of economic crisis is negatively related to the extent of audit committee authority for overseeing ERM.

Following Cheng (2008) and Faccio et al. (2011), we measure performance variability by the industry-adjusted five-year standard deviation of yearly ROE $\left(\sigma R O E_{0711}\right), \mathrm{ROA}\left(\sigma R O A_{0711}\right)$, and Stock Returns $\left(\sigma S R_{0711}\right)$. This so-called within-firm over-time performance variability approach collapses our performance data into a single cross-section, whereby all control variables are averaged (Nakano and Nguyen, 2012). With the industry adjustment using the GICS two-digit coding system, we aim to take out the variation in performance over time common to an industry. Hence, we focus on measures of the idiosyncratic volatility of firm performance. We then run the following cross-sectional regression: 
Performance Variability $=\quad A C$ Authority + AC Expertise + AC Stability + other Board of Director Controls + other Control Variables + error term.

Table 4.5 presents the empirical results related to Model (4). As predicated by Hypothesis 4, we find a significant and negative association between the extent of audit committee authority for overseeing risk management at the outset of the GFC in 2007 and firm performance variability measured by $\sigma R O E_{0711}$ and $\sigma S R_{0711}$ (both $\mathrm{p}<0.05$ ). Furthermore, our results suggest a negative relation between the firm expertise of audit committee members and our market-based firm performance measure $\sigma S R_{0711}(\mathrm{p}<0.05)$. In slight contrast to the results presented in Table 4, we find a negative coefficient for governance expertise $e_{07}$ for both accounting-based performance measures $\left(\sigma R O E_{0711}, \mathrm{p}<0.01, \sigma R O A_{0711}, \mathrm{p}<0.10\right)$. In line with Cheng (2008) and Nakano and Nguyen (2012), we document a negative relation between board size ${ }_{07}$ and outside directors ${ }_{07}$ and performance variability as measured by $\sigma S R_{0711}(\mathrm{p}<0.05$ ). As expected, the coefficients for volatility 307 and growth 0407 in Model (4) are both significant and positive across the performance measures used here. For the three measures in Model (4), the Adjusted $\mathrm{R}^{2}$ ranges between 16 and 21 percent.

\subsubsection{Endogeneity concerns}

Empirical corporate governance research is susceptible to endogeneity and omitted variable concerns (Schultz et al., 2010; Wintoki et al., 2012). Regarding the latter, our results remain unchanged after controlling for additional board and committee characteristics, including CEO duality, audit committee size and meeting frequency. While the results presented in Table 4.4 and 4.5 suggest a causal relationship between audit committee characteristics and firm performance, these findings could also be subject to reverse causality - boards of directors and board committees are endogenously determined (e.g. Hermalin and Weisbach, 1998, 2003). As far as this study is concerned, the endogeneity issue is whether firm performance drives the audit committee structure or whether some other variable (e.g. the CEO) drives both, instead of audit committees having an impact on firm performance (Aldamen et al., 2012). While endogeneity is present in much empirical research, it may lead to biased estimators, reducing the confidence in the conclusions we can draw from our analysis (Chenhall and Moers, 2007; Lent, 2007).

We believe that our research design should limit endogeneity in two primary ways. First, we address the endogeneity concern by replacing a firm's average value for the corporate governance measures employed in this study by the firm's first valid value in the period of observation. Accordingly, 2007 for Model (1), (2) and (4) and 2010 for Model (3). This method should mitigate the concern that performance (variability) leads to changes in audit committee and board of direc- 
tor characteristics (Cheng, 2008). A further aspect which should mitigate endogeneity concerns in our analysis, is that the GFC represents an unexpected external shock to firm performance. By choosing an exogenous and unexpected event, we assess the audit committee-firm performance relationship before firm performance can affect the design of the audit committees under study. These are our research design controls for the implicit endogenous relationship (Aldamen et al., 2012). 
Table 4.3: Descriptive statistics and variable definitions

\begin{tabular}{|c|c|c|c|c|c|c|c|c|c|c|c|c|}
\hline \multirow[b]{2}{*}{ Variable } & \multicolumn{4}{|c|}{$\begin{array}{l}\text { Model } 1 \\
\text { Early stage financial } \\
\text { crisis (2007-2008) }\end{array}$} & \multicolumn{4}{|c|}{$\begin{array}{l}\text { Model } 2 \\
\text { Late stage financial } \\
\text { crisis (2010-2011) }\end{array}$} & \multicolumn{4}{|c|}{$\begin{array}{l}\text { Model } 3 \\
\text { Total period of } \\
\text { observation }(2007-2011)\end{array}$} \\
\hline & Mean & SD & Min. & Max. & Mean & SD & Min. & Max. & Mean & SD & Min. & Max. \\
\hline ROE & .13 & .17 & -.29 & .46 & .14 & .13 & -.14 & .44 & .14 & .14 & -.16 & .47 \\
\hline ROA & .06 & .07 & -.18 & .27 & .06 & .06 & -.09 & .21 & .06 & .06 & -.12 & .25 \\
\hline Stock returns & -.39 & .25 & -.88 & .28 & .14 & .34 & -.61 & 1.10 & -.09 & .46 & -.88 & 1.41 \\
\hline Risk oversight & .12 & .33 & .00 & 1.00 & .42 & .50 & .00 & 1.00 & .27 & .34 & .00 & 1.00 \\
\hline Financial expertise & .56 & .30 & .14 & 1.00 & .58 & .30 & .14 & 1.00 & .57 & .28 & .14 & 1.00 \\
\hline $\begin{array}{l}\text { Governance } \\
\text { expertise }\end{array}$ & 1.31 & .69 & .00 & 3.33 & 1.18 & .58 & .00 & 3.00 & 1.25 & .57 & .00 & 2.69 \\
\hline Firm expertise & 7.60 & 4.00 & .00 & 23.00 & 7.86 & 3.64 & 1.00 & 22.00 & 7.73 & 3.46 & 1.50 & 22.50 \\
\hline Temporal stability & .50 & .34 & .00 & 1.75 & .35 & .31 & .00 & 2.00 & .86 & .47 & .00 & 2.75 \\
\hline Board size & 10.89 & 2.29 & 5.00 & 20.00 & 10.92 & 2.09 & 5.00 & 19.00 & 10.80 & 2.08 & 5.00 & 18.00 \\
\hline Board diligence & 32.70 & 9.87 & 13.00 & 69.00 & 32.53 & 10.53 & 14.00 & 89.00 & 32.62 & 9.35 & 13.00 & 74.00 \\
\hline Outside directors & .80 & .10 & .44 & .96 & .83 & .09 & .33 & .95 & .82 & .09 & .40 & .95 \\
\hline $\begin{array}{l}\text { Director } \\
\text { ownership }\end{array}$ & .04 & .07 & .00 & .70 & .03 & .06 & .00 & .53 & .03 & .06 & .00 & .59 \\
\hline Risk committee & .05 & .23 & .00 & 1.00 & .20 & .40 & .00 & 1.00 & .13 & .27 & .00 & 1.00 \\
\hline Firm size & 9.55 & 1.42 & 6.68 & 14.54 & 9.70 & 1.39 & 6.72 & 14.60 & 9.62 & 1.40 & 6.69 & 14.52 \\
\hline Leverage & .21 & .15 & .00 & 1.00 & .21 & .13 & .00 & .76 & .21 & .14 & .00 & .88 \\
\hline Volatility & .10 & .06 & .03 & .76 & .11 & .10 & .04 & 1.41 & & & & \\
\hline Growth & .11 & .12 & -.21 & .86 & .01 & .10 & -.33 & .45 & & & & \\
\hline
\end{tabular}

Notes: This table reports the descriptive statistics for the variables included in the empirical analyses of the study at hand. All performance and firm control variables are calculated as yearly averages. The reported audit committee and board of director control variables for models 1 and 2 are taken at one point in time, while temporal stability, volatility and growth are calculated over multiple years preceding the respective performance period. $R O E$ is net income divided by shareholders' equity and ROA is net income divided by net assets. Stock returns is the percentage change in share price. Risk oversight is a binary variable equal to one if the audit committee has substantial authority to oversee the management of risk and financial matters, and zero otherwise. Financial expertise is the percentage of audit committee members classified as financial experts. Governance expertise is the average number of other directorships held by audit committee members. Firm expertise is the average years of board service of audit committee members. Temporal stability is the number of directors leaving the audit committee between $\mathrm{t} 1$ and $\mathrm{t} 2$, scaled by audit committee size at $\mathrm{t} 1$. Board size is the number of directors serving on the board. Board diligence is the sum of yearly board and board committee meetings. Director ownership is the percentage of total common equity owned by all directors. Risk committee is a binary variable equal to one if the firm has established a dedicated risk committee, zero otherwise. Leverage is the ratio of debt to total assets. Volatility is the standard deviation of monthly stock returns over the previous five years. Growth is calculated as the sales growth in the preceding three years. 


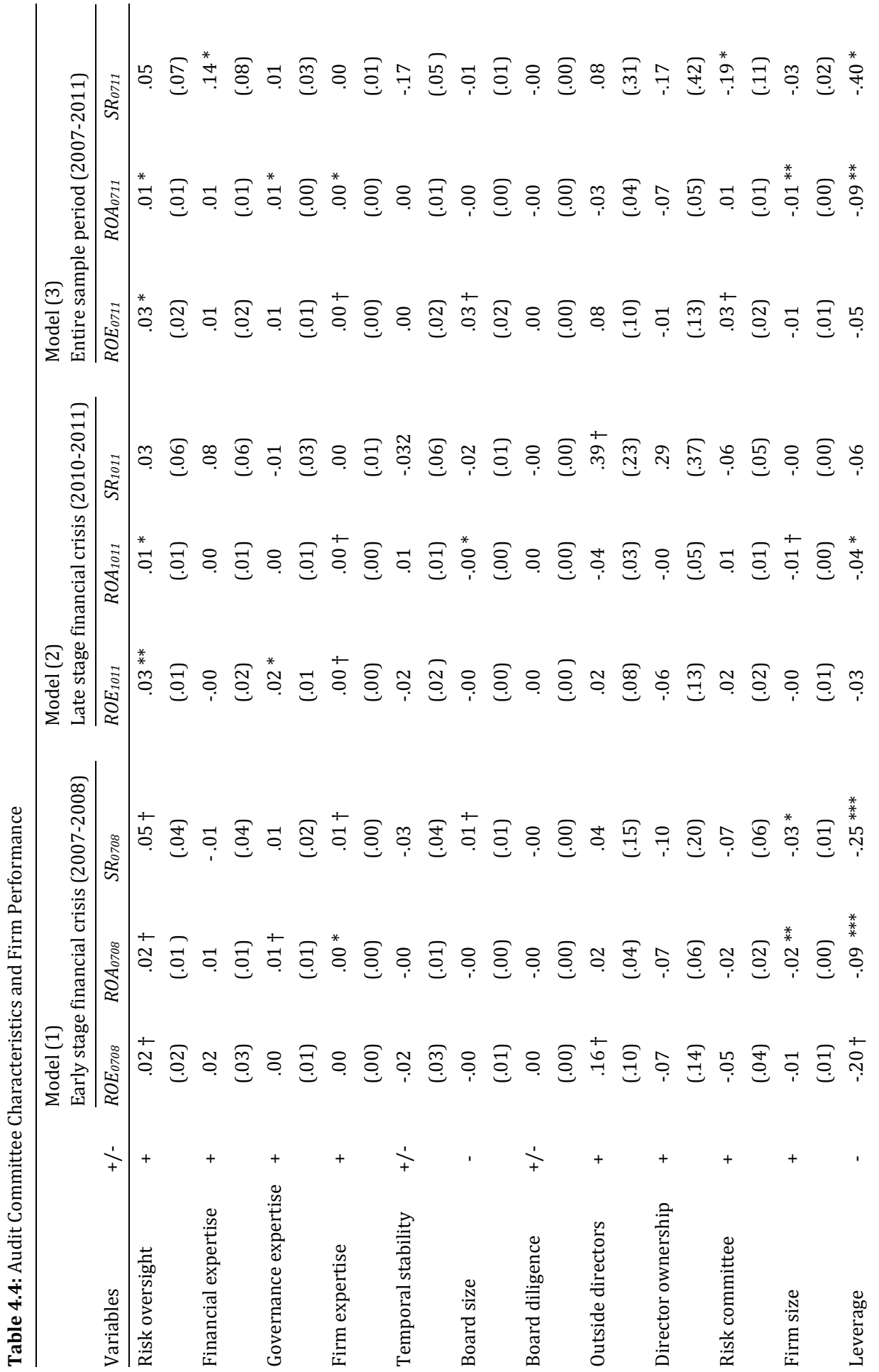




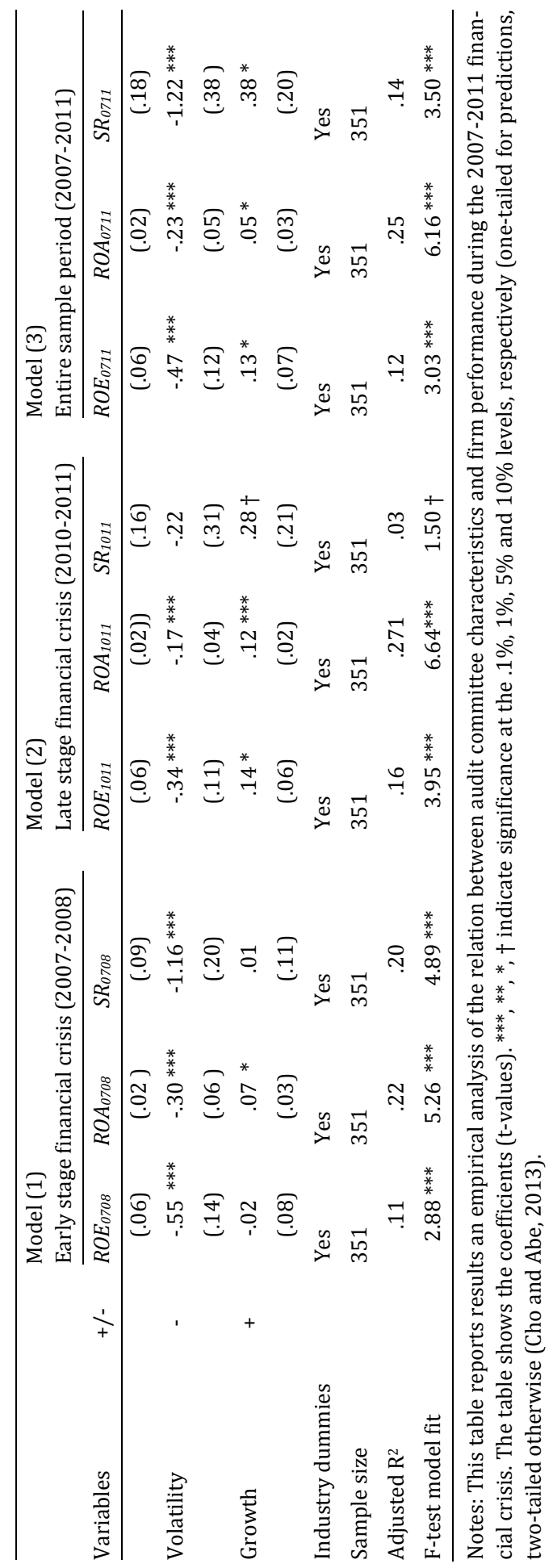


Table 4.5: Audit committee characteristics and firm performance volatility

\begin{tabular}{|c|c|c|c|c|}
\hline Variables & $+/-$ & $\sigma \mathrm{ROE}_{0711}$ & $\sigma \mathrm{ROA}_{0711}$ & $\sigma \mathrm{SR}_{0711}$ \\
\hline \multirow[t]{2}{*}{ Risk oversight $_{07}$} & - & $-.08 *$ & -.01 & $-.05 *$ \\
\hline & & $(.04)$ & $(.00)$ & $(.03)$ \\
\hline \multirow[t]{2}{*}{ Financial expertise $e_{07}$} & - & -.04 & -.01 & .05 \\
\hline & & $(.04)$ & $(.00)$ & $(.04)$ \\
\hline \multirow[t]{2}{*}{ Governance expertise 07} & - & $.04^{* *}$ & $.01 \dagger$ & .01 \\
\hline & & $(.02)$ & $(.00)$ & $(.02)$ \\
\hline \multirow[t]{2}{*}{ Firm expertise $e_{07}$} & - & -.00 & -.00 & $-0.01 *$ \\
\hline & & $(.00)$ & $(.00)$ & $(.00)$ \\
\hline \multirow[t]{2}{*}{ Temporal stability 0407} & $+/-$ & .02 & .01 & -.01 \\
\hline & & $(.03)$ & $(.01)$ & $(.04)$ \\
\hline \multirow[t]{2}{*}{ Board size $_{07}$} & - & .00 & -.00 & $-.02 *$ \\
\hline & & $(.01)$ & $(.00)$ & $(.01)$ \\
\hline \multirow[t]{2}{*}{ Board diligence $_{07}$} & - & $.00 *$ & .00 & .00 \\
\hline & & $(.00)$ & $(.00)$ & $(.00)$ \\
\hline \multirow[t]{2}{*}{ Outside directors 07} & - & -.06 & -.01 & $-.26 *$ \\
\hline & & $(.12)$ & $(.03)$ & $(.14)$ \\
\hline \multirow[t]{2}{*}{ Director ownership 07} & - & -.01 & .04 & .02 \\
\hline & & $(.18)$ & $(.04)$ & $(.21)$ \\
\hline \multirow[t]{2}{*}{ Risk committee 07} & - & -.02 & -.01 & -.05 \\
\hline & & $(.05)$ & $(.01)$ & $(.06)$ \\
\hline \multirow[t]{2}{*}{ Firm size $\mathrm{e}_{0711}$} & $+/-$ & -.01 & $-.01 \dagger$ & $.03 *$ \\
\hline & & $(.01)$ & $(.00)$ & $(.01)$ \\
\hline \multirow[t]{2}{*}{ Leverage $_{0711}$} & + & $.60 * * *$ & $.03 \dagger$ & $.19 *$ \\
\hline & & $(.09)$ & $(.02)$ & $(.10)$ \\
\hline \multirow[t]{2}{*}{ Volatility $_{0307}$} & + & $.34^{*}$ & $.17^{* *}$ & $1.33^{* * *}$ \\
\hline & & $(.18)$ & $(.04)$ & $(.21)$ \\
\hline \multirow[t]{2}{*}{ Growth $_{0407}$} & $+/-$ & .01 & .01 & .07 \\
\hline & & $(.10)$ & $(.02)$ & $(.11)$ \\
\hline Industry dummies & & Yes & Yes & Yes \\
\hline Sample size & & 351 & 351 & 351 \\
\hline Adjusted R2 & & .18 & .16 & .21 \\
\hline F-test model fit & & $4.27^{* * *}$ & $3.96^{* * *}$ & $4.95^{* * *}$ \\
\hline
\end{tabular}

Notes: This table reports the results regarding the relation between audit committee characteristics and the within-firm over-time performance variability during the 2007-2011 financial crisis. Performance variability is measured by the industry-adjusted standard deviation of yearly ROE, ROA and Stock returns. The table shows the coefficients (t-values). ${ }^{* * *},{ }^{* *},{ }^{*}, \dagger$ indicate significance at the $.1 \%$, $1 \%, 5 \%$ and $10 \%$ levels, respectively (one-tailed for predictions, two-tailed otherwise). 


\subsection{Conclusions}

This study finds systematic associations between firm performance and the characteristics of independent audit committees during the 2007-2011 global financial crisis. Our results square with mounting empirical evidence linking audit committee oversight to firm performance outcomes during the financial crisis (cf. Yeh et al., 2011; Aldamen et al., 2012; Sun and Liu, 2014). The main contribution of this study, however, is to provide novel insights regarding the factors that may determine the effectiveness of audit committees staffed exclusively with independent directors to safeguard firm performance during a crisis period.

Drawing from the literature on team effectiveness, we provide theoretical reasoning and empirical evidence that formal authority is an important determinant of audit committee effectiveness. More specifically, we show systematic and positive associations between the scope of audit committee authority to oversee risk management and firm performance during a financial crisis. Formal delegation of authority is important in the context of audit committee effectiveness for two primary reasons. Firstly, without formal authority independent directors may lack the power to make and influence decisions, which can ultimately have an impact on firm performance (Kalbers and Fogarty, 1993; McNulty and Pettigrew, 1996; Payne et al., 2009). Secondly, a formal mandate provides direction and discipline to audit committees (SEC, 2000). This is in so far important, as committee members are unlikely to assume responsibilities which are not part of a formal mandate and lead to an extra-role activity on top of their usual work (Whiteoak, 2007).

We also find evidence that cross-sectional differences in audit committee effectiveness can be explained by skill differentiation. Our analysis indicates that board tenure and multiple directorships can have a positive impact on the effectiveness of independent directors when it comes to overseeing risk matters. Other papers, in contrast, suggest that audit committee members serving on multiple boards may be too busy to effectively carry out their designated role and that longer tenure directors may not exercise independent judgment (Sharma and Iselin, 2012). In light of these seemingly conflicting findings, it is important to note that the majority of extant studies focus on individual dimensions of audit committee effectiveness. ${ }^{50}$ Our study suggests that effective risk oversight requires a deeper understanding of the respective firm from audit committee members. Multiple directorships, in turn, seem to promote rather than constrain the ability of independent directors to spot and oversee risks (cf. Ferris et al., 2003; Field et al., 2013).

However, the results of the study at hand should be interpreted with caution, given that our research design opens the door to a selection and survivorship bias in our empirical results (see, e.g., Brown et al., 1992). Regarding the former, we limit our empirical analyses to a comparatively small number of large US firms.

\footnotetext{
${ }^{50}$ Lee and Stone (1997) point out that the skills and capabilities required of audit committee members can differ depending on responsibilities assigned the audit committee.
} 
Furthermore, our results are prone to a survivorship bias, since in our analysis we include only those firms for which complete performance data is available for the entire period of observation from 2007 to 2011. S\&P 500 firms that vanished during the GFC are not included in our analysis. Consequently, we deem it interesting to extend our study design to non-US listed firms and to firms that did not survive a crisis. Finally, our findings are based on an analysis of one financial crisis and therefore cannot necessarily be extended to other periods of economic distress.

These limitations notwithstanding, we believe that the empirical results reported in this study provide insights for several key players in the corporate governance mosaic. For practitioners and policymakers alike, the question emerges whether it is not time to focus the scope of audit committees to a larger extent on risk oversight rather than on the more traditional roles of audit committees, such as overseeing the financial reporting and auditing process. In turn, the effective oversight of risk management may require formal designation of authority, and independent directors with a deeper understanding of the firm and a body of knowledge gained from discussions at other firms' board of directors.

Given the severity and persistence of the most recent financial crisis, further examination of the evolving role and responsibilities of audit committees in the context of risk oversight constitutes an interesting and timely subject which combines research and policy implications. While qualified, committed, independent and tough-minded audit committees were primarily seen as effective guardians for safeguarding the quality of external auditing and financial reporting in the 20th century, their role might well be evolving towards guarding the balance between risks and opportunities affecting value creation or the preservation of modern enterprises in the wake of the recent financial crisis. Therefore, we consider it important for future research to develop a more nuanced understanding of audit committee effectiveness, which takes into account audit committee authority differentiation. 


\section{Appendix:}

\section{Examples of Audit Committee Oversight of Risk Management}

\section{Responsibilities of an Audit \& Finance committee (AFC) \\ Audit \& finance committee charter of Allergan, Inc.}

In its role overseeing financial policy and strategy, the AFC shall be responsible for the review and oversight of the following areas: Capital structure; financial operations; banking; employee benefit plans assets and investment strategy; and financial operations. Capital structure: Review and recommend to the Board approval of the capital structure and the financing plan for the year including approval of short-term and long-term debt programs. Review dividend strategy. Review financing strategies in excess of $\$ 20$ million. Review interest rate and currency exposure management and hedging strategies and monitor performance. Review and evaluate financial management strategies designed to enhance stockholder value. $R e$ view cash flow forecasts on a periodic basis. Review strategy for investment of corporate funds and monitor performance. Review balance sheet performance. Review recommendations regarding stock splits and treasury share purchases. Review periodically the geographical source of the Corporation's earning power and the location of the Corporation's principal assets. Financial operations: Review longterm tax strategy, the annual tax rate calculation and the repatriation of Corporation earnings. Monitor effects of US and international tax regulations. Review risk assessment, risk management and insurance programs. Banking: Review the major commercial banking, financial consulting and other financial relations of the Corporation to ensure adequacy of coverage. Review on an annual basis with the Finance Department the fees paid to the Corporation's bankers and banking advisors....Financial Organization: Review and evaluate the Corporation's financial organization, staffing thereof, and succession planning.

\section{Responsibilities of an Audit \& Risk committee (ARC) Audit \& risk committee charter of American Express Company}

The Committee is responsible for assisting the Board of Directors in its oversight responsibilities relating to (i) the integrity of the Company's financial statements and financial reporting process; (ii) internal and external auditing, including the qualifications and independence of the independent registered public accounting firm and performance of the Company's internal audit services function; (iii) the integrity of the Company's system of internal accounting and financial controls, (iv) legal and regulatory compliance, (v) the assessment and management of the Company's risk and capital. Risk Management Governance: Reviews the Company's organizational governance approach to risk management and its methods for identifying and managing risks. Approve the Company's Enterprise-wide Risk Management Policy and risk management policies as appropriate. Risk Tolerance: Reviews the Company's risk tolerance in the context of the Company's business 
strategy, financial resources and performance. Approves enterprise-level risk management objectives and monitors management's execution of such objectives. Reviews the Company's risk escalation policies and thresholds. Risk Oversight: Reviews with the Chief Risk Officer the risk profile of the Company, including significant financial and other risk exposures, risk trends in the Company's portfolios and major risk concentrations, and steps management has taken to monitor, control and report such risk exposures, trends and concentrations. Discuss with the Chief Risk Officer the Company's risk management processes, controls and capabilities.

\section{Audit committee with a primary purpose to oversee risk and finance matters} Adit committee charter of BMC Software, Inc.

The Audit Committee is appointed by the Board of Directors of BMC Software, Inc. to assist the Board in fulfilling its oversight responsibilities with respect to: (i) the integrity of the Company's financial statements, financial reporting process and systems of internal controls regarding finance and accounting, (ii) the Company's legal and regulatory compliance, (iii) the quality and integrity of the Company's risk management processes, (iv) the qualifications, engagement, compensation and independence of the independent auditors... (v) the performance of the Company's internal audit function and independent auditors, (vi) the Company's capital structure and financing activities. 


\section{CHAPTER 5 Conclusion}

This dissertation brings together three studies that provide new insights into audit committee design and effectiveness from an international perspective. I define audit committee design as the operationalizion and stipulation of audit committee characteristics that are thought to contribute to the committees' effectiveness or legitimacy. Chapter 2 sheds light on the implementation of audit committee design standards in Europe by analysing the contents of the Eighth EU Directive on Company Law, national codes of governance and corporate audit committee charters. Chapter 3 investigates variations in audit committee scope as represented in publicly available audit committee charters and corresponding levels of audit committee activity across geographic regions that vary in regulatory structure. Chapter 4 , provides evidence on associations between audit committee characteristics and firm performance during the 2007-2011 financial crisis. In the following subsection, I will briefly summarize the main findings of each study presented in this dissertation, followed by a discussion of the main limitations. I then conclude my doctoral thesis by laying out implications and opportunities for future research.

\subsection{Summary of main findings}

In the first study, presented in Chapter 2, I shed light on the design of audit committees in continental Europe by analyzing and comparing the contents of the Eighth EU Directive on Company Law, national codes of governance and corporate audit committee charters. Specifically, I have conducted a content analysis of these documents along five factors: the responsibilities to be addressed by the audit committee, the expertise required of audit committee members, the required level of audit committee independence, the recommended size of the committee, and the number of meetings the committee should hold per year. 
In this manner, I provide evidence regarding: (1) the degree of isomorphism and differentiation in audit committee design standards across the EU; (2) whether coercive pressures to establish audit committee design standards enacted by the Eighth EU Company Law Directive have been implemented in national governance codes and corporate audit committee charters; and (3) whether audit committee charters contain boilerplate language as a proxy for mimetic isomorphism. The sample includes the corporate governance code from six European countries (Belgium, France, Germany, Italy, Spain, and the Netherlands) and the audit committee charters of 157 corporations with a listing on the respective stock exchanges.

The results tabulated in Tables 2.2, 2.3, and 2.4 reveal noticeable differences in the implementation of audit committee design standards among EU member states. Foremost, these differences concern the scope of responsibilities assigned to audit committees, the competencies that committee members should possess, and the proportion of independent directors serving on the audit committee. Standards related to audit committee size and meeting frequency, in turn, are fairly isomorphic across our sample. Regarding coercive isomorphism, I show that the requirements of the Eighth Directive have been effectively implemented on the level of national codes. At the corporate level, I find high levels of implementation of the Eighth Directive in the national governance code in the Netherlands, intermediate levels in Belgium and Spain, and low levels in France, Germany, and Italy.

I attribute these differences primarily to the fact that the corporate governance codes in the latter group of countries did not recommend or require the disclosure of audit committee charters at the time of this dissertation. The high disclosure and compliance rate found in the Netherlands, in turn, illustrates that one avenue for fostering compliance and transparency on audit committee design standards is to mandate the disclosure of complete audit committee charters. Nevertheless, regulators should carefully evaluate this step. Consistent with prior literature, I observe that regulatory pressure leads to an increase in the percentage of unoriginal content in audit committee charters. By passing audit committee charters through the content analysis software SafeAssign, I find that the level of unoriginal content increases when firms are required to place a charter on the public record.

These results support the proposition that regulation can lead to 'copy-andpaste' approaches when developing publicly available corporate narrative information. Furthermore, Forster et al. (2009) and Holder-Webb and Cohen (2012) provide evidence suggesting that actual (back-stage) organizational practices remain decoupled from publicly available (front-stage) information, perversely in those institutional settings characterized by a stringent disclosure regime.

In my second study, presented in Chapter 3, I directly address the aforementioned propositions by investigating variations in the scope of responsibilities set forth in publicly available audit committee charters and corresponding levels of audit committee activity across geographic regions that vary in regulatory structure. Thereby, I empirically examine whether audit committee charters of different 
firms become boilerplate copies of each other, and whether actual committee practices remain decoupled from the charters' content, when public disclosure turns from voluntary to coercive and then mandatory. Based on extant literature (Harvard Law Review, 2003; Okhmatovskiy and David, 2012), I predict that more demanding disclosure regimes are associated with higher levels of decoupling. However, the empirical results presented in Chapter 3 suggest differently.

By employing a negative binomial count model with the number of distinct responsibilities disclosed in audit committee charters as the explanatory variable, I show that audit committee charters differ systematically in content from one firm to another. In contrast to what I expected, this holds in institutional settings characterized by low as well as high levels of coercive pressure for the public disclosure of an audit committee charter. My analysis suggests further that the scope of responsibilities formally assigned to the audit committee is a function of businessrelated factors (firm size, industry, and profitability), the structure of the board and the prevalent disclosure regime on audit committee charters.

The second part of Chapter 3 contains an empirical analysis of the relationship between the nominal scope of responsibilities set forth in public charters and actual levels of audit committee activity. Conventional reasoning suggests a positive relationship between audit committee scope and diligence if actual audit committee activities are tied to the responsibilities set forth in the charters. The empirical results of an OLS regression show that levels of actual audit committee activity are significantly and positively related to the number of responsibilities set forth in audit committee charters in more stringent disclosure regimes (Anglo-Saxon countries). In institutional settings characterized by low levels of coercive pressure to disclose an audit committee charter (continental Europe), I find no association between audit committee diligence and the nominal scope of duties disclosed in audit committee charters. Chapter 3 suggests that in countries where the regulatory setting is more stringent, the professed activities of audit committees are more closely related to their actual work, relative to voluntary disclosure settings.

In my third study, presented in Chapter 4, I empirically examine the question of whether there is a relationship between firm performance during a period of economic distress and the characteristics of independent audit committees. To address this question, I apply a three-dimensional framework established by Hollenbeck et al. (2012) to audit committees of S\&P 500 firms during the 2007-2011 financial crisis period. This framework encompasses three dimensions: authority differentiation, skill differentiation, and temporal stability. Since data on inter-firm differences in audit committee authority to oversee risk was gathered via publicly available audit committee charters and reports, Chapter 4 can be seen as a natural extension of the first two chapters of my dissertation.

The empirical results presented in Chapter 4 show statistically significant and positive associations between S\&P 500 firm performance during the global financial crisis - measured by return on assets (ROA), return on equity (ROE) and stock 
returns (SR) - and the extent of audit committee authority to oversee enterprise risk management. I also document positive associations between firm performance during the crisis and audit committee skill differentiation in terms of firm-specific expertise as well as the governance expertise of audit committee members. No consistent relation is found between measures of financial expertise and the temporal stability of audit committees and firm performance indicators.

To further substantiate these results and the proposition that independent audit committees can safeguard firm performance in a crisis period by overseeing risk management matters, I ran an additional analysis looking into the industryadjusted within-firm over-time performance variability during the global financial crisis as a proxy for the level of risk taking (Cheng, 2008, Nakano and Nguyen, 2012). The empirical results show that firms where substantial authority for overseeing risk was assigned to an independent audit committee before the financial crisis took hold in 2007 exhibited lower performance variability during the 20072011 period. I also document a negative relation between firm performance variability and the firm-specific expertise of audit committee members. These results indicate that the formal designation of authority to oversee risk management and the degree of firm-specific and governance expertise that audit committee members bring to the table can be important determinants of audit committee effectiveness in safeguarding firm performance in times of economic distress.

\section{$5.2 \quad$ Limitations}

The findings presented in the previous section are subject to a number of limitations. First, the scope of all three studies is restricted to a subset of the largest economies by GDP, to large-cap firms and to short periods of observation, which may limit the generalisability of my findings. In addition, I see three inherent limitations that I will subsequently discuss in more detail before outlining implications and opportunities for future research. First, it is important to note that the three studies presented in this dissertation rely on archival data. In particular, the analysis of variations in audit committee scope is based on front-stage information set forth in publicly available charters that may not necessarily reflect the actual (back-stage) activities of audit committees. In spite of a number of informal conversations with audit committee members and the verification of my categorization scheme with them, the analysis presented in Chapter 3 and Chapter 4 would surely benefit from more direct observations of what audit committees are actually doing to address the various responsibilities set forth in their respective charters.

Second, my content analyses of audit committee charters and the construction of the audit committee scope measure in Chapter 3 are based on human-scored schemes. Extant literature generally distinguishes three types of content analysis approaches, namely, human-scored schemes, word-count approaches, and com- 
puterized methods (Morris, 1994). Human-scored approach to content analysis have limitations in comparison with computerized methods (Lewis et al., 2013). These limitations are primarily related to the labor intensiveness and subjectivity of human, self-constructed scoring schemes, which may limit the reliability and validity of my empirical analysis (Grüning, 2011). On the other hand, computerized methods may prevent the coder from detecting more sensitive rhetorical differences, such as the extent of audit committee oversight of risk management.

Third, the empirical results presented in Chapter 4 of this dissertation should be interpreted with caution, due to the small sample size and a possible survivorship bias. Regarding the latter, my research design includes only firms for which complete performance data is available for the entire period of observation from 2007 to 2011. Accordingly, firms that vanished as a result of the financial crisis are not included in my analysis. As a result, the findings provided in Chapter 4 might be overly optimistic and premature on the contribution of audit committees in safeguarding firm performance during a crisis period. Further research on the audit committee-firm performance link is surely warranted, paying particular attention to firms that do not survive a period of economic downturn. Finally, it should be noted that the results presented in Chapter 4 rely on data gathered during one crisis period. Notwithstanding these limitations, my research results have implications for practice and research, which I will discuss in turn.

\subsection{Implications and future research opportunities}

Publicly available audit committee charters serve two main purposes. They inform the investing public about the roles and responsibilities, composition, and operational standards of the audit committee of a given firm. At the same time, they specify standards that are thought to contribute to the committees' effectiveness. Hence, the intended purpose of audit committee charters is twofold, namely, to strengthen investor confidence and to elevate audit committee effectiveness. With this background, it is easy to see that there are two main groups which are likely to benefit most from the insights presented in this dissertation. The first group is comprised of parties which have a say on the way audit committees are designed, including the public disclosure of audit committee charters and their content. In particular, regulators and corporate boards which aim to strengthen investor confidence and increase audit committee effectiveness will benefit from the findings of my research. The second group is the investing public that has a legitimate interest in reliable information regarding the way audit committees are designed. I will 
first discuss the implications for both groups before closing with suggestions for further research. ${ }^{51}$

According to the results presented in Chapter 2, regulators can foster the implementation of audit committee design standards that strengthen audit committee effectiveness and corporate legitimacy by requiring firms to disclose an audit committee charter. I find three basic levels of pressure that regulators place on firms to disclose such a charter: recommended but voluntary (Belgium, Spain), comply or explain (Netherlands, UK), and mandatory (US). My analysis of the interplay between the responsibilities disclosed in audit committee charters and audit committee diligence and effectiveness manifests two important messages.

First, moving from a voluntary to coercive and then regulatory disclosure regime increases the implementation of audit committee standards at firm level but also the percentage of unoriginal content in audit committee charters. Second, despite an increase in the level of unoriginal language, audit committee charters seem to fulfill their designated purpose of providing authority, direction, and discipline to audit committee members in countries with a stringent disclosure regime. The data presented in Chapter 3 show significant associations between measures of actual audit committee activity and the responsibilities set forth in audit committee charters in mandatory disclosure regimes and an absence thereof in voluntary settings. Chapter 4 then gives evidence that cross-sectional differences in the roles and responsibilities set forth in the audit committee charters of US-listed firm (mandatory disclosure regime) had a significant impact on measures of audit committee effectiveness (cf. Bédard et al., 2004; Abbott et al., 2007).

More specifically, the empirical results presented in Chapter 4 suggest that the effectiveness of independent audit committees in safeguarding firm performance during a crisis period is contingent on the formal designation of authority to oversee risk management and the firm-specific and governance expertise that audit committee members bring to the table. Accordingly, the evidence presented in Chapter 4 adds to a body of literature which demonstrates that audit committees may safeguard firm performance during periods of economic distress (Yeh et al., 2011; Aldamen et al., 2012; Bolton, 2014). To the best of my knowledge, however, this is the first study to provide evidence for associations between firm performance during a crisis period and audit committee authority for overseeing risk and the firm-specific expertise of audit committee members. These results have several important implications for regulators, corporate boards and the investing public.

Post-Enron, policymakers and standard-setters on both sides of the Atlantic have placed substantial emphasis on implementing standards related to audit committee oversight of the financial reporting and auditing process and raising the bar on the financial expertise of audit committee members. Given the severity and

${ }^{51}$ Some of the implications discussed here may also apply to other corporate documents, which are publicly available and fulfill the dual purpose of providing both external organizational information and internal organizational direction (e.g. codes of conduct or ethics, board policies). 
persistence of the recent global financial crisis and the role of audit committees in this context, it may be worthwhile to focus efforts to better clarify the role of audit committees in the context of overseeing risk management. Such efforts could, for example, come in the form of guiding principles such as the BRC (1999). The evidence provided here suggests that the formal designation of authority and the firm-specific expertise of audit committee members are key topics in this context.

For boards of directors, the question emerges whether it is time to move the oversight of risk management to the top of the audit committee agenda and to firmly establish this responsibility in audit committee charters. A survey among audit committee members by KPMG and the NACD (2011) revealed that audit committee members would like to devote more time to oversee risk management. In this context, Sherman et al. (2009: 92) point out that "someone has to objectively analyze the myriad risks facing businesses today" and that "audit committee members have limited time and attention with which to conduct in-depth risk analysis". Given the audit committees' involvement in many of the key governance processes (i.e. financial reporting, auditing, internal control) and corresponding insights into a firm's operations, I tend to agree with Sherman et al. that audit committees are ideally positioned to assume substantial authority for overseeing risk. Accordingly, I would encourage boards to spell out the audit committees' responsibilities with respect to risk oversight in the committees' charter.

A number of implications for the investing public can be derived from my research. First, the content of audit committee charters from firms listed in voluntary disclosure environments may contain more symbolic rather than substantial content, and therefore little information on the audit committees' actual (back-stage) activities. In turn, in mandatory disclosure regimes on audit committee charters, it may well be worthwhile to read and compare the audit committee charters of different firm. Further, investors should keep an eye on the extent of authority delegated to the audit committee for overseeing enterprise risk management and the tenure of board service of independent audit committee members as an indication of their firm-specific expertise. Both factors may contribute to the audit committee's effectiveness in safeguarding firm performance against critical business risks.

Finally, I would like to point out three areas for further research on the topic of audit committee design and effectiveness. The first is related to the antecedents and economic consequences of risk oversight by independent audit committees during different economic cycles. Evidence is mounting that independent audit committees can mitigate the impact of significant adverse economic events such as the recent GFC on firm performance. I corroborate this stream of research and provide to the best of my knowledge the first empirical evidence that may explain how independent audit committees safeguard firm performance in a crisis period, namely by assuming substantial oversight of enterprise risk management. However, ultimately it is the choice of regulators and boards of directors to provide the audit committee with the specific designated authority to assume substantial over- 
sight of risk matters. In line with agency theory, the evidence presented in Chapter 4 suggests that fully independent audit committees may be better equipped to curtail excessive risk taking than the entire board. In this context, I see three research opportunities.

First, evidence is needed to confirm that substantial authority for overseeing risk matters should rest with an independent audit committee rather than with the entire board or a dedicated risk committee. Second, evidence is needed to identify and/or confirm factors that enhance audit committee effectiveness in safeguarding firm performance in a crisis period. Formal delegation of authority and firmspecific or industry expertise are two factors - others surely exist. Last but not least, delegating substantial oversight of risk matters to an independent audit committee might constrain firm performance in a period of economic growth. Accordingly, it is important to investigate the economic impact of charging audit committees with substantial oversight of risk matters in different economic cycles.

Second, further evidence is needed on the interplay between audit committee design and effectiveness in different institutional settings, specifically outside the Anglo-Saxon domain. In Chapter 2 and Chapter 3 I show substantial variation in audit committee design standards as defined by national governance codes and audit committee charters in continental Europe. As pointed out by Vanasco (1994) and Flesher et al. (2005), audit committees have historically been an Anglo-Saxon corporate governance mechanism and were extremely rare in continental Europe. However, since the turn of the century the audit committee concept has gained popularity among pan-European standard setters and national governance committees. Furthermore, despite the fact that audit committees have become a mandatory corporate governance mechanism with the passage of the Eighth EU Directive on Company Law, I show that key audit committee design standards remain largely differentiated among EU member states (cf. Collier and Zaman, 2005). I also provide evidence indicating that mandating the disclosure of a complete audit committee charter serves as one way to iron out these inconsistencies in audit committee design standards at country and firm level throughout the EU. However, before taking this step, further research is needed to better understand the factors that impede convergence of audit committee design standards throughout the EU and its 28 member states. In this context Yoshikawa and Rasheed (2009) outline a list of impediments to convergence, including multiple optima, complementarities, path dependence, rent seeking by national interest groups, and lack of consensus. The desirability of convergence in audit committee standards would then be driven by the degree of multiple optima and complementarities among EU member states.

Third, the question of what audit committees are responsible for and what they actually do should be focused on and explored in depth. Arguably, the existing audit committee literature is swamped by empirical studies that focus exclusively on the demographic characteristics of audit committees (i.e. independence, exper- 
tise, committee size) when studying audit committee effectiveness. The roles, responsibilities and concrete tasks of audit committees are rarely taken into account (DeZoort et al., 2002; Bédard and Gendron, 2010). The problem is that the extensive use of demographic variables in audit committee research constrains not only our understanding of what determines their effectiveness, but also the level of practical insights that will benefit the end users of corporate governance research (Zona and Zattoni, 2007; Ahrens et al., 2011). Out of 103 audit committee studies published between 1994 and 2008, Bédard and Gendron (2010) find merely seven studies that have incorporated the responsibilities addressed by the audit committees under study into their analysis. Consequently, further research is needed to better understand what boards of directors and audit committees are responsible for and actually do, and how members of these groups construct meanings of effectiveness. Promising works have been published by Gendron and Bédard (2006), Zona and Zattoni (2007), Beasley et al. (2009), and Schwartz-Ziv and Weisbach (2013) that offer interesting insights into the black box of boardroom dynamics by going beyond archival demographic board of directors information.

Given the severity and persistence of the most recent financial crisis, further examination of the evolving role and responsibilities of independent audit committees in the context of risk management constitutes an interesting and timely subject which combines research and policy implications. While qualified, committed, independent and tough-minded audit committees were primarily seen as effective guardians for safeguarding the quality of external auditing and financial reporting in the $20^{\text {th }}$ century, their role might well be evolving towards guarding the balance between risks and opportunities affecting value creation or the preservation of modern enterprises in the wake of the global financial crisis. 



\section{References}

Abbott, L. J., and S. Parker. 2000. Auditor selection and audit committee characteristics. Auditing: A Journal of Practice \& Theory 19 (2): 47-66.

Abbott, L. J., S. Parker, and G. F. Peters. 2004. Audit committee characteristics and restatements. Auditing: A Journal of Practice \& Theory 23 (1): 69-87.

Abbott, L. J., S. Parker, G. F. Peters, and D. V. Rama. 2007. Corporate governance, audit quality, and the Sarbanes-Oxley Act: Evidence from internal audit outsourcing. The Accounting Review 82 (4): 803-835.

Aguilera, R. V., I. Filatotchev, and H. G. Gregory Jackson. 2008. An organizational approach to comparative corporate governance: Costs, contingencies, and complementarities. Organization Science 19 (3): 475-492.

Ahrens, T., I. Filatotchev, and S. Thomsen. 2011. The research frontier in corporate governance. Journal of Management \& Governance 15 (3): 311-325.

Aldamen, H., K. Duncan, S. Kelly, R. McNamara, and S. Nagel. 2012. Audit committee characteristics and firm performance during the global financial crisis. Accounting and Finance 52 (4): 971-1000.

Allen, D., and R. Staff. 2012. The global financial crisis: Some attributes and responses. Journal of Accounting and Finance 52 (1): 1-7.

Altman, D. G. 1991. Practical Statistics for Medical Research. Chapman and Hall, London.

Anderson, R. C., S. A. Mansi, and D. M. Reeb. 2004. Board characteristics, accounting reporting integrity, and the cost of debt. Journal of Accounting and Economics 37 (3): 315-342.

Arrow, H., and J. E. McGrath. 1995. Membership dynamics in groups at work: A theoretical framework. Research in organizational behavior 17: 373-411.

Arya, A., J. Glover, B. Mittendorf, and G. Narayanamoorthy. 2005. Unintended consequences of regulating disclosure: The case of regulation fair disclosure. Journal of Accounting and Public Policy 24 (3): 243-252.

Ashforth, B. E., and B. W. Gibbs. 1990. The double-edge of organizational legitimation. Organization Science 1 (2): 177-194.

Bacon, J., and J. K. Brown. 1973. Corporate directorship practices: Role, selection, and legal status of the board. New York: Conference Board.

Baginski, S. P., J. M. Hassell, and M. D. Kimbrough. 2002. The effect of legal environment on voluntary disclosure: Evidence from management earnings forecasts issued in US and Canadian markets. The Accounting Review 77 (1): 25-50.

Baysinger, B. D., and H. N. Butler. 1985. Corporate governance and the board of directors: Performance effects of changes in board composition. Journal of Law, Economics \& Organization 1 (1): 101-124.

Beasley, M. S. 1996. An empirical analysis of the relation between board of director composition and financial statement fraud. The Accounting Review 71 (4): 443-465.

Beasley, M. S., J. V. Carcello, D. R. Hermanson, and P. D. Lapides. 2000. Fraudulent financial reporting: A consideration of industry traits and corporate governance mechanisms. Accounting Horizons 14 (4): 441-454. 
Beasley, M. S., and S. E. Salterio. 2001. The relationship between board characteristics and voluntary improvements in audit committee composition and experience. Contemporary Accounting Research 18 (4): 539-570.

Beasley, M. S., B. C. Branson, and B. V. Hancock. 2008. Rising expectations - audit committee oversight of enterprise risk management. Journal of Accountancy (April 2008): 44-51.

Beasley, M. S., J. V. Carcello, D. R. Hermanson, and T. L. Neal. 2009. The audit committee oversight process. Contemporary Accounting Research 26 (1): 65-122.

Bebchuk, L. A., and M. J. Roe. 1999. A theory of path dependence in corporate ownership and governance. Stanford Law Review 52 (1): 127-170.

Becht, M., and C. Mayer. 2003. European Corporate Governance: Harmonisation versus Competition, in C. Borio, W. C. Hunter, G. C. Kaufman and K. Tsatsaronis (eds.), Market Discipline across Countries and Industries, Cambridge, MA: MIT Press: 255-268.

Bédard, J., S. M. Chtourou, and L. Courteau. 2004. The effect of audit committee expertise, independence, and activity on aggressive earnings management. Auditing: A Journal of Practice \& Theory 23 (2): 13-35.

Bédard, J., and K. M. Johnstone. 2004. Earnings manipulation risk, corporate governance risk, and auditors' planning and pricing decisions. The Accounting Review 79 (2): 277-304.

Bédard, J., D. Coulombe, and L. Courteau. 2008. Audit committee, underpricing of IPOs, and accuracy of management earnings forecasts. Corporate Governance: An International Review 16 (6): 519-535.

Bédard, J., and Y. Gendron. 2010. Strengthening the financial reporting system: Can audit committees deliver? International Journal of Auditing 14 (2): 174-210.

Berle, A. A., Jr., and G. C. Means. 1932. The Modern Corporation and Private Property. MacMillan, New York.

Bernstein, W. J. 2004. The Birth of Plenty: How the Prosperity of the Modern World was created, 1st edn. New York: McGraw-Hill.

Blue Ribbon Committee (BRC). 1999. Report and Recommendations of the Blue Ribbon Committee on Improving the Effectiveness of Corporate Audit Committees. NYSE and NASD, New York.

Böhm, F., L. H. Bollen, and H. F. Hassink. 2013. Spotlight on the design of European audit committees: A comparative descriptive study. International Journal of Auditing 17 (2): 138-161.

Bolkenstein, F. 2004. The EU Action Plan for Corporate Governance, speech of European Commissioner Frits Bolkenstein at the conference on the German Corporate Governance Code in Berlin, June 24, 2004, available at: http://europa.eu/.

Bolton, B. 2014. Audit committee performance: Ownership vs. independence - did SOX get it wrong? Accounting and Finance 54 (1): 83-112.

Borchardt, K-D. 2010. The ABC of European Union Law, Publications Office of the European Union, available at: http://eur-lex.europa.eu/en/index.htm/.

Boubaker, S., R. Nguyen, and W. Rouatbi. 2012. Large shareholders and firm risk-taking behavior. Munich Personal RePEc Archive, available at: http://mpra.ub.uni.muenchen.de.

Bradbury, M. E. 1990. The incentives for voluntary audit committee formation. Journal of Accounting and Public Policy 9 (1): 19-36.

Braiotta, J., and J. Zhou. 2008. An exploratory study of the effects of the European Union 8th Directive on Company Law on audit committees: Evidence from EU companies listed on US stock exchanges. Advances in Accounting 24 (2): 262-272.

Brick, I. E., and N. K. Chidambaran. 2010. Board meetings, committee structure, and firm value. Journal of Corporate Finance 16 (4): 533-553.

Bronson, S. N., J. V. Carcello, C. W. Hollingsworth, and T. L. Neal. 2009. Are fully independent audit committees really necessary?. Journal of Accounting and Public Policy 28 (4): 265-280.

Brown, I., A. Steen, and J. Foreman. 2009. Risk management in corporate governance: A review and proposal. Corporate Governance: An International Review 17 (5): 546-558.

Brown, S. J., W. Goetzmann, R. G. Ibbotson, and S. A. Ross. 1992. Survivorship bias in performance studies. The Review of Financial Studies 5 (4): 553-580.

Burton, E. J. 2008. The audit committee: How should it handle ERM? Journal of Corporate Accounting and Finance 19 (4): 3-5. 
Cameron, A. C., and P. K. Trivedi. 1990. Regression based tests for overdispersion in the poisson model. Journal of Econometrics 46 (3): 347-364.

Carcello, J. V., D. R. Hermanson, and T. L. Neal. 2002. Disclosures in audit committee charters and reports. Accounting Horizons 16 (4): 291-304.

Carcello, J. V., and T. L. Neal. 2003. Audit committee characteristics and auditor dismissal following "new" going-concern reports. The Accounting Review 78 (1): 95-117.

Carcello, J. V., C. W. Hollingsworth, and T. L. Neal. 2006. Audit committee financial experts: A closer examination using firm designations. Accounting Horizons 20 (4): 351-373.

Carcello, J. V., D. R. Hermanson, and Y. Zhongxia. 2011. Corporate governance research in accounting and auditing: Insights, practice, implications, future research directions. Auditing: A Journal of Practice \& Theory 30 (3): 1-31.

Carroll, G. R., and J. Delacroix. 1982. Organizational mortality in the newspaper industries of Argentina and Ireland: An ecological approach. Administrative Science Quarterly 27 (2): 169-198.

Carson, E. 2002. Factors associated with the development of board subcommittees. Corporate Governance: An International Review 10 (1): 4-18.

Carter, D. A., F. D'Souza, B. J. Simkins, and W. G. Simpson. 2010. The gender and ethnic diversity of US boards and board committees and firm financial performance. Corporate Governance: An International Review 18 (5): 396-414.

Chan, K. M., and J. Li. 2008. Audit committee and firm value: Evidence on outside top executives as expert-independent directors. Corporate Governance: An International Review 16 (1): 16-31.

Chandler, A. D. Jr. 1990. Scale and Scope: The Dynamics of Industrial Capitalism. Harvard University Press, Cambridge: MA.

Chang, K. S. 2011. Membership stability and performance: A study of baseball clubs and laboratory groups. The International Journal of Human Resource Management 22 (2): 457-480.

Chen, F., and Y. Li. 2013. Voluntary adoption of more stringent governance policy on audit committees: Theory and empirical evidence. The Accounting Review 88 (6): 1939-69.

Cheng, S. 2008. Board size and the variability of corporate performance. Journal of Financial Economics 87 (1): 157-176.

Chenhall, R. H., and F. Moers. 2007. The issue of endogeneity within theory-based, quantitative management accounting research. European Accounting Review 16 (1): 173-196.

Cho, H-C., and S. Abe. 2012. Is two-tailed testing for directional research hypotheses tests legitimate? Journal of Business Research 66 (9): 1261-1266.

Christian, M. S., A. S. Garza, and J. E. Slaughter. 2011. Work engagement: A quantitative review and test of its relations with task and contextual performance. Personnel Psychology 64 (1): 89-136.

Clarke, T. 2007. International Corporate Governance: A comparative approach, London: Routledge.

Cohen, J. G., G. Krishnamoorthy, and A. M. Wright. 2002. Corporate governance and the audit process. Contemporary Accounting Research 19 (4): 573-94.

Cohen, J., G. Krishnamoorthy, and A. Wright. 2004. The corporate governance mosaic and financial reporting quality. Journal of Accounting Literature 23: 87-152.

Cohen, J., G. Krishnamoorthy, and A. Wright. 2008. Form versus substance: The implications for auditing practice and research of alternative perspectives on corporate governance. Auditing: A Journal of Practice \& Theory 27 (2): 181-198.

Cohen, J. R., G. Krishnamoorthy, G., and A. M. Wright. 2010. Corporate governance in the Post-SarbanesOxley era: Auditors' expectations. Contemporary Accounting Research 27 (3): 751-86.

Cohen, J. R., C. Hayes, G. Krishnamoorthy, G. S. Monroe, and A. M. Wright. 2012. The effectiveness of SOX regulation: An interview study of corporate directors. Behavioral Research in Accounting 25 (1): 67-87.

Cohen, J., U. Hoitash, G. Krishnamoorthy, and A. Wright. 2014. The effect of audit committee industry expertise on monitoring the financial reporting process. The Accounting Review 89 (1): 243-273.

Cohen, S. G., and D. E. Bailey. 1997. What makes teams work: Group effectiveness research from the shop floor to the executive suite. Journal of Management 23 (3): 239-290.

Collier, J. 2007. Corporate governance in the European context: Evolving and adapting. Business and Society Review 112 (2): 271-285. 
Collier, P., and A. Gregory. 1999. Audit committee activity and agency costs. Journal of Accounting and Public Policy 18 (4-5): 311-332.

Collier, P., and M. Zaman. 2005. Convergence in European corporate governance: The audit committee concept. Corporate Governance: An International Review 13 (6): 753-768.

Combined Code on Corporate Governance. July 2003. London: The Financial Reporting Council, available at: http://www.frc.org.uk/combined.cfm.

Committee of Sponsoring Organizations of the Treadway Commission (COSO). 2004. Enterprise Risk Management - Integrated Framework. Available at: www.coso.org.

Connelly, B. L., R. E. Hoskisson, L. Tihanyi, and S. T. Certo. 2010. Ownership as a form of corporate governance. Journal of Management Studies 47 (8): 1561-1589.

Conway, M. 2006. The subjective precision of computers: A methodological comparison with human coding in content analysis. Journalism \& Mass Communication Quarterly 83 (1): 186-200.

Daily, C. M. 1996. Governance patterns in bankruptcy organizations. Strategic Management Journal 17 (5): 355-375.

Daily, C. M., J. L. Johnson, and A. E. Ellstrand. 1998. Number of directors and financial performance: A meta-analysis. Academy of Management Journal 42 (6): 674-686.

Dalton, D. R., Daily, C. M., Ellstrand, A. E., and Johnson, J. L. 1998. Meta-analytical reviews of board composition, leadership structure, and financial performance. Strategic Management Journal 19 (3): 269-290.

Davidson, W. N., B. Xie, and X. Weihong. 2004. Market reaction to voluntary announcement of audit committee appointments: The effect of financial expertise. Journal of Accounting and Public Policy 23 (4): 279-293.

Day, D. W., and R. G. Lord. 1988. Executive leadership and organizational performance: Suggestions for a new theory and methodology. Journal of Management 14 (3): 453-464.

DeFond, M. L., R. N. Hann, and X. Hu. 2005. Does the market value financial expertise on audit committees of boards of directors? Journal of Accounting Research 43 (2): 153-193.

Deli, D. N., and S. L. Gillan. 2000. On the demand for independent and active audit committees. Journal of Corporate Finance 6 (4): 427-445.

Dellaportas, S., P. Leung, and B. J. Cooper. Observations on audit committee characteristics. Managerial Auditing Journal 27 (4).

Denis, K. D., and J. J. McConnell. 2003. International corporate governance. Journal of Financial and Quantitative Analysis 38 (1): 1-36.

DeZoort, F. T. 1997. An investigation of audit committees' oversight responsibilities. ABACUS 33 (2): 208-222.

DeZoort, F. T. 1998. An analysis of experience effects on audit committee members' oversight judgments. Accounting, Organization and Society 23(1): 1-21.

DeZoort, F. T., and S. E. Salterio. 2001. The effects of corporate governance experience and financial reporting and audit knowledge on audit committee members' judgments. Auditing: A Journal of Practice \& Theory 20 (2): 31-47.

DeZoort, F. T., D. R. Hermanson, D. S. Archambeault, and S. A. Reed. 2002. Audit committee effectiveness: A synthesis of the empirical audit committee literature. Journal of Accounting Literature 21: 3875.

DeZoort, F. T., D. R. Hermanson, and R. W. Houston. 2008. Audit committee member support for proposed audit adjustments: Pre-Sox versus Post-Sox judgements. Auditing: A Journal of Practice and Theory 27 (1): 85-104.

Dhaliwal, D., V. Naiker, and F. Navissi. 2010. The association between accruals quality and the characteristics of accounting experts and mix of expertise on audit committees. Contemporary Accounting Research 27 (3): 787-827.

DiMaggio, P. J., and W. W. Powell. 1983. The iron cage revisited: Institutional isomorphism and collective rationality in organizational fields. American Sociology Review 48 (2): 147-160.

DiMaggio, P. J., and W. W. Powell. 1991. The New Institutionalism in Organizational Analysis (pp. 1-38). The University of Chicago Press, Chicago. 
Dobbin, F., and J. Jung. 2010. The misapplication of Mr. Michael Jensen: How agency theory brought down the economy and why it might again. Research in Sociology of Organizations 30: 29-64.

Eaton, A. E., and T. Nocinero. 2000. The effectiveness of health and safety committees: Results of a survey of public-sector workplaces. Industrial Relations 39 (2): 265-290.

Edelman, L., C. Uggen, and H. S. Erlanger. 1999. The endogeneity of legal regulation: Grievance procedures as rational myth. The American Journal of Sociology 15 (2): 406-454.

Eichenseher, J. W., and D. Shields. 1985. Corporate director liability and monitoring preferences. Journal of Accounting and Public Policy 4 (1): 13-31.

Ellstrand, A. E., C. M. Daily, J. L. Johnson, and D. R. Dalton. 1999. Governance by committee: The influence of Board of Directors' committee composition on corporate performance. Journal of Business Strategies 16 (1): 67-88.

Erkens, D. H., M. Hung, and P. Matos. 2012. Corporate governance in the 2007-2008 financial crisis: Evidence from financial institutions worldwide. Journal of Corporate Finance 18 (2): 389-411.

Enriques, L., and P. Volpin. 2007. Corporate governance reforms in continental Europe. Journal of Economic Perspectives 21 (1): 117-140.

Ernst \& Young. 2011. Addressing Audit Committee Overload. Viewpoint of the audit committee Leadership Network in North America, Issue 36. Available at: https://www.ey.com.

Essen M., P.-J. Engelen, and M. Carney. 2013. Does "good" corporate governance help in a crisis? The impact of country- and firm-level governance mechanisms in the European financial crisis. Corporate Governance: An International Review 21 (3): 201-224.

European Commission. 2003. Modernising company law and corporate governance in the European Union - a plan to move forward, Brussels. Communication form the Commission to the Council and European Parliament.

European Parliament and Council. 2006. Directive 2006/43/EC on statutory audits of annual accounts. Brussels, European Parliament and Council.

Faccio, M., M-T. Marchica, and R. Mura. 2011. Large shareholder diversification and corporate risktaking. The Review of Financial Studies 24 (11): 3601-3641.

Fama, E., and M. Jensen. 1983. Separation of ownership and control. Journal of Law and Economics 26 (2): 301-325.

Farber, D. F. 2005. Restoring trust after fraud: Does corporate governance matter? The Accounting Review 80 (2): 539-561.

Fernandéz, C. and R. Arrondo. 2007. The effects of ownership structure and board composition $\mathrm{n}$ the audit committee meeting frequency: Spanish evidence. Corporate Governance: An International Review 15 (5): 909-922.

Ferrero-Ferrero, I., M. A. Fernández-Izquierdo, and M. J. Munoz-Torres. 2012. The impact of board of director characteristics in corporate performance and risk-taking before and during the global financial crisis. Review of Managerial Science 6 (3): 207-227.

Ferris, S. P., M. Jagannathan, and A. C. Pritchard. 2003. Too busy to mind the business? Monitoring by directors with multiple board appointments. The Journal of Finance 58 (3): 1087-1112.

Fich, E., and A. Shivdasani. 2007. Financial fraud, director reputation, and shareholder wealth. Journal of Financial Economics 86 (2): 306-336.

Field, L., M. Lowry, and A. Mkrtchyan. 2013. Are busy board detrimental? Journal of Financial Economics 109 (1): 63-82.

Fleiss, J. L., B. Levin, and M. C. Paik. 2003. Statistical Methods for Rates and Proportions. 3rd ed. John Wiley \& Sons, Hoboken, NJ.

Flesher, D. L., G. J. Previts, and W. D. Samson. 2005. Auditing in the United States: A historical perspective. ABACUS 41 (1): 21-39.

Forster, M., T. Loughran, and B. McDonald. 2009. Commonality in codes of ethics. Journal of Business Ethics 90 (1): 129-139.

Francis, B. B., I. Hasan, and Q. Wu. 2012. Do corporate boards matter during the current financial crisis? Review of Financial Economics 21 (2): 39-52.

Fraser, I, and W. Henry. 2007. Embedding risk management: structures and approaches. Managerial Auditing Journal 22 (4): 392-409. 
Galaskiewicz. 1985. Professional networks and the institutionalization of a single mind set. American Sociology Review 50 (5): 639-658.

García-Sánchez, I-M., J. V. Frias-Aceituno, and R. Garcia-Rubio. 2012. Determining factors of audit committee attributes: evidence from Spain. International Journal of Auditing 16 (2): 184-213.

Gaumnitz, B. R., and J. C. Lere. 2004. A classification scheme for codes of business ethics. Journal of Business Ethics 49 (4): 329-335.

Gendron, Y., J. Bédard, and M. Gosselin. 2004. Getting inside the Black Box: A field study of audit committee effectiveness. Auditing: A Journal of Practice \& Theory 23 (1): 153-171.

Gendron, Y., and J. Bédard. 2006. On the constitution of audit committee effectiveness. Accounting, Organizations and Society 31 (3): 219-239.

Ghosh, A., A. Marra, and D. Moon. 2010. Corporate boards, audit committees, and earnings management: Pre- and post-SOX evidence. Journal of Business Finance \& Accounting 37 (9-10): 1145-1176.

Gilson, S. C. 1990. Bankruptcy, boards, banks, and blockholders: Evidence on changes in corporate ownership and control when firms default. Journal of Financial Economics 27: 355-387.

Glebbeek, A. C., and E. H. Bax. 2004. Is high employee turnover really harmful? An empirical test using company records. Academy of Management Journal 47 (2): 277-286.

Goffman E. 1959. The Presentation of Self in Everyday Life. Doubleday, New York.

Golden, B. R., and E. Zajac. 2001. When will boards influence strategy? Inclination $\mathrm{x}$ power = strategic change. Strategic Management Journal 22 (12): 1087-1111.

Goodstein, J. D. 1994. Institutional pressure and strategic responsiveness: Employer involvement in work-family issues. Academy of Management Journal 37 (2): 350-382.

Gordon, J. N., and M. J. Roe. 2004. Convergence and Persistence in Corporate Governance. Cambridge University Press: Cambridge.

Greco, G. 2011. Determinants of board and audit committee meeting frequency - evidence from Italian companies. Managerial Auditing Journal 26 (3): 208-229.

Green, D. L. 1994. Canadian audit committees and their contribution to corporate governance. Journal of International Accounting \& Auditing 3 (2): 131-151.

Greene, E. F., and D. F. Falk. 1978. The audit committee - a measured contribution to corporate governance: A realistic appraisal of its objectives and functions. The Business Lawyer 34 (3): 1229-1249.

Greenspan, A. 1999. Lessons from the global crisis. Address to the World Bank group and International Monetary Fund.

Grüning, M. 2011. Artificial Intelligence Measurement of Disclosure (AIMD). European Accounting Review. 20 (3): 489-519.

Guzzo, R. A., and M. W. Dickson. 1996. Teams in organizations: Recent research on performance and effectiveness. Annual Review of Psychology 47: 307-38.

Hackman, J. R. 1987. The design of work teams. In Handbook of Organizational Behavior, ed. JW Lorsch, pp. 315-42. Englewood Cliffs, NJ: Prentice-Hall.

Harvard Law Review. 2003. The good, the bad, and their corporate codes of ethics: Enron, SarbanesOxley, and the problems with legislating good behavior. Harvard Law Review 116 (7): 2123-2141.

Hawley, A. 1968. Human Ecology, in D. L. Sills (ed.), International Encyclopedia of Social Sciences. New York: Macmillan: 328-37.

Hermalin, B. E., and M. Weisbach. 1998. Endogenously chosen boards of directors and their monitoring of the CEO. The American Economic Review 88 (1): 96-118.

Hermalin, B. E., and M. Weisbach. 2003. Boards of directors as an endogenously determined institution. Economic Policy Review 9: 7-26.

Higgs, D. 2003. Review of the role and effectiveness of non-executive directors. London: Department of Trade and Industry.

Hillman, A. J., and T. Dalziel. 2003. Boards of directors and firm performance: Integrating agency and resource dependence perspectives. Academy of Management Review 29 (3): 383-396.

Hoitash, U., R. Hoitash, and J. Bédard. 2009. Corporate governance and internal control over financial reporting: A comparison of regulatory regimes. The Accounting Review 84 (3): 839-867.

Holder-Webb, L., and J. Cohen. 2012. The cut and paste society: Isomorphism in codes of ethics. Journal of Business Ethics 107 (4): 485-509. 
Hollenbeck, J. R., B. Beersma, and M. E. Schouten. 2012. Beyond team types and taxonomies: A dimensional scaling conceptualization for team description. Academy of Management Review 37 (1): 82106.

Hopt, K. J., and P. C. Leyens. 2004. Board models in Europe. Recent developments of internal corporate governance structures in Germany, the United Kingdom, France and Italy', ECGI Working Paper Series in Law, available at: http://papers.ssrn.com/.

IIA (The Institute of Internal Auditors). 2011. The audit committee: A holistic view of risk. Available at www.theiia.org.

Jackling, B., and S. Johl. 2009. Board structure and firm performance: Evidence from India's top companies. Corporate Governance: An International Review 17(4): 492-509.

Jackson, S. E., J. F. Brett, V. I. Sessa, D. M. Cooper, J. A. Julin, and K. Peyronnin. 1991. Some differences make a difference: Individual dissimilarity and group heterogeneity as correlates of recruitment, promotions, and turnover. Journal of Applied Psychology 76 (5): 675-689.

Jamal, K. 2012. Dysfunctional consequences of disclosure. Accounting Horizons 26 (2): 381-383.

Jeffers, E. 2005. Corporate governance: Toward converging models?. Global Finance Journal 16 (2): 221232.

Jensen, M. C., and W. H. Meckling. 1976. Theory of the firm: Managerial behavior, agency costs and ownership structure. Journal of Financial Economics 3 (4): 305-360.

Jeppesen, K. K. 2010. Strategies for dealing with standard-setting resistance. Accounting, Auditing \& Accountability Journal 23 (2): 175-200.

Jiang, Y., V. Raghupathi, and W. Raghupathi. 2009. Content and design of corporate governance Web Sites. Information Systems Management 26 (1): 13-27.

Kalbers, L. P., and T. J. Fogarty. 1993. Audit committee effectiveness: An empirical investigation of the contribution of power. Auditing: A Journal of Practice \& Theory 12 (1): 24-49.

Kalbers, L. P., and T. J. Fogarty. 1998. Organizational and economic explanations for audit committee oversight. Journal of Managerial Issues 10 (2): 129-50.

Karamanou, I., and N. Vafeas. 2005. The association between corporate boards, audit committees, and management earnings forecasts: An empirical analysis. Journal of Accounting Research 43 (3): 453-486.

Katz, R. 1982. The effects of group longevity on project communication and performance. Administrative Science Quarterly 27: 81-104.

Kelton, A. S., and Y.-W. Yang. 2008. The impact of corporate governance in Internet financial reporting. Journal of Accounting \& Public Policy 27 (1): 62-87.

Kesner, I. F. 1988. Directors' characteristics and committee membership: An investigation of type, occupation, tenure, and gender. Academy of Management Journal 31 (1): 66-84.

Kirk, D. J. 2000. Experiences with the Public Oversight Board and corporate audit committees. Accounting Horizons 14 (March): 103-111.

Khanna, T., J. Kogan, and K. Palepu. 2006. Globalization and similarities in corporate governance: A cross-country analysis. The Review of Economics and Statistics 88 (1): 69-90.

Kirkbride, J., and S. Letza. 2004. Regulation, governance and regulatory collibration: Achieving a "holistic" approach. Corporate Governance: An International Review 12 (1): 85-92.

Kirkpatrick, G. 2009. The corporate governance lessons from the financial crisis. OECD Journal: Financial Market Trends 2009/1: 1-30.

Klein, A. 1998. Firm performance and board committee structure. Journal of Law and Economics 41 (1): 275-304.

Köhler, A. G. 2005. Audit committees in Germany - theoretical reasoning and empirical evidence. Schmalenbach Business Review 57 July: 229-252.

KPMG, 2014. 2014 Global Audit Committee Survey. Available at: http://www.kpmg.com/aci.

KPMG, NACD. 2011. 2011 public company audit committee members survey - highlights. Available at: www.kpmg.com/aci.

KPMG. 2009. The Audit Committee Journey - Recalibrating for the 'New Normal', 2009 public company audit committee member survey, available at: http://www.kpmg.com/aci. 
KPMG. 2008. The Audit Committee Journey - Chartering Gains, Gaps, and Oversight Priorities, 2007-2008 public company audit committee member survey, available at: http://www.kpmg.com/aci.

Krawiec, K. D. 2003. Cosmetic compliance and the failure of negotiated governance. Washington University Law Quarterly 81 (2): 487-544.

Krippendorff, K. 2004. Content Analysis: An Introduction to its Methodology. Sage, London.

Krishnan, J. 2005. Audit committee quality and internal control: An empirical analysis. The Accounting Review 80 (2): 649-675.

Krishnan, G. V., and G. Visvanathan. 2008. Does the SOX definition of an accounting expert matter? The association between audit committee directors' accounting expertise and accounting conservatism. Contemporary Accounting Research 25 (3): 852-857.

Krishnan, J., and J. E. Lee. 2009. Audit committee financial expertise, litigation risk, and corporate governance. Auditing: A Journal of Practice \& Theory 28 (1): 241-261.

Kuehl, C. R. 1977. Leader effectiveness in committee-like groups. The Journal of Business 50: 223-230.

Lamertz, K., and M. L. Martens. 2011. How do we make you look good? A social network study on upstream organizational impression management and the rhetorical construction of IPO firm images. Canadian Journal of Administrative Sciences 28: 373-387.

Laux, C., and V. Laux. 2009. Board committees, CEO compensation, and earnings management. The Accounting Review 84 (3): 869-891.

Lee, T., and M. Stone. 1997. Economic agency and audit committees: Responsibilities and membership composition. International Journal of Auditing 1 (2): 97-116.

Lent, van L. 2007. Endogeneity in management accounting research: A comment. European Accounting Review 16 (1): 197-205.

LePine, J. A., R. F. Piccolo, C. L. Jackson, J. E. Mathieu, and J. R. Saul. 2006. A meta-analysis of teamwork processes: Tests of a multidimensional model and relationships with team effectiveness criteria. Personnel Psychology 61 (2): 273-307.

Letza, S., X. Sun, and J. Krikbride. 2004. Shareholding versus stakeholding: A critical review of corporate governance. Corporate Governance: An International Review 12 (3): 242-262.

Levitt, A. 1998. The 'Numbers Game', remarks of Chairman Arthur Levitt at the NYU Center for Law and Business, September 28, 1998, available at: http://www.sec.gov/.

Lewis, S. C., R. Zamith, and A. Hermida. 2013. Content analysis in an era of big data: A hybrid approach to computational and manual methods. Journal of Broadcasting and Electronic Media 57 (1): 3452.

Lin, J. W., and M. I. Hwang. 2010. Audit quality, corporate governance, and earnings management: A meta-analysis. International Journal of Auditing 14 (1): 57-77.

MacLean, T. L., and M. Behnam. 2010. The dangers of decoupling: The relationship between compliance programs, legitimacy perceptions, and institutionalized misconduct. Academy of Management Journal 53 (6): 1499-1520.

Maddala, G. S. 1992. Introduction to Econometrics. 2nd ed. MacMillan, New York.

Mangena, M., V. Tauringana, and E. Chamisa. 2012. Corporate boards, ownership structure and firm performance in an environment of severe political and economic crisis. British Journal of Management 23 (1): 23-41.

Mathieu, J., M. T. Maynard, T. Rapp, and L. Gilson. 2008. Team effectiveness 1997-2007: A review of recent advancements and a glimpse into the future. Journal of Management 34 (3): 410-476.

Marks, M. A., J. E. Mathieu, and S. J. Zaccaro. 2001. A temporally based framework and taxonomy of team processes. The Academy of Management Review 26 (3): 356-376.

Martson, C. L., and P. J. Shrives. 1991. The use of disclosure indices in accounting research: A review article. The British Accounting Review 23 (3): 195-210.

Mautz, R. K., and F. Neumann. 1977. Corporate Audit Committee: Policies and Practices. Ernst \& Whitney, Cleveland, $\mathrm{OH}$.

McDaniel, L., R. D. Martin, and L. E. Maines. 2002. Evaluating financial reporting quality: The effects of financial expertise vs. financial literacy. The Accounting Review 77 (s-1): 139-167.

McGrath, J. E. 1984. Groups: Interaction and Performance. Englewood Cliffs, NJ: Prentice-Hall.

McMullen, J. A. 1974. Committees of the board of directors. The Business Lawyer 29: 755-804. 
McNulty, T. and A. Pettigrew. 1996. The contribution, power and influence of part-time board members. Corporate Governance: An International Review 4 (3): 160-179.

Menon, K., and J. D. Williams. 1994. The use of audit committees for monitoring. Journal of Accounting and Public Policy 13 (2): 121-139.

Merkl-Davies, D. M., and N. M. Brennan. 2011. A conceptual framework of impression management: New insights from psychology, sociology and critical perspectives. Accounting and Business Research 41 (5): 415-437.

Meyer, J. W., and B. Rowan. 1977. Institutionalized organizations: Formal structure as myth and ceremony. American Journal of Sociology 83 (2): 340-363.

Milliken, F. J., and L. L. Martins. 1996. Searching for common threads: Understanding the multiple effects of diversity in organizational groups. Academy of Management Review 21 (2): 402-433.

Minton, B. A., J. P. A. Tailard, and R. Williamson. 2010. Do independence and financial expertise of the board matter for risk taking and performance. Working paper of Ohio State University.

Mitton, T. 2002. A cross-firm analysis of the impact of corporate governance on the East Asian financial crisis. Journal of Financial Economics 64 (2): 215-241.

Morris, R. 1994. Computerized content analysis in management research: A demonstration of advantages \& limitations. Journal of Management 20 (4): 903-931.

Mueller-Kahle, M., and K. B. Lewellyn. 2011. Did board configuration matter? The case of US subprime lender. Corporate Governance: An International Review 19 (5): 405-417.

Murphy, P. E. 2005. Developing, communicating and promoting corporate ethics statements: A longitudinal analysis. Journal of Business Ethics 62 (2): 183-189.

NACD (The National Association for Corporate Directors). 2010. Report of the NACD Blue Ribbon Commission on the audit committee. Available at: www.theiia.org.

Nakano, M., and P. Nguyen. 2012. Board size and corporate risk taking: Further evidence from Japan. Corporate Governance: An International Review 20 (4): 369-387.

New York Stock Exchange (NYSE). 2003. Final NYSE Corporate Governance Rules (approved by the SEC on November 4, 2003). Section 303A of the NYSE's Listed Company Manual. New York: New York Stock Exchange.

New York Stock Exchange (NYSE). 2011. Listed Company Manual (NYSE, New York). Available at: www. Nysemanual.nyse.com/LCM/Sections/.

Ng, T. B-P., and H-T. Tan. 2003. Effects of authoritative guidance availability and audit committee effectiveness on auditor's judgments in an auditor-client negotiation context. The Accounting Review 78 (3): 801-818.

Okhmatovskiy, I., and R. J. David. 2012. Setting your own standards: Internal corporate governance as a response to institutional pressure. Organization Science 23 (4): 155-176.

Oliver, C. 1991. Strategic response to institutional pressure. Academy of Management Review 16 (1): 145-179.

Olson, J. F. 1999. How to really make audit committees more effective. The Business Lawyer 54 (May): 1097-1111.

Organization for Economic Co-operation and Development (2009, June). Corporate governance and the financial crisis: Key findings and main messages (Report).

Osma, B. G., and E. Guillamón-Saorín. 2011. Corporate governance and impression management in annual results press releases. Accounting, Organizations and Society 36 (4-5): 187-208.

Pathan, S. 2009. Strong boards, CEO power, and bank excessive risk-taking. Journal of Banking and Finance 33 (7): 1340-1350.

Payne, G. T., G. S. Benson, and D. L. Finegold. 2009. Corporate board attributes, team effectiveness and financial performance. Journal of Management Studies 46 (4): 704-731.

Peters Report. 1997. Recommendations on Corporate Governance in the Netherlands. Amsterdam: Committee on Corporate Governance.

Pfeffer, J., and G. Salancik. 1978. The external control of organizations: A resource-dependence perspective. New York: Harper \& Row.

Pincus, K., M. Rusbarsky, and J. Wong. 1989. Voluntary formation of corporate audit committees among NASDAQ firms. Journal of Accounting and Public Policy 8 (4): 239-265. 
Piot, C. 2004. The existence and independence of audit committee in France. Accounting and Business Research 34 (3): 223-246.

Piot, C., and R. Janin, R. 2007. External auditors, audit committees and earnings management in France. European Accounting Review 16 (2): 429-454.

Pomeranz, F. 1997. Audit committees: Where do we go from here?. Managerial Auditing Journal 12 (6): 281-284.

Premuroso, R. F., and S. Bhattacharya. 2007. Is there a relationship between firm performance, corporate governance, and a firm's decision to form a technology committee? Corporate Governance: An International Review 15 (6): 1260-1276.

PriceWaterhouse. 1997. Audit committees: A study in European corporate governance. London: PriceWaterhouse.

Pugliese, A., P-J. Bezemer, A. Zattoni, M. Huse, F. A. Van den Bosch, and H. W. Volberda. 2009. Boards of directors' contribution to strategy: A literature review and research agenda. Corporate Governance: An International Review 17 (3): 292-306.

Raghunandan, K., D. V. Rama, and W. J. Read. 2001. Audit committee composition, "gray directors", and interaction with internal auditing. Accounting Horizons 15 (2): 105-118.

Raghunandan, K., and D. V. Rama. 2007. Determinants of audit committee diligence. Accounting Horizons 21 (3): 265-279.

Rainsbury, E. A., M. E. Bradbury, and F. C. Steven. 2008. Firm characteristics and audit committees complying with 'best practice' membership guidelines. Accounting and Business Research 38 (5): 393-408.

Reuters. 2009. Three top economists agree 2009 worst financial crisis since Great Depression; Risks increase if right steps are not taken. Reuters, February 27, 2009, available at http://reuters.com.

Rowland, G. S. 2002. Earnings management, the SEC, and corporate governance: Director liability arising from the audit committee report. Columbia Law Review 102 (1): 168-207.

Ruiz-Barbadillo, E., E. Biedma-López, and N. Gómez-Aguilar. 2007. Managerial dominance and audit committee independence in Spanish corporate governance. Journal of Management and Governance 11 (3): 311-352.

Rupley, K., E. Almer, and D. Philbrick. 2011. Audit committee effectiveness: Perceptions of public company audit committee members post-Sox. Research in Accounting Regulation 23 (2): 138-144.

SafeAssign. 2011. Washington, DC: Blackboard Inc. http://safeassing.com/. (accessed 13 December 2011).

Schultz, E. L., D. T. Tan, and K. D. Walsh. 2010. Endogeneity and the corporate governance-performance relation. Australian Journal of Management 35 (2): 145-163.

Schwartz-Ziv, M., and M. S. Weisbach. 2013. What do boards really do? Evidence from minutes of board meetings. Journal of Financial Economics 108 (2): 349-366.

Securities and Exchange Commission (SEC), 1940. In the Matter of McKesson \& Robbins, Inc. Summary of Findings and Conclusions. Accounting Series Release No. 19, File No. 1- 1435, December 5. SEC, Washington, D.C.: SEC.

Securities and Exchange Commission (SEC). 2000. Final rule: Audit committee disclosure. Release No. 3442266. Washington, D.C.: SEC.

Sharma, V., V. Naiker, and B. Lee. 2009. Determinants of audit committee meeting frequency: Evidence from a voluntary governance system. Accounting Horizons 23 (3): 243-263.

Sharma, V. D., and E. R. Iselin. 2012. The association between audit committee multiple directorships, tenure, and financial misstatements. Auditing: A Journal of Practice \& Theory 31 (3), 149-175.

Sherman, H. D., D. Carey, and R. Brust. 2009. The audit committee's new agenda. Harvard Business Review 87 (6): 92-99.

Shleifer, A, and R. W. Vishny. 1997. A survey of corporate governance. The Journal of Finance 52 (2): 737-83.

Sikka, R. 2009. Financial crisis and the silence of the auditors. Accounting, Organizations, and Society 34 (6-7): 868-873.

Smith, A. 1776. The Wealth of Nations. Edited by Edwin Cannan, 1904. Reprint edition 1937. NY, Modern Library. 
Sonpar, K., and K. Golden-Biddle. 2008. Using content analysis to elaborate adolescent theories of organizations. Organizational Research Methods 11 (4): 795-814.

Spira, L. F. 1998. An evolutionary perspective on audit committee effectiveness. Corporate Governance: An International Review 6 (1): 29-38.

Spira, L. F. 1999. Ceremonies of governance: Perspectives on the role of the audit committee. Journal of Management and Governance 3 (3): 231-260.

Spira, L. F., and R. Bender, R. 2004. Compare and contrast: Perspectives on board committees. Corporate Governance: An International Review 12 (4): 489-98.

Staw, B. W. 1980. The consequences of turnover. Journal of Occupational Behavior 1 (4): 253-273.

Stewart, G. L. 2006. A meta-analytical review of relationships between team design features and team performance. Journal of Management 32 (1): 29-55.

Strang, D., and M. W. Macy. 2001. In search for excellence: Fads, success stories, and adaptive emulation. American Journal of Sociology 107 (1): 147-182.

Suchman, M. C. 1995. Managing legitimacy: Strategic and institutional approaches. Academy of Management Review 20 (3): 571-610.

Sun, J., and G. Liu. 2014. Audit committees's oversight of bank risk-taking. Journal of Banking and Finance 40 (March): 376-387.

Sundstrom, E., K. P. De Meuse, and D. Futrell, D. 1990. Work teams - applications and effectiveness. American Psychologist 45 (February): 120-133.

The Institute of Chartered Accountants in Australia (ICAA), Financial Reporting Council (FRC) \& The Institute of Chartered Accountants of Scotland (ICAS). (2012). Walk the Line: Discussion and Insights with Leading Audit Committee Members. Available at: http://www.frc.org.uk/publications/.

Talaulicar, T., and A. v. Werder. 2008. Patterns of compliance with the German corporate governance code. Corporate Governance: An International Review 16 (4): 255-273.

Thompson, J. 1967. Organizations in Action, New York: McGraw-Hill.

Tolbert, P. S., and L. G. Zucker. 1983. Institutional sources of change in the formal structure of organizations: The diffusion of civil service reform, 1880-1935. Administrative Science Quarterly 28 (1): 22-39.

Ton, Z. T., and R. S. Huckman. 2008. Managing the impact of employee turnover on performance: The role of process conformance. Organization Science 19 (1): 56-68.

Turley, S. and M. Zaman. 2004. The corporate governance effect of audit committees. Journal of Management and Governance 8 (3): 305-332.

Turley, S., and M. Zaman. 2007. Audit committee effectiveness: Informal processes and behavioral effects. Accounting, Auditing \& Accountability Journal 20 (5): 765-788.

US Congress. Sarbanes-Oxley Act of 2002. One hundred seventh Congress of the United States of America. H. R. 3763.

Vafeas, N., and E. Theodorou. 1998. The relationship between board structure and firm performance in the UK. The British Accounting Review 30 (4): 383-407.

Vafeas, N. 1999. Board meeting frequency and firm performance. Journal of Financial Economics 53 (1): 113-142.

Vafeas, N. 2003. Length of board tenure and outside director independence. Journal of Business Finance \& Accounting 30 (7): 1043-1064.

Vanasco, R. R. 1994. The audit committee: An international perspective. Managerial Auditing Journal 9 (8): 18-42.

Van der Vegt, G. S., S. Bunderson, and B. Kuipers. 2010. Why turnover matters in self-managing work teams: Learning, social integration, and task flexibility. Journal of Management 36 (5): 1168-1191.

Venkatraman, N., and V. Ramanujam. 1986. Measurement of business performance in strategy research: A comparison of approaches. Academy of Management Review 11 (4): 801-14.

Vera-Muñoz, S. C. 2005. Corporate governance reforms: Redefined expectations of audit committee responsibilities and effectiveness. Journal of Business Ethics 62 (2): 115-127.

Verschoor, C. C. 2008. Audit Committee Essentials, Hoboken, NJ: John Wiley \& Sons.

Vienot Report. 1995. Report of the Working Group of the Association Francaise Des Enterprises Privees and Conseil National du Patronet Francais. Paris: Le Conseil d'Administrative des Societes Cotees. 
Walker, R. G. 2004. Gaps in guidelines on audit committees. ABACUS 40 (2): 157-192.

Weaver, G. R., L. K. Trevino, and P. L. Cochran. 1999. Integrated and decoupled corporate social performance: Management commitments, external pressures, and corporate ethics practices. Academy of Management Journal 42 (5): 539-552.

Weber, R. P., 1990. Basic Content Analysis. Sage, London.

Weil, Gotshal \& Manges LLP. 2002. Comparative study of corporate governance codes relevant to the European Union and its member states, a study carried out by the law firm Weil, Gotsahl \& Manges on behalf of the EU, available at: http://ecgi.org/.

Westphal, J. D., R. Gulati, and M. S. Shortell. 1997. Customization or conformity? An institutional and network perspective on the content and consequences of TQM adoption. Administrative Science Quarterly 42 (2): 366-294.

Westphal, J. D., and E. Zajac. 2001. Decoupling policy from practice: The case of stock repurchase programs. Administrative Science Quarterly 46 (2): 202-228.

Whiteoak, J. W. 2007. The relationship among group process perceptions, goal commitment and turnover intention in small committee groups. Journal of Business and Psychology 22 (1): 11-20.

Wiersema, M. F., and K. A. Bantel. 1993. Top management team turnover as an adaptation mechanism: The role of the environment. Strategic Management Journal 14 (7): 485-504.

Willekens, M., H. Vander Bauwhede, and A. Gaeremynck. 2004. Voluntary audit committee formation and practices among Belgian listed companies. International Journal of Auditing 8 (3): 207-222.

Wintoki, M. B. J. S. Linck, and J. M. Netter. 2012. Endogeneity and the dynamics of internal corporate governance. Journal of Financial Economics 105 (3): 581-606.

Wójcik, D. 2006. Convergence in corporate governance: Evidence from Europe and the challenge for economic geography. Journal of Economic Geography 6 (5): 639-660.

Wolnizer, P. W. 1995. Are audit committees red herrings?. ABACUS 31 (1): 45-66.

Xie, B., W. N Davidson, and P. J. DaDalt. 2003. Earnings management and corporate governance: The role of the board and the audit committee. Journal of Corporate Finance 9: 295-316.

Yang, J. S., and J. Krishnan. 2005. Audit committees and quarterly earnings management. International Journal of Auditing 9 (3): 201-219.

Yeh, Y-H., H. Chung, and C-L. Liu. 2011. Committee independence and financial institution performance during the 2007-2008 credit crunch: Evidence from a multi-country study. Corporate Governance: An International Review 19 (5): 437-458.

Yermack, D. 1996. Higher market valuation of companies with a small board of directors. Journal of Financial Economics 40 (2): 185- 211.

Yermack, D. 2004. Remuneration, retention, and reputation incentives for outside directors. The Journal of Finance 59 (5): 2281-2308.

Yoshikawa, T., and A. A. Rasheed. 2009. Convergence in corporate governance: Critical review and future directions. Corporate Governance: An International Review 17 (3): 388-404.

Zaman, M. 2001. Turnbull - creating undue expectations of the corporate governance role of audit committees. Managerial Auditing Journal 16 (1): 5-9.

Zattoni, A., and F. Cuomo. 2008. Why adopt codes of good governance? A comparison of institutional and efficiency perspectives. Corporate Governance: An International Review 16 (1): 1-15.

Zattoni, A., and F. Cuomo. 2010. How independent and incentivized should non-executive directors be? An empirical investigation of good governance codes. British Journal of Management 21 (1): 6379.

Zhang, Y., J. Zhou, and N. Zhou. 2007. Audit committee quality, external auditor independence, and internal control weaknesses. Journal of Accounting and Public Policy 26 (3): 300-327.

Zona, F., and A. Zattoni. 2007. Beyond the black box of demography: Board processes and task effectiveness within Italian firms. Corporate Governance: An International Review 15 (5): 852-886. 


\section{Valorization}

This dissertation is about audit committee design and effectiveness. Audit committees are specialized committees of the board of directors or supervisory board that oversee certain activities of a company or organization. The valorization addendum of my dissertation is structured as follows. First, I point out why effective audit committees are important for society at large. Next, I outline how the research results presented in my dissertation can contribute to society's needs of having powerful and reliable audit committees. Subsequently, I provide recommendations for the three parties that have a say on the way audit committees are designed, that is regulators, corporate boards and shareholders. I close this addendum with pointing out the benefits and risks associated with implementing the audit committee design standards based on my research results.

Audit committee oversight is important due to the agency problem, which Adam Smith described in the Wealth of Nations (1776). According to Smith, professional managers of other people's money and assets cannot be expected to watch over them with the same anxious vigilance with which they would watch over their own. Smith also predicted in 1776 that negligence and profusion will, therefore, always prevail when companies are run by managers rather than owners. Ever since the industrial revolution in the late $19^{\text {th }}$ century, more and more companies have become to be operated by teams of salaried managers who have little or no equity in the firm. The vast majority of today's owners (shareholders), though, do not have the experience, information, time, or power to oversee managerial activities. So, while the separation of control from ownership is a driver of capitalism and economic growth, it does not come without risks. Corporate scandals, such as the demise of Enron and Lehman Brothers, have revealed the costs associated with the agency problem and reinforce the important role of corporate governance.

History has also shown that strong corporate governance is not only important for the shareholders of a given firm, but also for society at large. The revelation of one corporate scandal can lead to a domino effect where further scandals unfold in 
a short period of time, posing a serious threat to corporate legitimacy and investor confidence. When current and potential investors come to the conclusion that recent scandals present not just a few bad apples but rather the tip of an iceberg, the engine of modern capitalism and development starts to slow down. As pointed out by William J. Bernstein in The Birth of Plenty (2004) investor confidence in capital markets is a prerequisite for widely available sources of funding, which plays a key role in the evolution of capitalism and the prosperity of the modern world.

Today, audit committees are widely considered to be central elements of good corporate governance. Their popularity among regulators can be gauged from the fact that their formation has become mandatory for publicly held firms in all of the 30 largest economies by GDP. However, conventional reasoning suggests that merely setting up an audit committee is not enough. Critics of audit committee formation have pointed out that these committees are toothless tigers rather than effective guardians and that they act as ceremonial rubber stamps. It is important that regulators and corporate boards specify audit committee design standards that enhance audit committee effectiveness to prevent that these committees turn into toothless tigers that meet once in a while in a ceremonial setting.

One practical way to strengthen the role of the audit committee is to formalize its responsibilities, membership requirements and operating principles in a charter. Regulators in several countries have required firms to establish and publicly disclose a written charter for their audit committee. In this context, the expectation was raised that disclosing a formal written charter will prompt audit committees to articulate a clear mission, to establish appropriate practices, and to follow them. According to the US Blue Ribbon Committee (1999: 27), disclosure will guide audit committees to responsible practices, as sunlight generally does.

In nutshell, the following practical recommendations can be drawn from the dissertation at hand: First, companies should be required to establish and publicly disclose a written charter for their audit committee. This will improve audit committee effectiveness. Second, audit committees should oversee enterprise risk management and this needs to be defined in audit committee charters. Third, it is important to have independent directors with firm-specific and governance expertise on the audit committee. I will briefly elaborate on these recommendations.

My research results show that it is important to define the responsibilities of the audit committee in a charter and to make this document publicly available. I present empirical evidence that audit committee diligence and effectiveness are positively related to the scope of responsibilities disclosed in the audit committee charter. There are two main explanations. First, the disclosure of a charter will decrease the probability that audit committees fulfill a ceremonial role. Second, a formal charter serves as a source of power for audit committees. Well-crafted charters can provide audit committee members with the necessary direction and power to discharge their role effectively. I believe that committees in general tend to have limited authority, meet infrequently and represent for most members an 
extra role activity that constitutes only a small portion of their usual work. As a consequence, I claim that (audit) committees will benefit more than other work groups from a formal mandate that promotes authority, direction, and discipline.

However, it is important to make it mandatory for firms to place an audit committee charter on the public record. I have studied the interplay between the contents of audit committee charters and actual committee activity in different disclosure regimes. The results show that in countries where the regulatory setting is more stringent, the professed activities of audit committees are more closely related to their actual work, relative to voluntary disclosure settings. When being voluntarily disclosed, audit committee charters seem to function primarily as vehicles to gain external legitimacy via front-stage impression management, but not as a means for providing authority, direction, and discipline to audit committee members. Thus, audit committee charters that are being voluntarily disclosed do not appear to strengthen the effectiveness of audit committees from an agency theory perspective.

There is one caveat here: regulatory pressure leads to mimetic isomorphism due to 'copy-and-paste' behavior between firms. As a result, audit committee charters of different firms closely resemble each other. However, I do believe that the benefits of a disclosure regime outweigh the risks associated with isomorphism in audit committee design, because the actual activities of audit committees are more closely related to the charters contents in countries with a disclosure regime.

Based on my research results, I recommend that independent audit committees oversee enterprise risk management and this needs to be defined in a charter. This recommendation is based on contemporary research on the role of audit committees during periods of economic distress. During a crisis period, the quality of a firm's financial decision and risk-management process mitigates the adverse performance effects of exogenous shocks (Yeh et al., 2011; Aldamen et al., 2012). Consistent with this proposition, a number of studies have shown that effective audit committees can have a positive impact on firm performance during a period of economic downturn. My own research of 351 firms during the 2007-2011 financial crisis shows that those firms performed better where audit committees were charged with oversight of enterprise risk management. To substantiate this finding, I provide evidence that firm performance variability was lower during the financial crisis (a proxy for effective risk management) when substantial oversight of risk management was inscribed in the audit committee charter.

There are four reasons why audit committees should be given a strong mandate to oversee enterprise risk management. First, most audit committees are composed almost exclusively or entirely of independent directors. Arguably, independent directors are less susceptible to the agency problem. As a result they should have more objective views on the risk appetite of executives and on the way risks are being managed by them. Second, independent directors have incentives to prevent excessive risk-taking due to reputation and career concerns. Research 
has shown, for example, that directors sitting on boards of firms in trouble are less likely to receive new appointments. Third, audit committees are involved in the core governance processes from financial reporting to external/internal auditing, and internal control. Fourth, audit committee members typically bring more financial and risk management expertise to the table compared to non-audit committee directors.

However, audit committee members also need firm-specific and governance expertise to effectively oversee the management of risks. My research indicates that firm-specific expertise contributes to the ability of independent directors to effectively oversee risk management. More specifically, I find positive associations between the board tenure of independent directors on audit committees and firm performance during the financial crisis. Agency theory dictates that the tenure of independent directors should be limited due to the development of social ties with management. I would argue, though, that the degree of firm-specific expertise that independent directors should bring to the table depends on the role of the audit committee. Audit committees charged with oversight of risk management need firm-specific expertise and knowledge in order to effectively oversee and appraise managerial decisions and stand up to management in case of disputes on risk management topics. At present, there is no policy regarding the tenure of audit committee members and it is generally not implemented in audit committee charters. Kesner (1998) points out that it takes at least three to five years for independent directors to gain a solid understanding of large and complex firms. Therefore, I believe that it is important to ensure a reasonable tenure of audit committee members to ensure audit committees effectiveness, rather than limiting their tenure to two to three years.

The results presented in this dissertation also support the proposition that an asset that outside directors bring to the board of a given firm - in addition to an independent view - is their body of knowledge and experiences gained at other firms, e.g., in the form of holding additional directorships. Regulators have placed substantial emphasis on limiting the number of additional directorships of independent directors. The main concern is that too many directorships impair the monitoring effectiveness of audit committee members because they become too busy. However, I find empirical evidence suggesting that additional directorships seem to promote rather than constrain the ability of independent directors to spot and oversee risks. Arguably, the question whether multiple directorships should be constrained depends, once again, on the responsibilities of the audit committee. In the case of overseeing risk management, though, I would challenge the approach to minimize the additional directorships of all audit committee members.

Next, I will give more concrete recommendations for implementing audit committee design standards. Based on the outcomes of my research, I see different priorities for strengthening the role of audit committees in the US and continental Europe. For each setting, I point out specific recommendations as well as expected 
benefits and risks that result from the implementation of audit committee design standards. For continental Europe, my primary recommendation is to place more coercive pressure on firms to place an audit committee charter on the public record. The EU Eight Directive, which came into effect in 2006 requires firms to establish an audit committee. It also gives a number of audit committee design recommendations. However, it remains silent on the topic of establishing and disclosing an audit committee charter. I would expect an audit committee charter disclosure regime to have a positive impact on audit committee effectiveness for three reasons. First, important audit committee design standards will be effectively implemented at firm level (which is currently not the case). Second, there will be less room for ceremonial type audit committees. Third, audit committees will be equipped with more power to effectively fulfill their important mandate.

The main risk associated with implementing a disclosure regime on audit committee charters in Europe is that it will lead to isomorphism in audit committee design across firms. In other words, 'copy-and-paste' type audit committee charters may lack firm- or industry-specific content. Since interdependencies between organizations and their environments may lead to variations in the effectiveness of governance practices (Aguilera et al., 2008), it cannot be assumed without further evidence that an effective audit committee should be designed in the same way in Germany, France, or Spain. I would argue, though, that as long as the EU Eight Directive sets minimum standards in terms of audit committees design, EU Member States and companies enjoy sufficient leeway to define audit committee standards that are sufficiently differentiated and fit for purpose.

My recommendation for firms listed in the US, in turn, is to reinforce the role of audit committees with respect to overseeing risk management. The global financial crisis that took hold in 2007 has been described as the most serious financial crisis since the Great Depression. One of the central corporate governance lessons that can be drawn from the financial crisis is that risk management and governance systems need to be strengthened (Kirkpatrick, 2009). My dissertation suggests that it is important to give independent audit committees the authority to assume substantial oversight of risk management. The recommended way to achieve this is through formalizing the responsibilities for risk oversight in the audit committee charter. Board of directors should be best equipped to do this. Shareholders, in turn, can use active engagement strategies, such as the filing of a shareholder proposal or private negotiations to strengthen the mandate of audit committees to oversee risk management. In case substantial oversight of enterprise risk management is assigned to the audit committee, my recommendation is to ensure that audit committee members have sufficient firm-specific expertise. I also suggest to build on the governance expertise of directors with multiple directorships when it comes to overseeing risk matters. Once again, I see the board of directors in the driver seat to implement these recommendations. 
My main concern is that expanding the scope of audit committee oversight in the area of risk management leads to audit committee overload. According to Olson (1999), overloading audit committee members with too many responsibilities can have three unintended consequences: (1) committee effort and energy may be dissipated in too many directions that audit committees become ever more busy but ever less effective; (2) good directors may decline to take on the burden of serving on the committee (3) those who do serve may face the risk of personal liability or a greater chance of being named as defendants in shareholder lawsuits. Therefore, boards of directors need to be careful in expanding the mandate of audit committees without de-prioritizing some other duties. Given the apparent effectiveness of audit committees when it comes to risk oversight, I recommend to prioritize rather than de-prioritize the role of audit committees in this context.

The results presented in my dissertation can contribute to the difficult and important task of strengthening audit committee design and effectiveness. The way that I plan to disseminate my results and recommendations is by means of publishing in academic and practitioner journals. Recent developments show that some of the recommendations given here are already being implemented. A global survey among 1,500 audit committee members by the audit firm KPMG (2014) shows that many audit committees today are already assuming primary responsibility for overseeing a host of business risks. 


\section{Nederlandse samenvatting (Summary in Dutch)}

Dit proefschrift gaat over het ontwerp en de effectiviteit van de auditcommissies. Auditcommissies zijn gespecialiseerde commissies van de raad van bestuur of de raad van commissarissen van organisaties. Toezichthouders over de hele wereld beschouwen ze van het grootste belang voor de kwaliteit van corporate governance en het vertrouwen van beleggers in de financiële markten. Ze worden door sommigen zelfs beschouwd als "de meest betrouwbare hoeders van het algemeen belang" (Levitt, 1999). De vorming van een auditcommissie is verplicht voor beursgenoteerde bedrijven in vrijwel elk van de 30 grootste economieën op basis van BNP. De resultaten van eerder onderzoek bevestigen in grote lijnen een positieve invloed van de aanwezigheid van een auditcommissie op de kwaliteit van de jaarrekeningcontrole, de financiële rapportering, de interne controle, en meer recent ook op het vlak van risicomanagement.

Echter, de belangrijkste vraag waarmee toezichthouders, bestuursraden en investeerders momenteel worden geconfronteerd is niet de vraag of er een auditcommissie moet worden opgericht, maar de vraag hoe een effectieve en efficiënte auditcommissie te ontwerpen. Het is van belang om deze vraag te beantwoorden, omdat auditcommissies zich in de ogen van de toezichthouders inmiddels hebben ontwikkeld tot een van de belangrijkste hoeders van het algemeen belang. Auditcommissie worden verondersteld om de corporate governance te versterken en daarmee het vertrouwen van beleggers in de financiële informatie en markten te beschermen. Omdat het vertrouwen van beleggers in de kapitaalmarkten een voorwaarde is voor algemeen beschikbare financieringsbronnen en de evolutie van het kapitalisme en de welvaart, mag van beleidsmakers, bestuursraden en beleggers worden verwacht dat zij een grote belangstelling aan de dag te leggen voor de verdere ontwikkeling van normen en standaarden die de kracht en de effectiviteit van de auditcommissie verder versterken. 
Eén manier voor toezichthouders om normen voor de inrichting van auditcommissies vast te stellen, is bedrijven te verplichten een schriftelijk handvest met betrekking tot hun auditcommissie openbaar te maken. Dergelijke auditcommissie "charters" zouden specifieke normen voor auditcommissies moeten aangegeven, zoals het vereiste niveau van deskundigheid en onafhankelijkheid van de leden van de auditcommissie. Het belangrijkste is echter dat dergelijke auditcommissie charters, de taken en verantwoordelijkheden van het auditcommissie bij een bepaalde onderneming in detail beschrijven. De regulerende invloed hiervan is tweeledig. Aan de ene kant worden beleggers geïnformeerd. Aan de andere kant bieden zij autoriteit alsmede een richtinggevend en disciplinerend kader aan de leden van auditcommissies. Met name het laatste punt is interessant. Door de openbaarmaking van een auditcommissie charter zullen deze commissies ertoe worden aangezet een duidelijke missie te verwoorden, daarbij passende gedragsregels vast te stellen, en deze vervolgens ook na te leven.

Er is echter relatief weinig bekend over de wisselwerking tussen de taken en verantwoordelijkheden zoals die zijn vastgelegd in auditcommissie charters en de effectiviteit van auditcommissies. Het is verrassend dat de resultaten van wetenschappelijk onderzoek op dit gebied beperkt zijn, gezien het belang dat de toezichthouders en deskundigen op het gebied van corporate governance toeschrijven aan deze charters, als instrument voor het verschaffen van autoriteit, richting en discipline aan de leden van auditcommissies en voor het informeren van relevante belangengroepen - met name de huidige en potentiële aandeelhouders, schuldeisers en regelgevende instanties - over de taken en verantwoordelijkheden van deze commissies op bedrijfsniveau.

Dit proefschrift brengt drie studies bij elkaar die nieuwe inzichten bieden in de opzet en de werking van auditcommissies vanuit een internationaal perspectief. Hoofdstuk 2 werpt licht op de uitvoering van de auditcommissie charters in continentaal Europa, waar de auditcommissie een relatief nieuw concept is. In 2006 heeft de Europese Commissie de 8e EU-richtlijn aangenomen waarin voor de lidstaten de verplichting is opgenomen om een auditcommissie verplicht te stellen voor beursgenoteerde ondernemingen. Echter, op het tijdstip van dit onderzoek waren de standaarden waarin de verplichtingen m.b.t. de inrichting van een auditcommissie zijn vastgelegd verschillend per lidstaat. Een reden voor het gebrek aan standaardisatie binnen de EU op dit punt is dat de 8ste EU-richtlijn veel speelruimte geeft aan de lidstaten om dergelijke standaarden te definiëren. Hoofdstuk 2 laat zien dat het uitoefenen van druk op bedrijven om hun auditcommissie charter openbaar te maken, een effectieve manier is om de implementatie van auditcommissie charters te bevorderen. Echter, toezichthouders dienen een dergelijke stap zorgvuldig te overwegen. De resultaten van hoofdstuk 2 tonen aan dat het uitoefenen van een dergelijke druk leidt tot een toename van het percentage van standaard tekstpassages in auditcommissie charters, tot op het punt waar de auditcommissie charters van verschillende bedrijven nog nauwelijks van elkaar te on- 
derscheiden zijn. Consistent met Institutionele theorie toont dit aan dat overmatige regelgevende druk leidt tot mimetische isomporphism (DiMaggio en Powell, 1991). Met andere woorden, regulering kan leiden tot 'copy-and-paste' of' 'boxticking' benaderingen van corporate governance.

Een belangrijk probleem voor beleggers, toezichthouders en andere belanghebbenden is dat het vrijwel onmogelijk is om te observeren of de auditcommissie van een bepaalde onderneming ook daadwerkelijk uitvoering geeft aan de in het auditcommissie charter opgenomen verantwoordelijkheden. Als gevolg daarvan kunnen de werkelijke (back-stage) activiteiten van auditcommissies afwijken van de in auditcommissie charter opgenomen activiteiten (de frontstage) zonder dat dit tot consequenties leidt. Deze situatie kan leiden tot het optreden v an een zogenaamde 'performance-expectation gap' in het bijzonder in landen waar er een hoge druk op ondernemingen wordt uitgeoefend om de taken van de auditcommissie uit te breiden en deze taken vervolgens in een auditcommissie charter openbaar te maken. Hoofdstuk 3 laat zien dat in landen waar de regelgeving meer restrictief is (de VS), de in de charter vermelde activiteiten nauwer samenhangen met hun feitelijke werkzaamheden, in vergelijking met landen waar er sprake is van een meer liberaal regime (continentaal Europa). De openbaarmaking van auditcommissie charters heeft niet alleen tot doel om investeerders te informeren, maar ook om autoriteit, richting alsmede een disciplinerend kader te geven aan de leden van een auditcommissie (BRC, 1999). Kalbers en Fogarty (1998) wijzen er op dat een effectieve auditcommissies gebaseerd is op een sterk organisatorisch kader, institutionele steun en toewijding. Cohen et al. (2010; 2012) en DeZoort et al. (2008), laten zien dat in de VS auditcommissies aanzienlijk actiever en krachtiger optraden na de introductie van de Sarbanes-Oxley Act van 2002. We schrijven deze ontwikkeling deels toe aan de eis om de verantwoordelijkheden van het auditcommissie te formaliseren in een schriftelijk charter. Echter, de resultaten van onze studie tonen aan dat de waarde en relevantie van dergelijke charters afneemt wanneer zij op vrijwillige basis worden openbaar gemaakt. Hoofdstuk 3 laat zien dat - bij vrijwillige openbaarmaking - publiek beschikbaar charters minder informatie verschaffen over de daadwerkelijk uitgevoerde activiteiten van de auditcommissie. De vrijwillige openbaarmaking van een auditcommissie charter heeft in veel gevallen slechts een symboolfunctie waar organisaties legitimiteit aan trachten te ontlenen, maar niet als een mechanisme om de effectiviteit van de auditcommissies te vergroten vanuit een agency perspectief.

Ongetwijfeld een van de meest interessante aspecten van het toezicht van auditcommissies betreft enterprise risk management. In 2007 ontplooide zich in de VS een economische crisis, die wordt beschouwd als de ergste financiële crisis sinds de Grote Depressie van de jaren 1930. In de nasleep van deze crisis, is er een toenemende hoeveelheid bewijs dat de aanwezigheid van onafhankelijke auditcommissies de gevolgen van deze crisis op de bedrijfsprestaties hebben gemitigeerd (Yeh et al, 2011; Aldamen et al, 2012). De in hoofdstuk 4 gepresenteerde 
resultaten bevestigen deze bevindingen. De belangrijkste bijdrage van hoofdstuk 4, betreffen echter de inzichten in de factoren die de effectiviteit van een auditcommissie in de context van enterprise risk management bepalen. De eerste relevante factor is de toekenning van de formele bevoegdheid in het auditcommissie charter om substantieel toezicht op het risicobeheer te houden. Daarnaast dragen bedrijfsspecifieke en governance deskundigheid bij de onafhankelijke leden binnen het auditcommissie in belangrijke mate bij aan de effectiviteit van het toezicht op het risicobeheer.

Deze resultaten hebben implicaties voor regelgevers, onderzoekers, raden van bestuur en het beleggend publiek. Post-Enron, hebben zowel beleidsmakers, regelgevers, als onderzoekers de nadruk gelegd op het belang van de auditcommissie bij het toezicht op de financiële verslaggeving en de controle van processen alsmede op het belang van het verhogen van het niveau van de financiële expertise van de leden van auditcommissies. Gezien de ernst en de hardnekkigheid van de recente wereldwijde financiële crisis en de rol van auditcommissies in deze context, kan het nuttig zijn om de focus te verleggen naar de rol en de effectiviteit van auditcommissies in het kader van enterprise risk management. Terwijl gekwalificeerde, toegewijde, en onafhankelijke auditcommissies reeds worden gezien als een effectieve bescherming voor het waarborgen van de kwaliteit van de externe controle en financiële verslaglegging in de 20e eeuw, zou hun rol vervolgens kunnen evolueren in de richting van het bewaken van de balans tussen risico's en kansen die van invloed zijn op de waarde creatie en de continuïteit van moderne ondernemingen. 


\section{Curriculum Vitae}

Falko Böhm was born on 17 April 1981 in Leverkusen, Germany. He attended primary school and high school from 1994 to 2000 in Leverkusen. From 1997 to 1998, Falko lived one year in the US, attending a high school near San Francisco. From 2001 to 2002, he spent one year working in elderly care for Malteser Hilfsdienst. Subsequently, he studied International Business Studies at Maastricht University, the Netherlands. In 2005, he spent a semester at Universidad Carlos III in Madrid, Spain. During his studies he embarked on a number of internships, including Volkswagen AG and Bayer AG. In 2006, he received his Master's degree in International Business. His final thesis was supervised by Prof. Harold Hassink and is titled "From Financial Planning to Integrated Business Planning".

After graduating from Maastricht University, Falko worked as a consultant in the pharmaceutical and financial services sector. He joined the Department of Accounting and Information Management at Maastricht University as a part-time Lecturer and external PhD student in 2008. For the next four years he combined working for the consulting firm Otto \& Company with research and teaching at Maastricht University. During that time he conducted the three studies presented in this dissertation. His first research project has been published in the International Journal of Auditing. He presented his research at academic congresses and workshops including the European Accounting Association (EAA) and the European Institute for Advanced Studies in Management (EIASM). Falko also taught undergraduate students in the fields of accounting and corporate governance.

In 2012, Falko joined Merck KGaA, a global pharmaceutical, chemical and life science company. He currently lives in Frankfurt, Germany. 


\section{risk provide finandial error performance inquiry quality oversight lav \\ honesty standard authorization}

liance cost

internal Legitimacy disclosure assistance securitv facts tatements Oversig statements Oversight confirmation

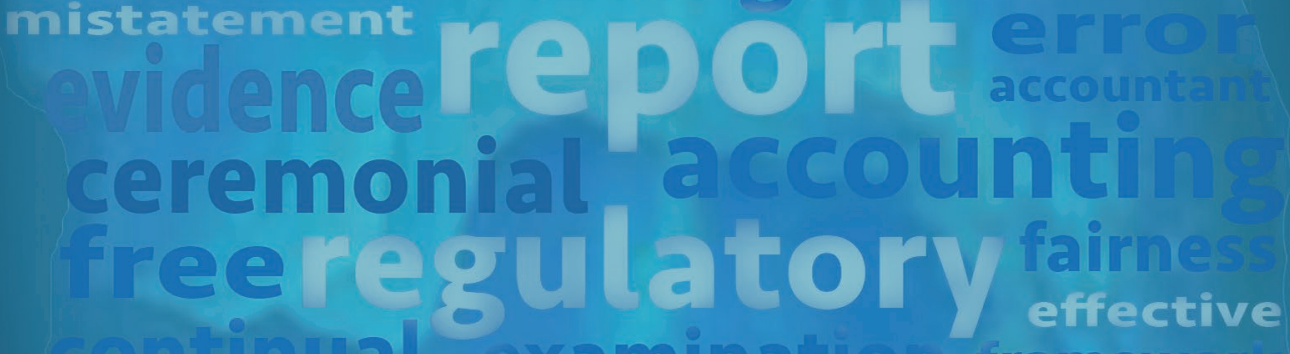
ual examination framewori requirement engagedtax procedures verification $100 \%$ management enhanceview employes
benchmark uniffed confidence banks stock holders banks thus qualitative required 